\title{
Microplastics in soils: an environmental geotechnics perspective
}

Brendan C. O'Kelly PhD, FTCD, CEnv, CEng, MICE

Associate Professor, Department of Civil, Structural and Environmental Engineering, Trinity College Dublin, Dublin, Ireland (Orcid:0000-00021343-4428) (corresponding author: bokelly@tcd.ie)

Abbas El-Zein PhD

Professor of Environmental Engineering, School of Civil Engineering, Faculty of Engineering, The University of Sydney, Sydney, Australia

Xiaoli Liu PhD

Professor, State Key Laboratory of Hydroscience and Engineering, School of Civil Engineering, Tsinghua University, Beijing, China (Orcid:0000-00026204-4485)

\section{Anjan Patel PhD}

Assistant Professor, Department of Civil Engineering, Visvesvaraya National Institute of Technology, Nagpur, India (Orcid:0000-0003-2645-613X)

Xunchang Fei PhD

Assistant Professor, School of Civil and Environmental Engineering, Nanyang Technological University, Singapore; Deputy Director, Residues and Resource Reclamation Centre, Nanyang Environment and Water Research Institute, Singapore

\section{Susmita Sharma PhD}

Assistant Professor, Department of Civil Engineering, National Institute of Technology Meghalaya, Shillong, India

\section{Arif Mohammad BE}

Research Scholar, Department of Civil Engineering, Indian Institute of Technology Bombay, Mumbai, India (Orcid:0000-0002-1815-5073)

\section{Venkata Siva Naga Sai Goli MTech}

Research Scholar, Department of Civil Engineering, Indian Institute of Technology Bombay, Mumbai, India (Orcid:0000-0003-1916-725X)

Jing Jing Wang PhD

Senior Photonics Scientist, Amber Research Centre and Centre for Research on Adaptive Nanostructures and Nanodevices, Trinity College Dublin,

Dublin, Ireland

\section{Dunzhu Li PhD}

Research Scholar, Amber Research Centre and Centre for Research on Adaptive Nanostructures and Nanodevices, Trinity College Dublin, Dublin, Ireland
Yunhong Shi PhD

Research Scholar, Amber Research Centre and Centre for Research on Adaptive Nanostructures and Nanodevices, Trinity College Dublin, Dublin Ireland

Liwen Xiao PhD

Assistant Professor, Department of Civil, Structural and Environmental Engineering, Trinity College Dublin, Dublin, Ireland (Orcid:0000-00033621-9568)

Ganaraj Kuntikana MTech

Research Scholar, Department of Civil Engineering, Indian Institute of Technology Bombay, Mumbai, India

\section{Bettadapura Subramanyam Shashank PhD}

Assistant Professor, Department of Civil Engineering, Birla Institute of Technology and Science (BITS) Pilani, Pilani, India

Theo S. Sarris MEng, MSc, PhD, CPEng

Science Leader, Health and Environment Division, Institute of

Environmental Science and Research, Christchurch Science Centre,

Christchurch, New Zealand (Orcid:0000-0002-1429-2185)

Bendadi Hanumantha Rao PhD

Assistant Professor, Geotechnical Engineering Division, School of Infrastructure, Indian Institute of Technology Bhubaneswar, Bhubaneswar, India

Abdel Mohsen O. Mohamed PhD

Professor of Geotechnical and Geo-environmental Engineering and General Managing Director, EX Scientific Consultants, Abu Dhabi, UAE; Senior Advisor, Uberbinder, Inc., Seattle, WA, USA (Orcid:0000-0002-0971-6940)

Evan K. Paleologos PhD

Professor of Civil Engineering, Department of Civil Engineering, Abu Dhabi University, Abu Dhabi, UAE (Orcid:0000-0002-3582-2288)

Mohaddeseh Mousavi Nezhad PhD

Associate Professor, School of Engineering, The University of Warwick, Coventry, UK

Devendra N. Singh PhD, FASCE, FNAE, FICE

D.L. Shah Chair Professor for Innovation, Department of Civil Engineering, Indian Institute of Technology Bombay, Mumbai, India (Orcid:0000-00033832-1507)

Microplastics (MPs) are emerging persistent contaminants in the terrestrial subsurface, and evidence has emerged for significant effects of MPs on the biological and ecosystem functions of soils. Main MP sources include land spreading of sewage sludge and biowaste composts, plastic mulching film used in horticultural fields, waste water irrigation and leachate from the landfills, among others. This updated state-of-the-art review paper describes recent experimental and numerical research and developments in understanding the accumulation and fate and effects of MPs in the soil environment (focusing on their storage, degradation, transportation, leaching to groundwater etc.), followed by mitigation and bioremediation measures, including MP-eating soil bacteria and fungi and the best management practices for reducing MP pollution of soil. Other areas covered are the combined effects of MPs and various other environmental contaminants (heavy metals, organic pollutants and antibiotics) in soil ecosystems and the standardisation of methods for detection, quantification and characterisation of MPs in soils, which is critical for MP research. The paper concludes by identifying knowledge gaps and presents recommendations on prioritised research needs.

\section{Introduction}

Pollution due to microplastics (MPs) is listed by the UN Environmental Programme (UNEP, 2014) as one of the top ten environmental issues due to their $(a)$ presence in, and harmful impacts on, aquatic and terrestrial ecosystems (mainly soils) and (b) action as a transport vector for other potential pollutants, including human pathogens, organic contaminants and heavy metals (Qi et al.,
2020). Although no internationally agreed definition of the size below which a small piece of plastic should be called an MP presently exists (Hartmann et al., 2019), MPs are generally defined as plastic debris with particle sizes between 0.1 and $5000 \mu \mathrm{m}$ (Galgani et al., 2013; Thompson et al., 2004). Concern about MP pollution is due to their extremely small size, slow rate of degradation under ambient conditions and lack of efficient detection 
techniques in environmental systems. Although numerous studies on the deleterious effect of MPs have been presented for the aquatic environment, much less is known on the fate, transport and harmful impacts of MPs in terrestrial ecosystems. Sources of MPs in terrestrial ecosystems are generally divided into primary and secondary. The primary sources of MPs are mainly due to the application of organic fertilisers, composts and sewage sludge (SS); use of plastic mulches in agriculture; flooding and irrigation with MP-contaminated waste water in agricultural practice; and atmospheric deposition, whereas secondary sources mainly include degradation of the macroplastics (MAPs) in the environment and leachate from landfills (Guo et al., 2020).

With the notable exception of karst aquifers (comprising terrain with distinctive hydrology and landforms that arise from a combination of high rock solubility and well-developed secondary porosity due to fracture), no significant amounts of MPs have yet been detected in groundwater. This is most likely due to filtration by the porous medium that separates it from surface sources of plastics (Bläsing and Amelung, 2018). Notable concentrations of MPs have been detected in karst aquifers because of the latter's macroporous structure, faster flow regimes and stronger connections to the ground surface (Panno et al., 2019). In any case, research on the prevalence of MPs in terrestrial ecosystems is in its infancy and the number of studies still limited, and it is therefore far too early to draw definitive conclusions regarding the risk of MPs to groundwater. On the other hand, three factors, not directly related to groundwater protection, currently drive interest in the transport and fate of MPs in soil. First, MPs entrained and weakly absorbed by soils can find their way into fluvial systems, oceans and the atmosphere (Campanale et al., 2020; Cook et al., 2020; Horton et al., 2017; Unice et al., 2019). For example, there is evidence that wind-driven soil erosion contributes to atmospheric transport of low-density MPs (Rezaei et al., 2019) and, in some cases, of almost total release into freshwater of MPs in SS applied to agricultural soils (Crossman et al., 2020). Second, soils can be a conduit for the entry of MPs into the food chain through fauna and flora capable of absorbing MPs (Huerta Lwanga et al., 2018; Li et al., 2020a). For instance, evidence of bioaccumulation was reported by Huerta Lwanga et al. (2017a), who assessed MP transfer from soil to earthworm and chicken in Mayan households in Mexico. They found that the number of MPs per gram increased from the soil $(0.87 \pm 1.9$ particles $/ g)$ to earthworm casts $(14.8 \pm 28.8$ particles/g), chicken faeces (129.8 \pm 82.3 particles/g) and chicken gizzards $(10.2 \pm 13.8$ particles/g) used for human consumption. Third, MPs can alter the behaviour of other contaminants, both organic (Hüffer et al., 2019; Zhang et al., 2020c) and inorganic (Hodson et al., 2017; Yu et al., 2020), potentially including priority pollutants such as plasticisers and flame retardants that enter in the manufacturing of plastics to enhance their engineering properties (van Praagh et al., 2018). Hence, MPs can become an important conduit for the migration of these contaminants in the subsurface.

\section{Definition of MPs (sizes and compositions)}

In this paper, plastic particles are classified into macro- $(>25 \mathrm{~mm})$, meso- (between 5 and $25 \mathrm{~mm}$ ), micro- (between $100 \mathrm{~nm}$ and
$5 \mathrm{~mm}$ ) and nano-plastics (NPs) $(<100 \mathrm{~nm}$ ) (Alimi et al., 2018; Jahnke et al., 2017). Note that some authors refer to particles in the lower MP range (between 100 and $200 \mathrm{~nm}$ ) as NPs (Hu et al., 2020; Keller et al., 2020). It is clear that this definition does not distinguish between different types (i.e. chemical composition) and origins (e.g. primary against fragmented) and physical properties (i.e. shape and texture) of plastic, all of which have a strong influence on their prevalence, transport and impacts on the environment. In terms of particle shape, MPs occur in different forms such as fibres, fragments, beads, pellets and film.

Six types of MP particles seem to account for most of MPs hitherto found in the environment - namely, polyethylene (PE), poly(vinyl chloride) (PVC), polyamide (PA), polypropylene (PP), poly(ethylene terephthalate) (PET) and polystyrene (PS) (Alimi et al., 2018; Imhof et al., 2013; Rochman et al., 2013). However, this is mostly based on studies in marine and freshwater environments, and it remains to be seen whether other plastic types are important in terrestrial ecosystems, including soils. Other plastic pollutants might be important in soils because soils are often the first recipient of MP contaminants and are closer to the source of emission than water bodies.

\section{Degradation of plastics}

Physical, chemical and biological degradation of plastics in terrestrial ecosystems can form a source of MPs by breaking down MAPs with particle sizes of $>25 \mathrm{~mm}$ and meso-plastics (MEPs) with particle sizes between 5 and $25 \mathrm{~mm}$. Furthermore, it can be stated that due to degradation of MPs, they are reduced to lower-sized plastics, such as $\mathrm{NPs}$, or completely converted to carbon dioxide $\left(\mathrm{CO}_{2}\right)$ and water $\left(\mathrm{H}_{2} \mathrm{O}\right)$ in soil ecosystems (Helmberger et al., 2020; Shah et al., 2008). Plastic degradation can be driven by photo-oxidative, thermal, ozone-induced, mechanochemical, catalytic and biological processes and is one of the major secondary sources of MPs in terrestrial ecosystems (Guo et al., 2020; Singh and Sharma, 2008; Wang et al., 2020; Zhu et al., 2019). These processes increase oxygen-containing functional groups, thereby producing changes in the surface properties and chemical structure of polymers (Zhu et al., 2019). However, among these degradation processes, photo-oxidative degradation, ozone-induced degradation and biodegradation are primarily responsible for the formation of MPs from MAPs and MEPs in soils, landfills and so on. The degradation of these plastics depends on $(a)$ the type of polymers and their physico-chemical characteristics, such as molecular weight, size, chemical bonding, tacticity, mobility, crystallinity and hydrophobicity of the surface, and (b) environmental conditions, mainly temperature, $\mathrm{pH}$, moisture content and availability of suitable microbes and enzymes (Shah et al., 2008; Zhu et al., 2019). Photodegradation that occurs under the action of ultraviolet (UV) radiation, within 290-400 nm wavelength, reduces the mechanical strength, extensibility and transparency of the polymer, depending on the type of polymer and its chemical bonds (Andrady, 2011). Although the process is slow, ozone present in the atmosphere can degrade the polymer under natural conditions (Singh and Sharma, 2008). Incidentally, the actions of abiotic agents (i.e. UV irradiation, thermal stress and ozone) break 
down the polymer chain and make it more bioavailable, which subsequently enhances its biodegradation. For instance, in the review paper by Shah et al. (2008), it was reported that thermal actions on polymers mainly reduce their molecular weight and deteriorate their physical properties, such as ductility and embrittlement, leading to cracking. Also, Yoshida et al. (2016) reported that owing to the glass transition temperature of $75^{\circ} \mathrm{C}$ of PET, the polyester (PEST) chain present in it is in a glassy state at moderate temperature, conducive for the action of mesophilic enzymes. Heterotrophic microorganisms are involved in the degradation of polymers, which act as a source of organic carbon and energy for the microbes (Shah et al., 2008). The biodegradation of polymer occurs due to the action of extracellular and intracellular enzymes, such as lipase, cutinases, proteinase, dehydrogenases, depolymerase and PETase, which are capable of biodegradation (Shah et al., 2008; Yoshida et al., 2016).

On the other hand, there are presently few studies on the degradation of MPs in soil, which is a very slow process (Cooper and Corcoran, 2010; Krueger et al., 2015; Zhu et al., 2019) and mainly occurs due to biodegradation, whereas the degradation effects of soil environment, mechanical crushing, high-temperature oxidation and UV radiation appear to be limited. In farmland soils, Briassoulis et al. (2015) found that PE MP fragments of plastic mulching film (PMF) are difficult to degrade, persisting for several years or even decades and finally forming small MP residues. It was found that the weight loss of MPs in soil was only $0.1-0.4 \%$ after 800 days for PE (Albertsson, 1980) and $0.4 \%$ after 1 year for PP (Arkatkar et al., 2009). In contrast, PVC and PS did not exhibit any change 32 years after burial in soil (Zhu et al., 2019). MPs may persist in soils for as long as 100 years due to low light and oxygen availability, which eventually suppress photo-oxidative degradation (Barnes et al., 2009). Moreover, incomplete biodegradation of biodegradable polymers (oxo-biodegradable and compostable plastics used as carrier bags) (O'Brine and Thompson, 2010) is one of the significant sources of MPs in leachate generated by landfills and uncontrolled dumpsites (Chandana et al., 2021; Qi et al., 2020; Weinstein et al., 2016). To the best of the authors' knowledge, no study in the literature has provided an in-depth account of the degradation products of MPs.

\section{MPs in the soil environment}

Sources of MPs in soils

An important source of MP pollution has been found to be waste water discharges and biosolids/SS, which are major by-products of waste-water-treatment plants (WWTPs) (Enfrin et al., 2019; Mason et al., 2016; Sun et al., 2019). MPs have been detected in agricultural soils (Corradini et al., 2019a; Dehghani et al., 2017; Liu et al., 2018; Ng et al., 2018; Panno et al., 2019; Piehl et al., 2018; Rillig et al., 2017a), particularly those to which sludge compost has been applied (Corradini et al., 2019a; Li et al., 2018a; van den Berg et al., 2020); soils within suburban built environments (Liu et al., 2018); coastal soils (Zhou et al., 2018); forest soils adjacent to farmlands (Zhang and Liu, 2018); and landfill refuse and leachates (He et al., 2019; Su et al., 2019; van
Praagh et al., 2018). Apart from the aforementioned ones, MPs enter soil ecosystems through agricultural mulching layers and waste water irrigation (Conley et al., 2019; Kleinteich et al., 2018; Lares et al., 2018; Talvitie et al., 2017a). Other pathways include landfills, beach littering and run-off from farming and recreational, industrial and urban spaces (Hurley and Nizzetto, 2018). Several studies have shown that the migration of MPs through the food chain significantly changes the biological community and, with the decreasing particle size of MPs, leads to the accumulation and transmission of MPs in food chains, reaching humans (Farrell and Nelson, 2013; Kiyama et al., 2012; von Moos et al., 2012; Wright et al., 2013a, 2013b).

\section{Land application of organic fertilisers, composts, SS and waste water irrigation}

Organic fertilisers and composts, which are derived from different wastes such as unsegregated municipal solid waste (MSW), SS and animal manure, are a potential source of MPs in agricultural lands due to the nature of initial feedstocks for composting/ digestion ( $\mathrm{Ng}$ et al., 2018; Qi et al., 2018). It appears that the majority of reported studies in this field investigated SS application to agricultural soils. It has been estimated that annually about 2800-19000, 63000-430000 and $44000-300000 \mathrm{t}$ of MPs are being released into Australian, European and North American agricultural fields, respectively, through SS application (Ng et al., 2018; Nizzetto et al., 2016). The presence of MPs has also been reported in agricultural soils that have not been amended with composts/organic fertilisers, which may be attributed to the disintegration of PMFs.

WWTPs, although not specifically designed to treat MPs, can remove up to $99 \%$ of MPs from waste water (Carr et al., 2016). Owing to the low biodegradability of plastics, MPs are not eliminated during the waste-water-treatment processes but are transferred from the waste water to the sludge residues. Subsequent SS-treatment processes, such as thermal stabilisation and anaerobic digestion, cannot efficiently remove these MPs. Since land-spread municipal SS could be important MP sources for soil, a total of 18 studies have been recently performed to investigate the MPs in SSs from 65 WWTPs in 13 countries (refer to Table 1). These studies have found that the MP abundance in SSs ranges between $1 \times 10^{3}$ and $3.14 \times 10^{5} \mathrm{MP}$ particles/kg dry soil, with these limiting values deduced from reported data for the UK (Murphy et al., 2016) and Spain (Edo et al., 2020), respectively. The variation may be due to differences in MP testing methods/protocols employed and (or) the WWTP parameters, including source waste water.

Studies showed that land application of SS could increase MP abundance in soil (Corradini et al., 2019a; Li et al., 2018a; Talvitie et al., 2017b; van den Berg et al., 2020; Zubris and Richards, 2005). van den Berg et al. (2020) compared MP concentrations in 16 agricultural fields, before and after SS application, and found that MP abundance in the top $30 \mathrm{~cm}$ soil layer increased by about $7.1 \times 10^{2}$ particles $/ \mathrm{kg}$ soil when 


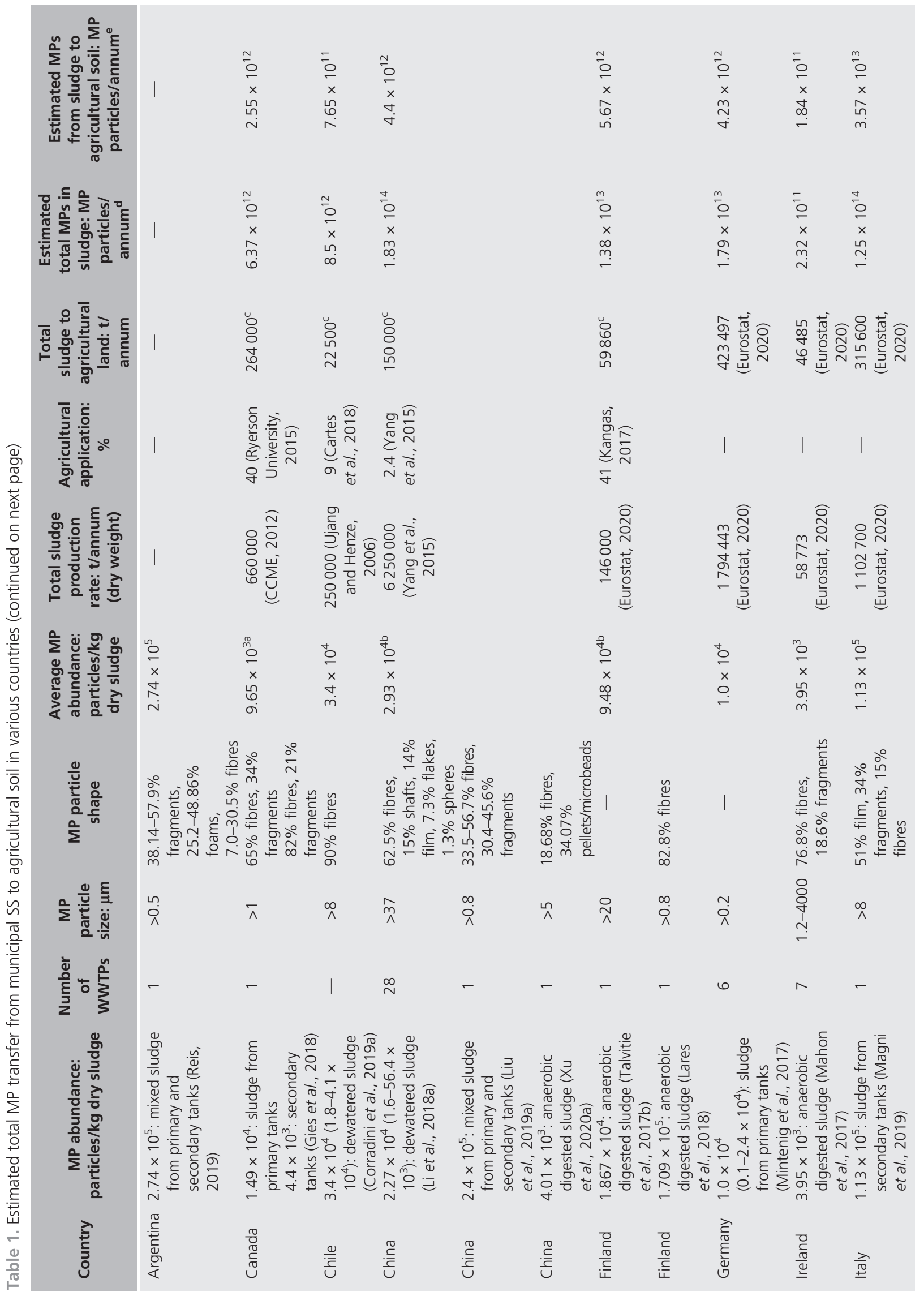




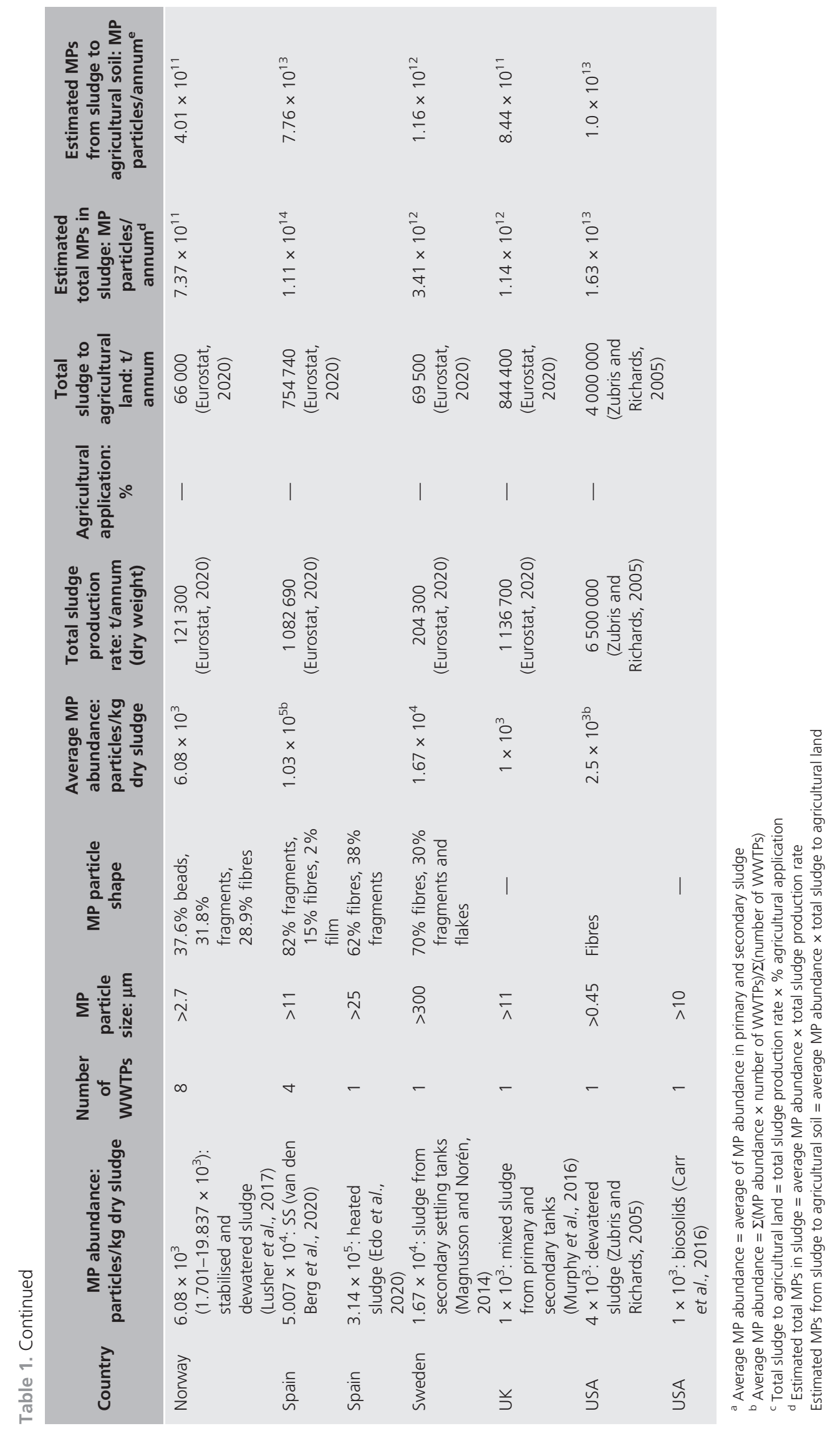


22-25 t/ha of SS with an average MP abundance of about $5.0 \times 10^{4}$ particles $/ \mathrm{kg}$ sludge had been applied. Similarly, Corradini et al. (2019a) studied MPs in the topsoil $(0-25 \mathrm{~cm})$ of 31 agricultural fields and found that MPs accumulated in soils with successive sludge application. By considering MP abundances in SS and the amount of sludge applied to agricultural land, the amount of MPs transferred from SS sources to agricultural soil for the 13 countries considered could be estimated (refer to Table 1), ranging between $1.84 \times 10^{11}$ and $7.76 \times 10^{13} \mathrm{MP}$ particles/annum, with the limits of this range corresponding to Ireland and Spain, respectively. Aside from agricultural land spreading, SSs are mainly disposed of by compost/soil amendment, landfilling and incineration, although the proportion treated by the last approach in Europe is low (Eurostat, 2020). Hence, it is reasonable to assume that most MP particles accumulated in SSs are eventually transferred to soils.

The use of treated waste water from WWTPs for irrigation of arable land has also increased over the past few decades (Lee et al., 2013; Sun et al., 2019). However, variations in treatment methodologies adopted in the WWTPs have also resulted in changes in the concentration of MP particles in irrigable waste water. Researchers have reported that up to $40 \%$ of MPs persist in the effluent discharge of WWTPs (Conley et al., 2019; Lares et al., 2018; Li et al., 2018a; Talvitie et al., 2017a) - some of which enter agricultural soils through irrigation.

\section{Mulching activities}

Extensive use of plastic or mulch film, as covering material, in agriculture consumes $2 \%$ of global production, amounting to approximately $6.96 \mathrm{Mt}$ of plastic annually (Espi et al., 2006). PMFs are a water-efficient agricultural method that enhances crop growth, reduces weeds and pests, conserves moisture and soil nutrients and leads to higher crop yields (Bläsing and Amelung, 2018; Cook et al., 2006; Egley, 1983; Halley et al., 2001). It has been reported that more than $128652 \mathrm{~km}^{2}$ of agricultural land around the world is covered with PMFs (Bläsing and Amelung, 2018; Briassoulis and Giannoulis, 2018), which has produced large amounts of PMF residue, owing to its low recovery from agricultural fields. In the mechanised cultivation approach, thin sheets of PMF are spread over the farm field, with PMF thicknesses of $<0.008 \mathrm{~mm}$ used in China, $0.020 \mathrm{~mm}$ in the USA and EU and $0.015 \mathrm{~mm}$ in Japan (Cook et al., 2006; Kyrikou and Briassoulis, 2007). The PMF material is subjected to seasonal weathering, which causes embrittlement and disintegration of the sheet (Kasirajan and Ngouajio, 2012; Kyrikou and Briassoulis, 2007), with macroscopic plastic debris eventually fragmenting into MPs. Since PMF is mainly composed of PE, the residual PMF does not readily degrade in soil (Halley et al., 2001). Even small degradation of PE-based PMF residue (or MPs) would result in leaching from the mulch film of the plasticising agents, such as phthalate, which is carcinogenic and a widely studied soil contaminant (Hüffer and Hofmann, 2016; Kijchavengkul and Auras, 2008; Liu et al., 2018; Wang et al., 2018). Thus, the existence of MPs with associated harmful counterparts may pose a significant risk to the sustenance of essential ecosystem services in agricultural landscapes. Such contaminants with MPs may disseminate in the environment by plant uptake and run-off into the surface and groundwater sources. For instance, MPs smaller than $0.5 \mu \mathrm{m}$ accumulate in biota, which do not 'ingest' their food, such as filamentous bacteria and yeast; this may indicate potential MP magnification in soil and the food chain (Hodson et al., 2017; Huerta Lwanga et al., 2016; Schmid and Stoeger, 2016). Studies undertaken by Albertsson (1980) indicated that biodegradation of low-density PE (LDPE) buried in soil might take more than 10 years. Otake et al. (1995) conducted a study on $60 \mu \mathrm{m}$ thin LDPE film buried in the soil for 32 years, only to observe partial degradation of the film. Under such conditions, MP concentrations as high as 78.0 and 62.5 particles $/ \mathrm{kg}$ in shallow and deep agricultural soils, respectively, observed in Shanghai, China (Liu et al., 2018), or as low as $0.34 \pm 0.36$ particles $/ \mathrm{kg}$ of dry soil in agricultural farmland in Germany (Piehl et al., 2018) may result in soil degradation and pose a potential threat to both aquatic and terrestrial life in the long run (Fuller and Gautam, 2016).

\section{Landfills and landfill leachate}

Three recent studies reported the detection of MPs in landfilled solid waste ( $\mathrm{Su}$ et al., 2019), landfill-mined-soil-like-fractions (LFMSFs) obtained from landfill mining (Zhang and Liu, 2018) and landfill leachate (He et al., 2019), but without tracing their origins. The fate of MAPs (Levis et al., 2017) and MPs (Hale et al., 2020) in solid waste in landfills, and their transport beyond the waste, is even less understood than MP and NP transport in soil. Yadav et al. (2020) present a framework for quantifying environmental losses of plastics from landfills, although the transport of MPs is not considered explicitly. Key environmental transport pathways for landfilled plastic waste are flooding, manual scavenging (rag-picking), surface run-off, wind-driven transport and animal scavenging. Waldschläger et al. (2020) include landfills as reservoirs of secondary MPs in their source-pathway-receptor model, despite the lack of actual measurements of MP transport from solid waste.

$\mathrm{Su}$ et al. (2019) reported that oxidative degradation of plastics present in landfill refuse could be one of the pathways for the presence of MPs in landfill leachate. To substantiate it, Su et al. (2019) determined the change in carbonyl index (CI), which is defined as the ratio of the absorption peak area of carbonyl moieties to the reference peak of methylene moieties at $1780-1600$ and $1490-1420 \mathrm{~cm}^{-1}$, respectively, measured through Fourier transform infrared (FTIR) spectroscopy. For instance, it was reported that $\mathrm{CI}$ increased from 0.18 (for virgin $\mathrm{PE}$ ) to 1.3 for MPs over time in landfills (Su et al., 2019). Based on this finding, Su et al. (2019) considered that one of the main indicators of PE biodegradation in landfill is the presence of oxidised carbonyl group at wave number $1780-1600 \mathrm{~cm}^{-1}$ of FTIR spectra. Analysing leachates from six MSW landfills, He et al. (2019) identified 17 types of MPs in the leachates, including PE, PP, PVC, PS, PET, acrylonitrile butadiene styrene and polyurethane 
(PUR), with the MP concentration ranging between 0.42 and 24.58 particles/l of leachate. The majority $(\sim 77 \%)$ of the MP particles were in the $0.1-1.0 \mathrm{~mm}$ size range and were extracted and identified by slightly modifying the National Oceanic and Atmospheric Administration laboratory methods (Masura et al., 2015). The smallest detectable size in their study was $100 \mu \mathrm{m}$. He et al. (2019) reported that PE and PP MPs were found in the majority of leachate. A study of MPs in landfills in Finland, Iceland and Norway detected concentrations of up to about $5 \mathrm{MP}$ particles/l of leachate and found evidence that treatment of leachate is effective in reducing MP concentrations by more than one order of magnitude (van Praagh et al., 2018). Further, the type of MPs in refuse and leachate depends on the state of degradation, which is generally correlated to the age of the landfill, with $\mathrm{Su}$ et al. (2019) reporting that the average abundances of MPs in refuse were over $80 \mathrm{MP}$ particles/g (maximum 102 particles/g) detected in new refuse, reducing to an average of $35 \mathrm{MP}$ particles/g in old refuse. Remarkably, the quoted values of MPs in refuse are comparable with, or higher than, MP concentrations in SS reported by Li et al. (2018a) (ranging from 1.6 to 56 particles/g of dry sludge) and around one order of magnitude higher than concentrations found by van den Berg et al. (2020) in agricultural soils to which MP-rich SS has been applied (5.19 particles per gram of soil). No study appears to have assessed the extent of penetration of MPs into base or cover liners in landfills or the soils beneath landfill sites. Hence, from an environmental geotechnics perspective, there is now a need to quantify plastic sources in landfills, processes of plastic fragmentation in the waste and the extent of migration of MPs into the wider environment around landfills.

\section{Coastal beaches and deep-sea sediments}

Coastal shorelines are highly dynamic environments, and MP deposition depends on various factors, which include (Gesamp, 2019) the proximity and type of human activity; the geology, geomorphology and vegetation of the coast; rainfall and prevailing wind speed and direction; and tides, ocean currents and sea temperature, among others. Depending on these factors, plastics may be transported towards the sea or the land. Plastic fragmentation results from exposure to UV radiation, followed by abrasion and/or biodegradation taking place on the shore or the sea (Andrady, 2011). Studies have reported that MP accumulation has occurred in deep-sea sediments (Kane et al., 2020; Pohl et al., 2020). Van Cauwenberghe et al. (2013) revealed the presence of MP particles in the top centimetre of sediment samples collected from the Porcupine Abyssal Plain (North Atlantic Ocean), distal lobe of Congo Canyon (Gulf of Guinea, South Atlantic Ocean) and the Nile deep-sea fan (Eastern Mediterranean Sea), with depths ranging from 1100 to $5000 \mathrm{~m}$. Woodall et al. (2014) collected sediment samples from the Atlantic Ocean, Mediterranean Sea and Indian Ocean, at water depths from 300 to $2200 \mathrm{~m}$, and found that MP fibres ranged between 28 and 800 pieces/l. MP abundance in deep-sea sediments (per unit volume) is hence four orders of magnitude greater than that found in contaminated sea-surface waters, indicating that the deep sea is a major sink for MP debris (Woodall et al., 2014). Bergmann et al.
(2017) found MP abundance of 44-3464 pieces/1 in Arctic deep-sea sediment samples from depths of 2340-5570 m. Peng et al. (2018) reported that MPs were found at depths of up to $11000 \mathrm{~m}$, at the deepest point on Earth, at the southern Mariana Trench, with MP abundance ranging from 200 to 2200 pieces/ 1 in the sediment samples. Eleven different polymers were identified in this study, and the abundance of each polymer (pieces/l) at various depths in the sediments is shown in Figure 1. These authors hypothesised that the MPs found in Mariana bottom water and sediments may be derived from industrialised regions in the Northwest Pacific and the North Pacific Subtropical Gyre, where the Pacific surface circulation may lead to long-distance transport of MPs to the Mariana Trench. Except for PP and PE, all the polymer types recorded in this study are negatively buoyant and would eventually sink. Colonisation by organisms, adherence to phytoplankton and aggregation with organic debris and small organic particles will eventually enhance settling. Deposition of MPs in the Mariana Trench may have occurred because of fast vertical transport of surface-derived material or may be due to erratic downslope sediment transport triggered by occasional earthquakes and/or repeated resuspension and deposition of material. The narrow V-shaped topography of the trench may also enhance the downslope flux of MPs into the hadal zone, and bottom currents together with propagating internal tides, may further enhance the downwelling of particles and foster the accumulation of MPs in the Mariana Trench (Peng et al., 2018).

\section{Groundwater systems}

Despite the increasing number of studies investigating the presence of MPs in surface waters, only a few address their presence in groundwater (e.g. Bouwman et al., 2018; Mintenig et al., 2019; Panno et al., 2019; Połeć et al., 2018). Not surprisingly, MPs in groundwater are found at lower counts and particle sizes than those of surface waters, because of the longer timescales of the groundwater cycle and the potential filtration through the finer sediments. As Re (2019) points out, however, the presence of non-naturally occurring fibres such as asbestos in groundwater suggests that other similarly sized emerging contaminants, such as MP fragments and fibres, should also be expected to be transported to, and through, aquifers.

Referring to Figure 2, the MPs can be transported or introduced into the soil geoenvironment in numerous ways, such as $(a)$ transportation through the vadose zone during recharge events (Bläsing and Amelung, 2018), (b) migration through the activity of earthworms (Huerta Lwanga et al., 2016; Rillig et al., 2017b), (c) transportation of the MPs in the soil matrix caused by tilling operations and crop rotation, (d) domestic septic tank discharges in rural areas (Panno et al., 2019) and/or (e) discharges of leachate through leaking landfill liners. MPs can also be introduced directly into an aquifer from losing streams, where fast-flowing stream water (often contaminated with MP-rich industrial discharges) recharges the aquifer (Re, 2019). Finally, MPs can be introduced much deeper in an aquifer, by managed aquifer recharge or aquifer storage and recovery systems (Re, 2019). These systems use surface run-off, stream water or treated WWTP effluent to recharge the aquifer, often at great depths in fully confined conditions, by means of injection. 


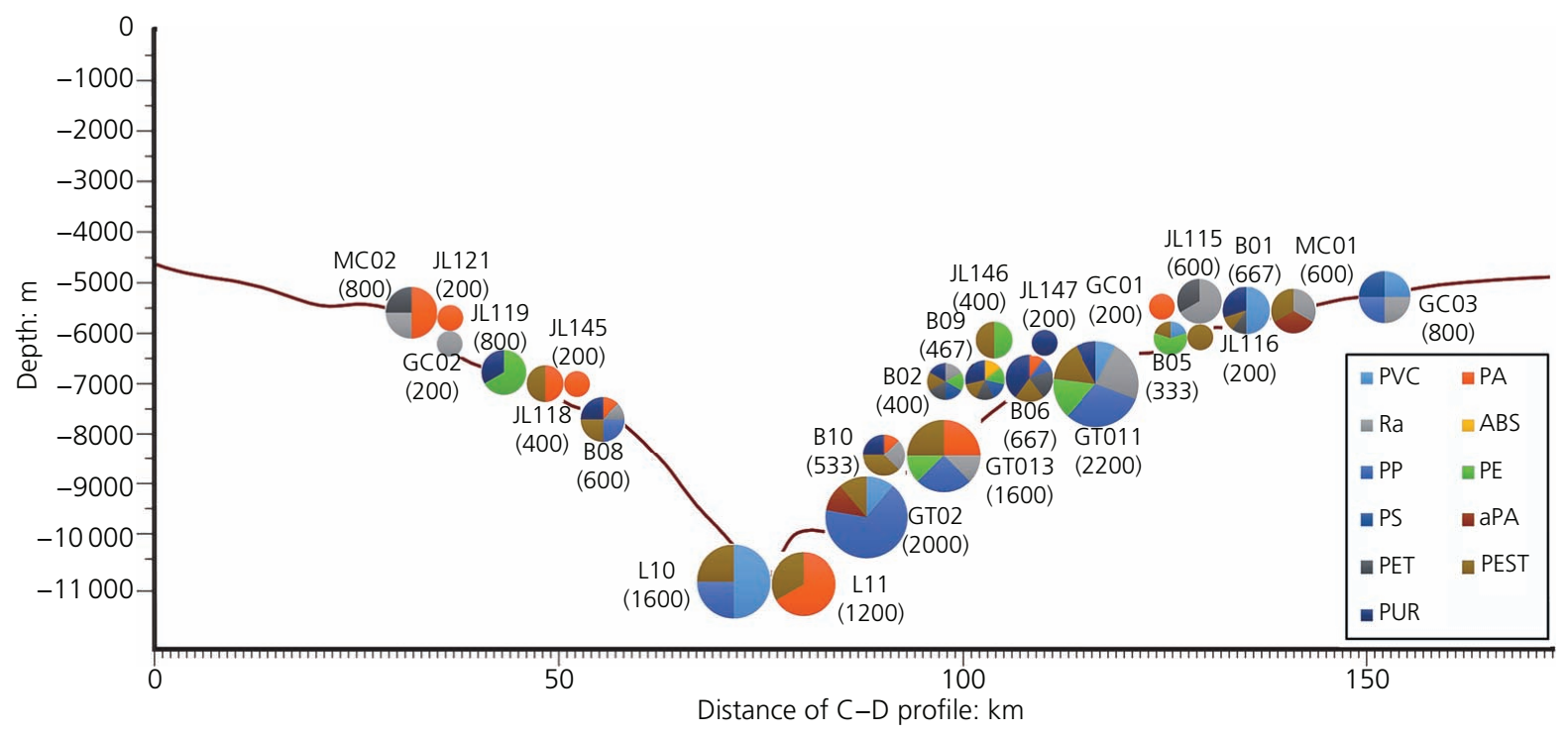

Figure 1. Profile of MP abundances and compositions in sediment samples from the Mariana Trench. Pie charts represent the MP compositions, and numbers in the brackets are the MP abundances (pieces/l). ABS, acrylonitrile butadiene styrene; aPA, aromatic polyamide; PA, polyamide; PE, polyethylene; PEST, polyester; PET, poly(ethylene terephthalate); PP, polypropylene; PS, polystyrene; PUR, polyurethane; PVC, poly(vinyl chloride); Ra, rayon. The $x$-axis corresponds to the cross-line from point $C\left(12^{\circ}\right.$ north, $141.9^{\circ}$ east) to point $\mathrm{D}$ (10.5 north, $141.3^{\circ}$ east) (adapted from Peng et al. (2018))

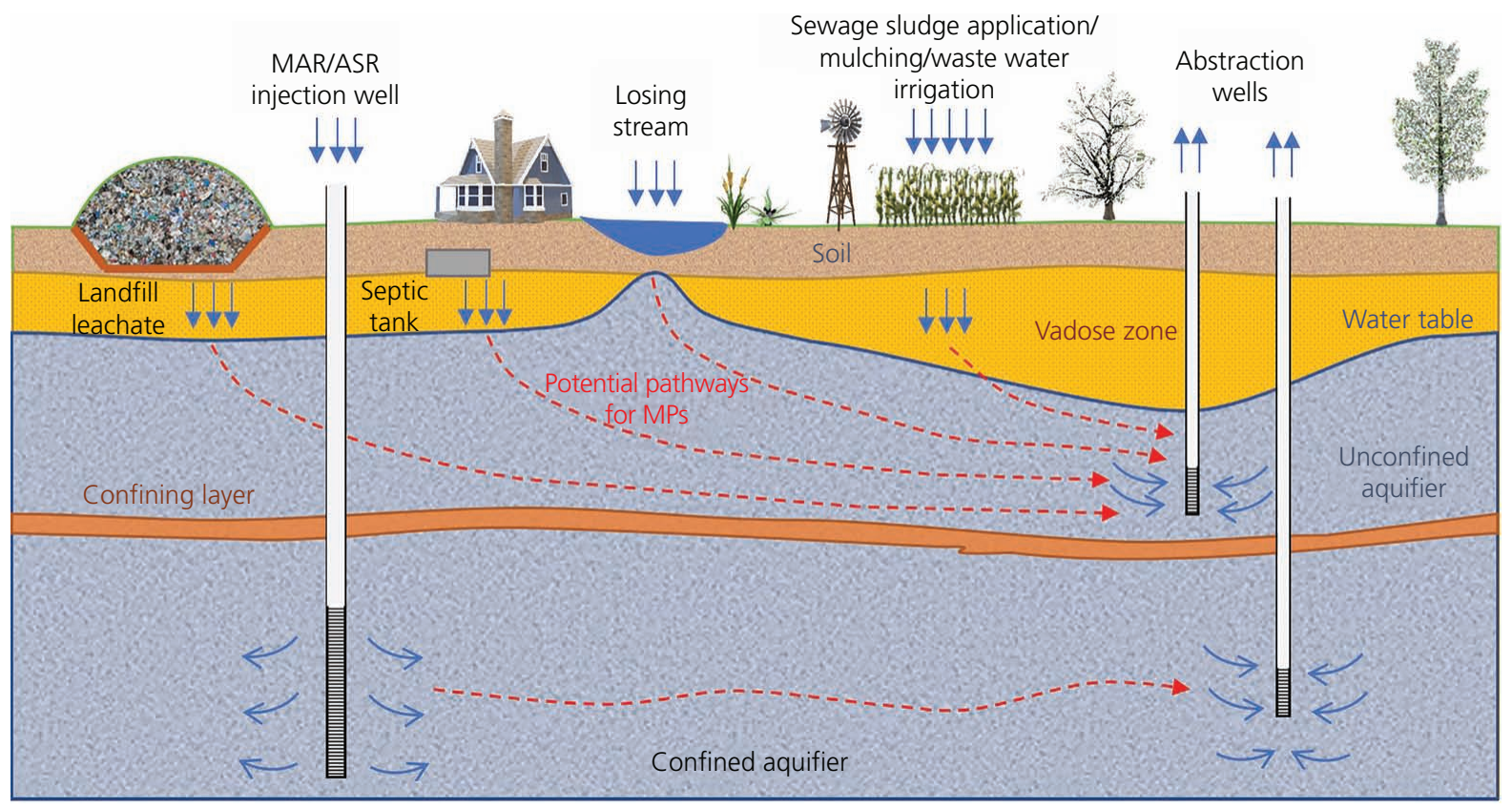

Figure 2. Schematic representation of possible pathways for MPs to enter and be transported through groundwater. ASR, aquifer storage and recovery; MAR, managed aquifer recharge

Fate and effects of MPs on the soil environment

As elaborated in the following sections, the published literature on the fate of MPs in soils and their effects on soil function is building up but remains limited, and this review is based on existing research.

\section{Processes affecting the fate of MPs in soil}

The migration, partitioning and degradation of MPs in soil environments are affected by the characteristics of the MP particles (size, shape, density and polymer type), climate (wind, rainfall and temperature), soil physics and biochemistry (e.g. soil 
biota) and other environmental factors (e.g. mechanical disturbance) (Bläsing and Amelung, 2018). Moreover, MP surfaces could be positively or negatively charged due to the weathering of friction with soil particles and oxidation of sunlight to produce an electric charge, which will affect the properties and migration processes of the MPs (Mammo et al., 2020).

The vertical and horizontal distribution of MPs in the soil can be influenced by soil physical properties, soil biota and agronomic practices (Rillig, 2012). The migration of MPs in the horizontal direction is assisted by wind erosion and/or surface run-off (Nizzetto et al., 2016). It is found that the migration depth of MPs increases significantly with an increase in number of wetting-drying (w-d) cycles. O'Connor et al. (2019) studied MP migration in sand column experiments and reported the mobility of five different MPs, including PE and PP, of various particle sizes and densities. They reported that the smallest-sized PE MPs had the greatest movement potential, and when these MPs were subjected to greater numbers of w-d cycles, the migration depth significantly increased. Increasing the volume of infiltration liquid or the surface MP concentration had only weak effects on migration depths. Further, based on the observed w-d cycle trend, they forecasted 100-year migration depths using weather data for 347 cities across China and suggested that currently accumulated MPs in sand soils could potentially penetrate into the subsurface to depths that, in the long term, could expose subterranean fauna or aquifer system receptors.

Soil microorganisms can greatly affect the migration and transformation process of MPs. These are transported downwards from the ground surface by soil biota, such as earthworms and indigenous fungal mycelia, affecting the various soil horizons (Huerta Lwanga et al., 2016; Rillig et al., 2017b; Zhu et al., 2018). Earthworms can move MPs from the surface of the soil into its pores, horizontally and vertically; the smaller the MP particle size, the easier the migration (Huerta Lwanga et al., 2016; Rillig et al., 2017b). Zhu et al. (2018) investigated the effects of three soil arthropods on the migration and transformation of soil MPs. This migration increases the risk of other microorganisms contacting MPs, affects the retention time of MPs in soil, and increases the risk of MPs entering groundwater (Huerta Lwanga et al., 2016). Several studies (Huerta Lwanga et al., 2016, 2018) have shown that earthworm gut can decompose MPs in soil, but the specific mechanism needs to be verified further by experiments. Huerta Lwanga et al. (2016) found that earthworms selectively absorbed LDPE MPs $(<150 \mu \mathrm{m}$ sized), which accumulated in their body and were then transferred to other soil organisms. Figure 3 shows LDPE MP particle-size distribution due to Gram-positive bacterial biodegradation in the earthworm gut for a period of 4 weeks (Huerta Lwanga et al., 2018). From this figure, it can be seen that there are significant reductions in biodegradation time occurring for the larger-sized particles and an increase in the smaller particle ranges measuring an average of $53.1-41.3$ to $35.4-23.6 \mu \mathrm{m}$. The authors have reported that detection of NPs and some long-chain alkanes compounds, such as octadecane, eicosane, docosane and tricosane, after 4 weeks indicates that the long-chain alkanes are products of the breakdown of the long-carbon

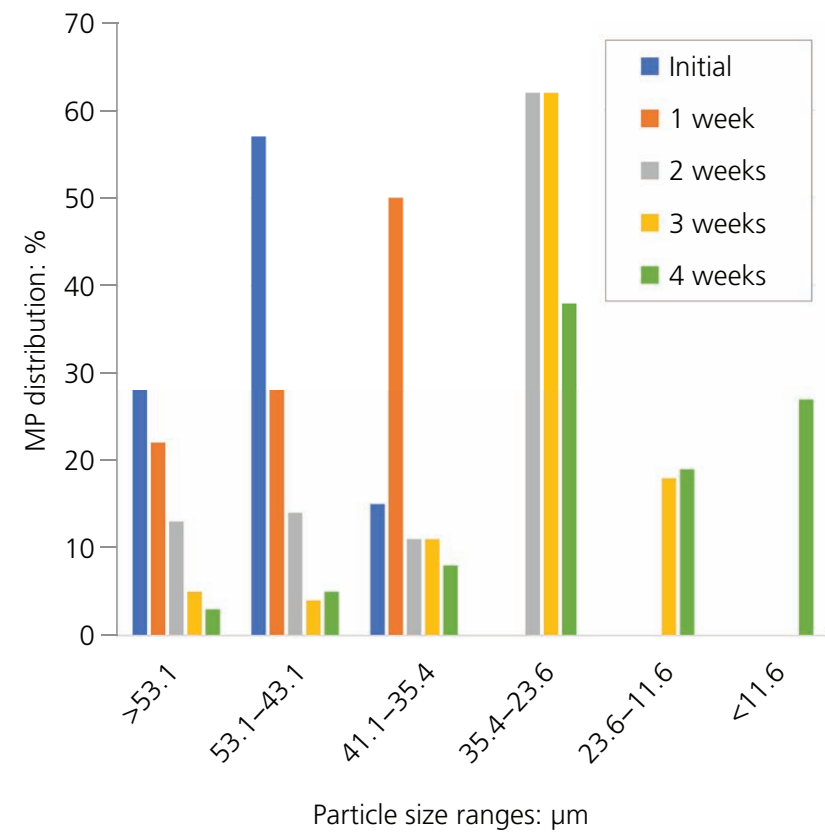

Figure 3. Particle-size distribution of LDPE MPs due to biodegradation in the earthworm gut Gram-positive bacteria, belonging to phyla Actinobacteria and Firmicutes, during a treatment period of 4 weeks (adopted from Huerta Lwanga et al. (2018))

chains of the LDPE MPs, since they were not detected in sterile soil with LDPE MPs or in soils without bacteria. Hence, it is possible that soil biota not only acts as a vector of transport of MPs in soil but can also enhance their further mobility by reducing their size.

Within the soil matrix, MPs may also bind to microorganisms and other pathogens in the soil ecosystem. Since the microbial population is smaller in deeper parts of the soil profile, decomposition/degradation of MPs by native microorganisms will be very slow, thus leading to higher retention of MPs in deeper soil layers (Kleinteich et al., 2018; Nizzetto et al., 2016). Native fungal mycelia may also aid in the downward migration of MPs through air-filled pores (Mammo et al., 2020).

It is clear from the above that the focus in the literature so far has been on agricultural soils, with little to no research on the fate of MPs in non-agricultural soils, such as landfill systems and their surroundings, which appear to be a major sink of MPs.

\section{Effects of MPs on soil}

MPs have a profound impact on the material cycle and energy flow of terrestrial ecosystems. Due to their adsorption characteristics, not only do entering MPs absorb organic pollutants (Beckingham and Ghosh, 2017), but they also act as carriers of heavy metals, increasing the bioavailability of the latter (Hodson et al., 2017) and their accumulation in the food chain through the ingestion of animals (Huerta Lwanga et al., 2016, 2017b). High MP levels may change soil chemistry by interfering with the degradation of soil organic 
matter (SOM) (Liu et al., 2017; Rochman et al., 2014). Besides, the presence of MPs can alter the soil physical structure (i.e. bulk density and water-stable aggregate), thereby affecting water dynamics in the pores (de Souza Machado et al., 2018a; Piehl et al., 2018) and impacting on soil function and biodiversity (Rillig, 2012). For instance, PMF residue can decrease soil porosity and air circulation, change microbial communities and potentially lower farmland fertility by increasing the salt content in the topsoil (Huerta Lwanga et al., 2017a). MPs have been found to affect soil aggregation and, hence, water retention and hydraulic conductivity (Zhang et al., 2020c) and desiccation potential (Wan et al., 2019). de Souza Machado et al. (2018b) reported laboratory experiments in which PEST MPs (sized between 1.54 and $6.3 \mathrm{~mm}$, with an average of $5 \mathrm{~mm}$ ) increased the water-holding capacity of a loamy sand soil, while PEST, PE and polyacrylic MPs (average sizes between 0.643 and $3.76 \mathrm{~mm}$ ) reduced its bulk density and microbial activity. However, adding MPs to the soil did not cause significant changes in hydraulic conductivity. Liu et al. (2017) found that the addition of MPs to loess soil led to a decrease in the rate of decomposition of dissolved organic matter and was hence considered beneficial for soil nutrient content. Zhang and Zhang (2020) reported that adding PEST MP fibres (mean size $2-3 \mathrm{~mm}$ ) to a reconstituted and aggregated clayey silt led to an increase in soil organic carbon in the small soil macroaggregates $(0.25-2 \mathrm{~mm})$ but not the total soil samples. This increase cannot be accounted for by the distribution of the fibres themselves among the aggregates.

\section{Effects of MPs on organisms, plants and the biogeochemical cycle}

The presence of MPs in the soil alters the biotic component of the terrestrial ecosystem. The interaction of soil microorganisms with MPs leads to alteration of their metabolic pathways through changes in their enzymatic activity (Huang et al., 2019) and the biogeochemical cycle. The surface charges on MPs give rise to electrostatic interaction between them and microorganisms - that is, a positively charged surface of an MP could adsorb onto the surface of the microbes, or vice versa, and, in turn, be ingested when these microorganisms are fed upon by their predators (Wright et al., 2013b). Further, size-selective ingestion of MPs by soil-burrowing organisms, such as earthworms, contributes to the creation of MPs with reduced sizes (Rillig, 2012), which accumulate in the body of these organisms (Gaylor et al., 2013; Huerta Lwanga et al., 2016), and/or egestion of MPs $(<50 \mu \mathrm{m})$ in the casts. Leaching of xenobiotic compounds, such as phthalates and bisphenol, from MPs and the bioaccumulation of toxic chemicals within the earthworm body significantly disrupt the endocrine system of these organisms (de Souza Machado et al., 2018a; Hodson et al., 2017; Huerta Lwanga et al., 2016). For instance, investigations by Gaylor et al. (2013) and Hodson et al. (2017) on the toxicological impact of MP ingestion on Eisenia fetida and Lumbricus terrestris earthworm species found that at lower MP concentrations $(\leq 0.5 \%$ (w/w)), exposure of E. fetida to PS MPs $(58 \mu \mathrm{m})$ in soils showed negligible effects, whereas higher concentrations (i.e. 1 and $2 \%$ ) led to stunted growth and higher mortality rates, presumably due to the damage incurred on the self-defence mechanism (Cao et al., 2017). Similar observations were made on $L$. terrestris exposed to PE MPs $(<150 \mu \mathrm{m})$. Sublethal harm to soil organisms (earthworms, springtails and nematodes) includes reproductive dysfunction (Lei et al., 2018), stunted growth (Galloway et al., 2017), weakened adaptability, internal damage (e.g. laceration), influence of substitute food on nutrient intake (Wright et al., 2013a, 2013b), inflammatory reactions, liver pressure and oxidative stress (Alomar et al., 2017). An adverse effect on the digestive system functioning of the terrestrial isopod Porcellio scaber exposed to PE MPs was reported by Kokalj et al. (2018). Further, the hydrophobic surfaces of MPs act as binding sites for various organic matter, such as lipids, proteins and nucleic acid (Shashank et al., 2020). The higher surface-area-to-volume ratio of MPs provides an arena for adsorption of organic matter and hence biological activity, and colonisation of microorganisms on MPs leads to the formation of MP biofilms - that is, the incorporation of MPs into the microbial cells and the extracellular polymeric substance matrix. These biofilms alter the metabolic activities of the microbial communities, leading to the development of pathogenicity, antibiotic resistance and so on among these communities, aside from the development of metabolic pathways aiding in the degradation of the MPs.

To date, the influence of MPs on plants has seldom been studied in the literature (Ebere et al., 2019; Li et al., 2020b). In the recent past, a few studies have demonstrated the influence of MPs on different plant species, such as Lepidium sativum, Triticum aestivum and Vicia faba (Bosker et al., 2019; Jiang et al., 2019; Qi et al., 2018). Bosker et al. (2019) demonstrated the reduction in germination rates of L. sativum seeds exposed to different sizes of MPs, while Qi et al. (2018) established the adverse effects of LDPE and biodegradable PMF residues on the root and shoot parts of the wheat plant T. aestivum during vegetative and reproductive growth. Significant changes were observed in plant biomass, elemental tissue composition, root traits, leaf traits and soil microbial activities for Allium fistulosum grown in the presence of various MPs - namely, PEST fibres, PA beads, PE, PP, PS and PEST terephthalate (de Souza Machado et al., 2019). Another study performed by seeding and planting Lolium perenne (perennial ryegrass) in soils containing biodegradable poly(lactic acid) (PLA), high-density PE and MPclothing fibres observed a significant influence on shoot lengths, dry root biomass, dry root/shoot ratio and chlorophyll $a / b$ ratio. Comparatively less seed germination success was achieved in the presence of MP-clothing fibres or PLA, as compared with the control soil (Boots et al., 2019). The study conducted by Taylor et al. (2020) observed no uptake of MPs in the internal root structure of Arabidopsis and wheat plant species, rather the accumulation of PS beads at the root surface for both species. Conversely, the study conducted by $\mathrm{Li}$ et al. (2019a), using fluorescent markers of PS, established the uptake, distribution, transportation and accumulation of $0.2 \mu \mathrm{m}$ size PS microbeads in an edible plant species (Lactuca sativa). Further, microscopic examination of the shoot system also revealed the movement of PS microbeads through intercellular spaces of the vascular system, driven along the transpiration stream. Similarly, the roots of $V . f a b a$ exposed to fluorescent MPs of various sizes have shown that the accumulation of these polymers in their 
roots resulted in reduced growth (Jiang et al., 2019). The latter studies have contradicted the conventional understanding - that polymer molecules, being larger in size compared with plant cells, should not accumulate in plants (Li et al., 2020b) - and opened a new horizon in the interaction of MPs with plants from the perspective of their fate and transmission in the food chain. While the accumulation of MPs in different regions of a plant species poses serious risks and challenges from the standpoint of transmission through the food chain, it is encouraging from the perspective of a remediation strategy, in that the plants could potentially be used as means of harvesting the MPs from a contaminated soil, although the plants themselves would still pose a risk. These issues necessitate further research to understand the mechanisms of interactions and the level of susceptibility of different plant species to MP contamination.

\section{Tools and techniques for quantification and characterisation of MPs in soils and associated challenges}

Precise quantification of MPs presence in soils is critical not only for mapping their distribution and understanding their impacts but also for developing suitable remediation strategies. However, no widely accepted testing protocol exists for identifying the level of MP contamination in soils. Focusing on the studies of MPs in natural soil, manufactured polluted soil, landfill refuse, landfill leachate and compost/fertiliser, Table 2 summarises detection details in terms of currently available identification equipment, spectral range, filter material/size, quality control test and MP type/concentration in the top 21 studies published since 2016 .

Based on this literature review and the authors' own experiences, the following steps, or different combinations thereof, are usually employed:

(a) determination of target MPs

(b) sample preparation

(c) visual inspection

(d) destructive and non-destructive testing

(e) fast detection methods

$(f)$ reporting of results.

These steps are discussed in turn next.

\section{Determination of target MPs}

Identifying test targets, including plastic type, shape and size, is an important first step because, collectively, they will guide the choice of test methods as described below. In typical soil samples, PE and PP are the most commonly found MPs, while others (e.g. PVC and PET) are also widely reported.

\section{Sample preparation}

After representative soil samples were collected, they were dried, disaggregated, sieved, floated, filtered, density-separated and/or pretreated depending on their SOM content (He et al., 2018a). Although sieving and density separation appear to be effective in isolating MPs in soil, concern may arise due to the presence of
- SOM that may potentially embed MPs and hence interfere with extraction efficiency (Zhang et al., 2018) and chemical identification accuracy (Bläsing and Amelung, 2018)

- higher-density MPs (e.g. PVC, PET and nylon) that settle out, even in density separation columns filled with saturated salt solutions, such as sodium chloride $(\mathrm{NaCl})$, calcium chloride $\left(\mathrm{CaCl}_{2}\right)$ or zinc chloride $\left(\mathrm{ZnCl}_{2}\right)$.

To address the first issue, an intermediate stage of oxidising the SOM can be performed, either by addition of oxidising chemicals (e.g. acids, alkalis or hydrogen peroxide) or through enzymatic digestions. Among these pretreatment methods, treatment with hydrogen peroxide has been the most preferred because of its minimal influence on MP surfaces compared with other methods. For separating higher-density MPs from sediments, another methodology has been proposed that consists of a number of extraction cycles using saturated sodium chloride solution, followed by ultrasonic treatment prolonging the time of floatation (Liu et al., 2018).

Pretreated samples are usually filtered through a filter membrane before visual inspection and chemical identification. The filters used for MPs identification in previous soil studies vary and include filters based on nylon, glass fibre, cellulose nitrate and aluminium oxide (see Table 2). To detect MPs accurately, it is vital to ensure that the filter has a smooth surface, good contrast and low spectroscopic background. According to the authors' own experiences, a filter with a very rough surface, such as glass fibre filter, is not suitable for MP detection. This is particularly true for the detection of small, thin and nearly transparent MPs $(<100 \mu \mathrm{m})$. For the test of MPs larger than $20 \mu \mathrm{m}$, cellulose nitrate and aluminium oxide filters are suggested due to their relatively smooth surface. For MPs between 1 and $20 \mu \mathrm{m}$, metalcoated polycarbonate (PC) filters (e.g. gold (Au)-coated PC or aluminium (Al)-coated $\mathrm{PC}$ ) are suggested because of their very smooth surface and low background Raman signal (Oßmann et al., 2017; Schymanski et al., 2018). Table 2 shows that a wide range of filter pore sizes have been reported in the literature (from 0.2 to $20 \mu \mathrm{m}$ ), which makes comparability a challenging task.

Besides filter requirements, it is also necessary to ensure that samples are well mixed to avoid potential floating or sedimentation of MPs. When high quantities of MPs are present in the sample, care must be taken to avoid aggregation or overlapping particles in the filtering process.

\section{Visual inspection}

Visual inspection of MPs by particle shape, size, texture and colour using a microscope is suitable for the detection of large MPs (ranging 0.5-5 mm) (Doyle et al., 2011), due to the significant differences of plastics from other organic/inorganic soil particles that is, apart from aluminium silicates, which have identical visual appearance (i.e. illuminating surface) as that of the MPs and, if present in the soil, would lead to misidentification and inaccurate assessment. Combined with a high-resolution camera, it is possible to detect smaller MPs and determine their size. This method is non- 


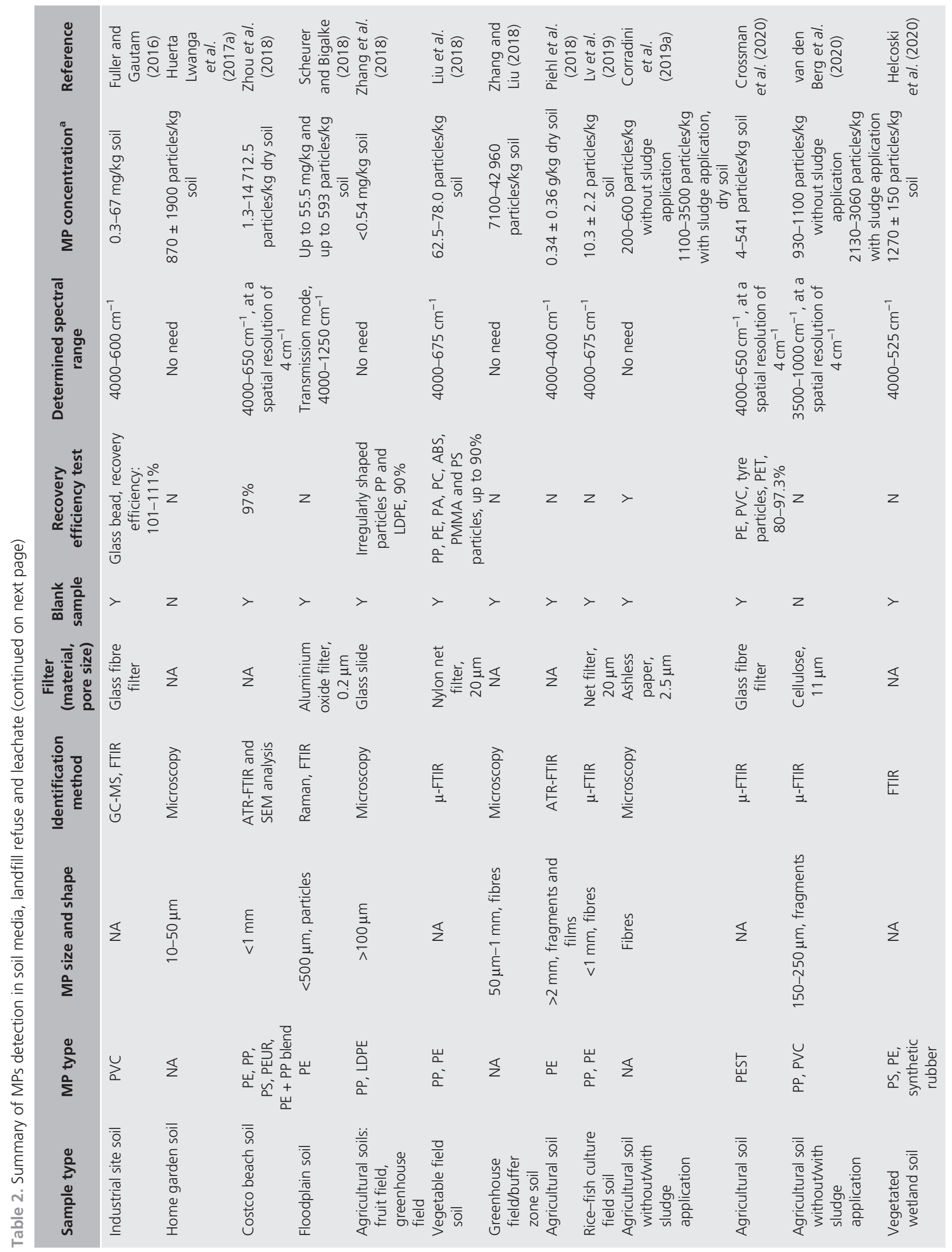




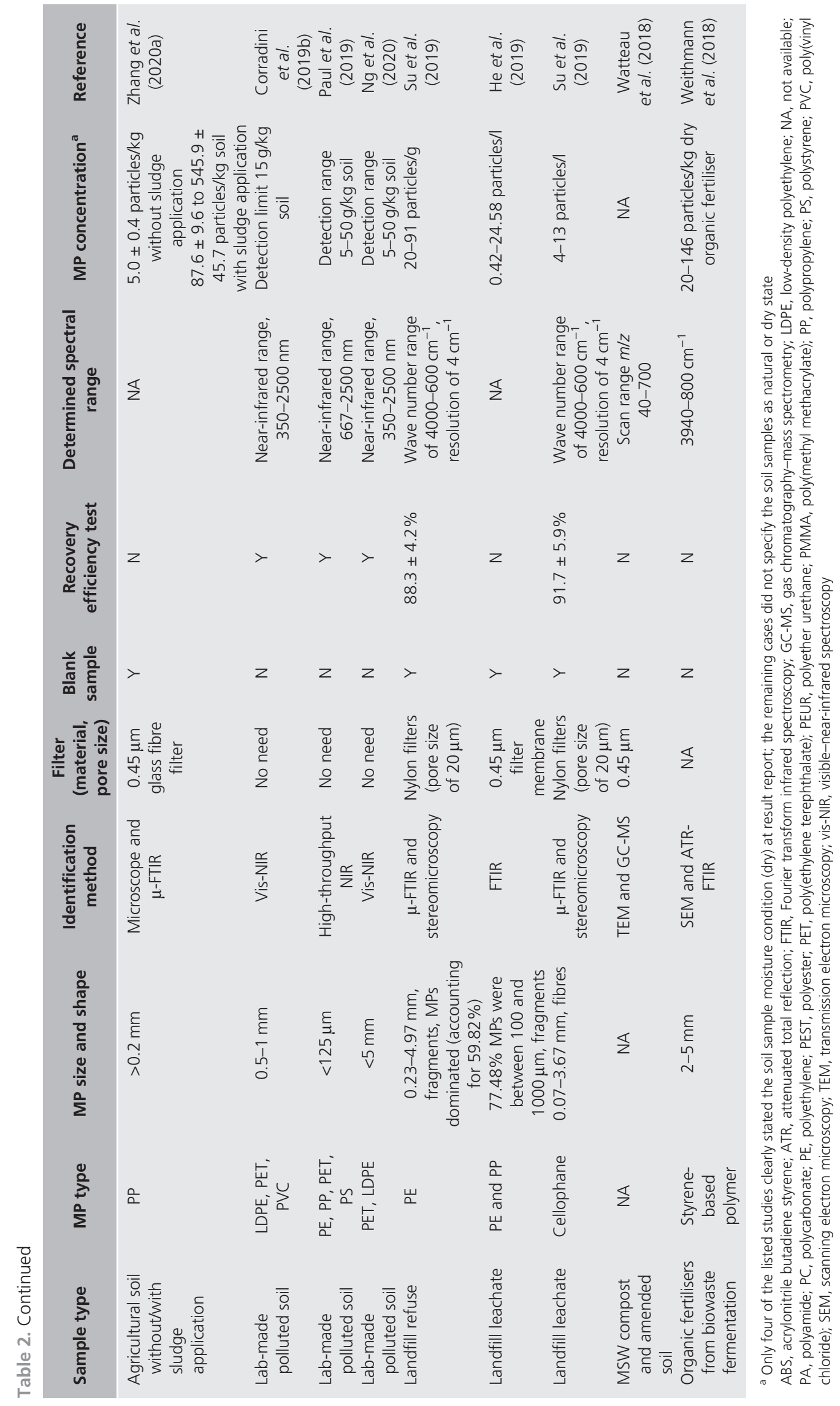


destructive, particle number countable and easy to perform by an operator. Hence, it is a relatively fast method to obtain preliminary results. Image technology, such as scanning electron microscopy (SEM), can also be used to obtain detailed surface morphology. The SEM technique has been employed to obtain magnified and clearer micrographs of MP particles, although the time required in sample preparation and the need for coating the samples with conductive paints make the identification of MPs based on surface texture and colour a difficult task (Shim et al., 2017). Furthermore, the size, shape and surface area of the determined MPs can be analysed by using image-processing software, such as ImageJ.

The main disadvantage of visual inspection is its potentially low accuracy because the results are influenced by operators' experience and quality of eyesight, sample type, location of the observation point and microscope quality (e.g. resolution and contrast). Furthermore, visual inspection does not allow the operator to distinguish different types of plastics.

\section{Destructive and non-destructive testing}

The limitations of visual inspection can be overcome by combining it with non-destructive (FTIR or Raman spectroscopy) and/or destructive (gas chromatography-mass spectrometry (GCMS)) chemical identification analyses. FTIR-based methods can screen out MPs larger than $20 \mu \mathrm{m}$, while the Raman method can detect MPs larger than $1 \mu \mathrm{m}$ (Araujo et al., 2018; Käppler et al., 2016; Li et al., 2020c; Schwaferts et al., 2019). With a highnumerical-aperture objective and a short excitation wavelength, the spatial resolution of Raman spectroscopy can be extended to around $0.5 \mu \mathrm{m}$. SEM, mentioned earlier, can provide clear images up to nanometre resolution. Overall, as the size of MPs decreases, the test time and the cost of characterisation increase. Both FTIR and Raman spectroscopy are accurate and reliable in determining the chemical identity and lateral size of MPs. However, both methods are time consuming, although FTIR is relatively more efficient than Raman for MPs larger than $20 \mu \mathrm{m}$.

There are usually three different spectral ranges used to distinguish MPs in Raman spectroscopy: 759-709 $\mathrm{cm}^{-1}$ (symmetric stretching vibration of $\mathrm{CF}_{2}$ ), $1640-1580 \mathrm{~cm}^{-1}$ (aromatic bending vibration) and $2780-2980 \mathrm{~cm}^{-1}$ (stretching vibrations of $\mathrm{CH} / \mathrm{CH}_{2} / \mathrm{CH}_{3}$ groups). For FTIR spectroscopy, there are five different spectral ranges: $1174-1087 \mathrm{~cm}^{-1}\left(\mathrm{CF}_{2}\right.$ stretching vibration), $1480-1400 \mathrm{~cm}^{-1}\left(\mathrm{CH}_{2}\right.$ bending vibration), $\quad 1760-1670 \mathrm{~cm}^{-1}(\mathrm{C}=\mathrm{O}$ stretching vibration), $1800-1740 \mathrm{~cm}^{-1}(\mathrm{C}=\mathrm{O}$ stretching vibration $)$ and $2980-2780 \mathrm{~cm}^{-1}$ (stretching vibrations of $\mathrm{CH} / \mathrm{CH}_{2} / \mathrm{CH}_{3}$ groups) (Käppler et al., 2016). It is also necessary to consider the potential filter background interference when choosing the detection spectral range.

Moreover, during testing of MPs using Raman spectroscopy, a low excitation laser power should be applied on the particles to avoid damaging or decomposing small-sized MPs (Schymanski et al., 2018). To obtain the clear spectra of small MPs, increasing accumulation and exposure times is suggested rather than directly increasing laser intensity.
The GC-MS method can rapidly and precisely quantify PE, PP, PS and PET contents (Dümichen et al., 2017) However, melting polymeric particles would lead to loss of information about particle-size distribution, which is critical information for pollution assessment. Hence, if data on the size and number of MPs are required, GC-MS is not recommended. Other recent advancements for detecting MPs in soil include the thermal extraction desorption and hyperspectral imaging technology with the potential to assess directly the presence of MPs in the soil surface (Shan et al., 2018). Finally, energy-dispersive X-ray analysis gives the atomic composition of the specimen.

It is noteworthy that the analysis time of soil samples varies dramatically depending on sample complexity, MP content and size, test area of the filter, chemical determination method and personal experience. Given a typical soil sample and the current technology, the digestion and separation time is usually around 1 to $10 \mathrm{~h}$ (Liu et al., 2018), although it could be weeks for organicrich samples (Scheurer and Bigalke, 2018). After proper filtration, the visual inspection and chemical detection for a whole filter (e.g. $47 \mathrm{~mm}$ in diameter) ranges from approximately $9 \mathrm{~h}$ to a few days using FTIR (Chen et al., 2020; Renner et al., 2020; Tagg et al., 2015). Hence, the total analysis time, including proper sample preparation and chemical identification, of a single soil sample could be at least approximately 10 to $100 \mathrm{~h}$.

\section{Fast detection methods}

In addition to the methods discussed earlier, extraction-free methods for rapid MP detection in soil have also been reported. The nearinfrared (NIR)-based method has been attracting increasing attention in the past 2 years (Corradini et al., 2019b; Ng et al., 2020; Paul et al., 2019). Using a portable spectroradiometer over the range $350-2500 \mathrm{~nm}$ (vis-NIR), the concentration of spiked MPs (PET and LDPE) can be successfully determined (Ng et al., 2020). Although it is still in the early stage of laboratory testing, the NIR-based method is a noteworthy technology for cost-effective detection of MPs.

\section{Reporting of results}

Due to the differences in measurement approaches and units reporting results, it is difficult to compare between soil studies. For example, in terms of units, 'mass of MPs per mass of soil', 'number of MP particles per mass of soil' and both of these have been adopted in 2, 11 and 1 studies, respectively, out of the top 14 studies shown in Table 2. By combining size distribution and number of MPs, it is possible to assess roughly the mass of MPs in soil. However, it is impossible to do the reverse. The water content of soil is another important information, but only three of the 14 studies referred to specify whether the test soil is dry. Hence, standardisation of the reporting format is critical to increase the comparability of studies. For instance, the number of particles $/ \mathrm{kg}$ wet soil for critical size ranges marked by agreed classification points (e.g. 100, 20 and $1 \mu \mathrm{m}$ ) should be an agreed part of result reporting, along with measured soil water content and calculated MP particles $/ \mathrm{kg}$ dry soil values. Furthermore, it is important to supply the details of a blank sample and recovery efficiency test, which can be used for study comparison 
and for uncertainty assessments. Figure 4 shows the suggested analytical protocol for the determination of MPs in soil media.

Table 3 summarises the advantages/disadvantages of the main inspection and detection methods discussed earlier.

It can be seen from Tables 2 and 3 that the most commonly used test procedures are collection and pretreatment (e.g. density separation and digestion) for MP extraction, followed by MP characterisation and identification. In terms of MP detection, out of the 21 cases summarised in Table 2, four studies have used visual inspection alone (e.g. microscopy) to determine large-sized MPs. In comparison, 14 studies have used FTIR spectroscopy (usually equipped with a microscope) to determine the chemical identity of MPs. Among these, four studies combined FTIR with GC-MS, SEM or Raman spectroscopy in order to obtain more data on the MPs (e.g. morphology and chlorine concentration). There is a clear tendency of moving away from visual inspection of large-sized MPs towards accurate chemical identification of small-sized MPs. For NPs and MPs smaller than a $500 \mathrm{~nm}$ size, however, there is no robust method to determine simultaneously the size and chemical properties due to the limits of current detection methodologies. Some studies

Two types of samples

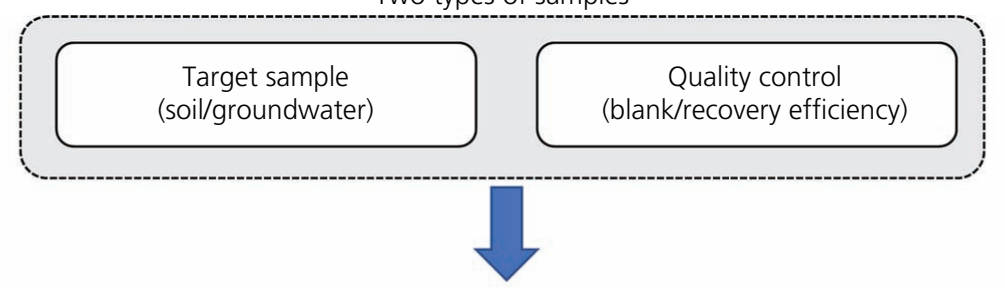

Suggested standard analytical protocol

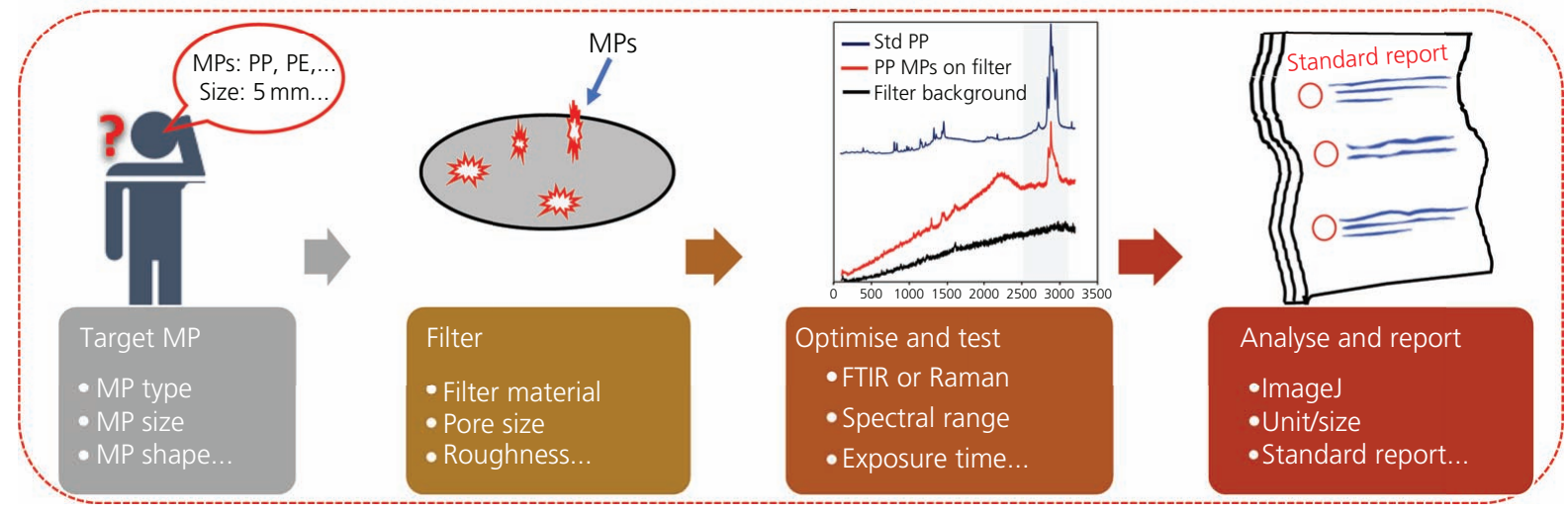

Figure 4. Suggested standard analytical protocol for determination of MPs in soil/groundwater

Table 3. Comparison of MPs detection methods

\begin{tabular}{|c|c|c|c|c|c|c|}
\hline \multirow{2}{*}{ Advantage } & \multicolumn{3}{|c|}{ Typical methods } & \multicolumn{3}{|c|}{ Extraction-free methods } \\
\hline & Visual/microscopy & FTIR & Raman & GC-MS & SEM/SEM-EDX & Vis-NIR/HT-NIR \\
\hline Low cost & ;) & 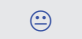 & :- & $\odot$ & 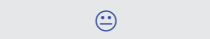 & 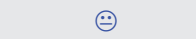 \\
\hline Low professional training requirement & ;) & (:) & : & (:) & : & 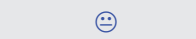 \\
\hline Fast test & :) & 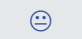 & :) & 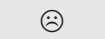 & $\dot{2}$ & $\odot$ \\
\hline Particle number countable & (:) & (;) & (:) & $\dot{2}$ & (:) & $\dot{2}$ \\
\hline Non-destructive & ;) & 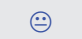 & $\odot$ & 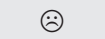 & 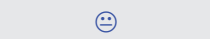 & $\odot$ \\
\hline Suitable for large MPs $(0.5-5 \mathrm{~mm})$ & (:) & (:) & (:) & 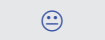 & (:) & :) \\
\hline Suitable for median MPs $(20-500 \mu \mathrm{m})$ & $\dot{2}$ & (;) & (:) & (-) & (:) & 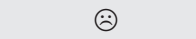 \\
\hline Suitable for small MPs $(1-20 \mu \mathrm{m})$ & $\dot{2}$ & (:) & (:) & :) & (-) & 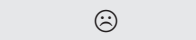 \\
\hline Suitable for nano-sized MPs $(<1 \mu \mathrm{m})$ & 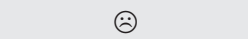 & : & (: & :) & (;) & (:) \\
\hline Suitable for chemical identification & $\dot{2}$ & (;) & (;) & (;) & ;) & ;) \\
\hline Wide range of particle sizes & (:) & 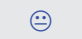 & $\odot$ & $\dot{2}$ & (:) & 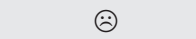 \\
\hline High accuracy & (2) & :) & (:) & (;) & (;) & 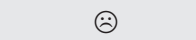 \\
\hline
\end{tabular}

$(-)$, has this advantage; $:-$, potentially has this advantage; $(;$, does not have this advantage

EDX, energy-dispersive X-ray analysis; FTIR, Fourier transform infrared spectroscopy; GC-MS, gas chromatography-mass spectrometry; HT-NIR, high-throughput near-infrared spectroscopy; Raman, Raman spectroscopy; SEM, scanning electron microscopy; Vis-NIR, visible-near-infrared spectroscopy 
(Hernandez et al., 2019; Schwaferts et al., 2019) have been successful in detecting these particles in pure and simple samples using light scattering, microscopy imaging, spectroscopy or pyrolysis GC-MS methods. For instance, the sizes of NPs and small MPs released from a teabag in hot water (Hernandez et al., 2019) were determined by SEM, while the chemical properties were determined by X-ray photoelectron spectroscopy, separately. Since the majority of these particles in the samples are NPs, the detected size can be assumed to be highly representative of the actual NP particle-size distribution. However, this is not the case for NPs in soil samples mixed with many other types of interference particles. The nature of NP aggregation is also a challenge to analyses. Hence, robust test methods for NPs and small-sized MPs in complex media, such as soil, are required. Further, no discussions have been found in the literature on how to avoid physical breakdown of degraded MP particles into smaller-sized MPs during sample preparation or how to adapt extraction procedures specifically to coarse- and fine-grained soil samples.

In summary, there is no single perfect method for MP detection in soil media. The combined application of different methods (visual inspection and chemical detection) seems a better choice for MP research, although the balance of cost, accuracy and time must be taken into consideration.

\section{MPs as carriers for other contaminants}

Role of MPs as carriers into and within aquifers

Although MPs are considered chemically inert, they can absorb persistent organic pollutants (POPs) and metals and thereby become carriers of harmful substances in the subsurface (Połeć et al., 2018). As they are transported through varying terrestrial subsurface chemistry conditions (Sarris et al., 2019; Wilson et al., 2020), points or locally distributed sources of MPs can form at locations further along the flow path. In the marine environment, MPs have been shown to function as vectors for the extended survival and dispersal of pathogens (Kirstein et al., 2016). Similar effects should be expected in the terrestrial subsurface environment, potentially resulting in significantly reduced pathogen die-off rates and increased travel distances, with consequent significant implications for the safety of groundwater drinking supplies and the characterisation of wells as safe sources of drinking water.

Notably, in manufacturing of plastics, toxic additives are included to enhance their final functional properties, such as plasticisers, flame retardants, antioxidants, acid scavengers, light and heat stabilisers, lubricants, pigments, anti-static agents, slip compounds and thermal stabilisers (Hansen et al., 2013). Only the reactive organic additives - for example, some flame retardants - are polymerised with the plastic molecules and become part of the polymer chain, while most additives are not chemically bound to the plastic polymer (Hansen et al., 2013). Release of toxic additives from various plastic products has been reported in earlier studies - for instance, phthalates (Rijk and Ehlert, 2001; Tønning et al., 2010); brominated flame retardants (Kim et al.,
2006); bisphenol-A dimethacrylate (Olea et al., 1996); lead (Pb), tin and cadmium (Al-Malack, 2001); formaldehyde and acetaldehyde (Mutsuga et al., 2006); 4-nonylphenol (Fernandes et al., 2008; Loyo-Rosales et al., 2004); methyl tert-butyl ether; benzene (Skjevrak et al., 2003); and many other volatile organic compounds (Hennesuse-Boxus and Pacary, 2003).

\section{Combined effect of MPs with other pollutants in soil ecosystem}

Due to their small particle size, large specific surface area (SSA) and strong hydrophobicity, MPs can increase the mobility of other pollutants in the terrestrial subsurface by

- sorbing and carrying them

- changing soil properties that lead to more release and transport.

Heavy metals, POPs and antibiotics have been detected on the surfaces of MPs (Hartmann et al., 2017; Rochman et al., 2013; Teuten et al., 2009). As a suitable carrier of these substances, MPs have a complex effect on the soil environment, which, depending on the setting, may contain a large number of clay minerals, metal oxides and hydroxides, humus and microorganisms along with other natural substances that can be combined with environmental pollutants. MPs can also trigger changes in the soil properties that affect the uptake of other soil pollutants present in the geoenvironment, altering the chemical forms and bioavailability of these soil contaminants (see the section headed 'Effects of MPs on soil'). However, far more research is still required to generate solid evidence on these interactions and their effects on the environment.

\section{Affinity of heavy metals towards MPs in soil}

The intrusion of MPs affects the bioavailability of heavy metals in the soil environment and their mobility into deep soil layers (or groundwater) by way of cracks in the soil and/or its porous matrix. There is no doubt that MPs can adsorb heavy metals from soil matrices and act as a vector for their transfer to soil biota and/or groundwater. Hence, it is important to understand the mechanisms driving the affinity of heavy metals towards MPs in soils and soil-groundwater. The authors' review of the literature has revealed that, while several studies have been conducted on the interaction between MPs and heavy metals in various environments, knowledge pertaining specifically to such interactions in the terrestrial subsurface remains sparse, sporadic and not always consistent (Boots et al., 2019; Brennecke et al., 2016; de Souza Machado et al., 2018a; Ebere et al., 2019; Hodson et al., 2017; Liu et al., 2018; Rillig et al., 2019; Rochman et al., 2014; Tang et al., 2018; Wang et al., 2017, 2018, 2020; Wirnkor et al., 2019; Xu et al., 2020b; Zhou et al., 2019; Zon et al., 2018). This may be due to the large number of influencing factors, with each reported experimental study investigating only a limited few.

Accumulation of metals may proceed through interactions between divalent cations and oxyanions with charged or polar sites of the plastic surface and through non-specific interactions between neutral metal-organic complexes and the hydrophobic 
MP surfaces (Holmes et al., 2012; Wang et al., 2017). For example, Zou et al. (2020) found that lead exhibited significantly stronger sorption than did copper (II) $\left(\mathrm{Cu}^{2+}\right)$ and cadmium $\left(\mathrm{Cd}^{2+}\right)$ because of strong electrostatic interactions. Furthermore, a clear trend of higher concentration of MP-sorbed heavy metals (aluminium and lead) with a higher temperature has been established based on experiments performed on PET, PA and ethylene vinyl acetate granules for temperatures ranging from 25 to $55^{\circ} \mathrm{C}$ (Oz et al., 2019). However, the effect of $\mathrm{pH}$ on interactions between MPs and heavy metals is not yet clear.

Possible attributes affecting the tendency of MPs to attract heavy metals can be grouped into two categories:

- those inherent to the MP particles (e.g. size, surface properties, porosity, morphology, material type, manufacturing process, pigments/masterbatch used for colour, natural ageing of the MP material)

- environmental conditions (e.g. dissolved organic matter, ionic concentration and salinity of the soil pore water, properties of the soil solids, contact time, $\mathrm{pH}$ value, temperature, outdoor weathering effects, formation of biofilm on MP surfaces).

In view of the different physical and chemical properties of MPs, the adsorption rate of heavy metals by MPs will vary greatly. Further, the surface structure of MPs changes due to oxidation and weathering by sunlight, and surfaces easily obtain charge, such that they readily adsorb metal ions to achieve charge balance (Hodson et al., 2017; Massos and Turner, 2017). The residence time is another important factor. For example, after a long time of UV irradiation of PVC MP fragments, the amount of copper (II) and zinc $\left(\mathrm{Zn}^{2+}\right)$ ions adsorbed on MPs has been found to increase (Bandow et al., 2017). Besides, metal cations are adsorbed by combining with polar regions or oxygen anions on the surface of plastics and forming complexes with organic compounds. For convenience, a list of several of the aforementioned factors investigated with respect to metal and plastic types is presented in Table 4. A note of caution here is that given the affinity of heavy metals towards MPs is dependent on many factors, it may be misleading to estimate accumulation based on one-to-one correlations.

The affinity of heavy metals towards MPs in the terrestrial subsurface can be significantly altered through the bioaccumulation process (Dobaradaran et al., 2018; Rochman et al., 2014; Wang et al., 2017). The reactivity of the MP surfaces is further enhanced by a change in their inherent properties due to ageing/weathering or, as shown in Figure 5, by the formation of a biofilm and chemical precipitates (Holmes et al., 2012). In fact, biofilm becomes the strongest predictor variable of metal accumulation, dominating over the substrate material and locations from where the MPs were collected. Accumulation of biofilms on MP surfaces alters their physical properties (Rummel et al., 2017), such that they attract higher concentrations of heavy metals. Similarly, aged MPs have a greater affinity towards heavy metals, as shown in Figure 5(b), on account of their higher SSA and roughness caused by the degradation of plastics mainly due to long-term photo-oxidation, corrosion, friction or other processes (Brennecke et al., 2016; Lang et al., 2020; Wang et al., 2020).

Furthermore, pigments used in the manufacturing of plastic contain certain components, such as titanium and iron oxide, which favour the formation of negatively charged surface complexes that subsequently have a greater affinity for metal cations. The adsorption of MPs is greatly enhanced with an increase in SSA and polarity. For example, accumulation of copper (II) ions is significantly greater in PVC than in PS, probably due to higher SSA and higher polarity (Brennecke et al., 2016). Finally, although the sorption coefficients of heavy metals on MPs are rather low compared with those of hydrophobic organic compounds (HOCs) on MPs, considering a similar initial concentration range, aged MPs of smaller sizes have a greater affinity towards heavy metals (Xu et al., 2020b).

\section{Affinity of organic pollutants towards MPs in soil}

Organic pollutants, such as polycyclic aromatic hydrocarbons (PAHs), hexachlorinated hexanes, polybrominated diphenyl ethers and polychlorinated biphenyls (PCBs), in the geoenvironment may sorb to MPs depending on the type of polymer (Kleinteich et al., 2018; Rochman et al., 2013; Yu et al., 2019). As such, MPs in the soil are ideal carriers of PAHs, PCBs, pesticides, herbicides and other hydrophobic organic substances, which can directly affect the distribution of POPs in the soil environment and directly threaten the health of the soil ecosystem. Several studies (Horton et al., 2017; Hüffer and Hofmann, 2016; Seidensticker et al., 2018) have found that the concentration of organic pollutants on MPs in the soil is much higher than that in the surrounding soil environment, indicating the synergistic threat of MPs and POPs on the soil regional system. Any synergetic or antagonistic effects between POPs and MPs depend on the molecular polarity of persistent organic compounds. HOCs usually lead to more serious synergetic pollution. The main factors affecting physical adsorption are the SSA and van der Waals forces, while the affinity of organic pollutants to the hydrophobic surface of MPs is the key factor affecting chemical adsorption. The hydrophobicity, crystallinity, functional groups and electrostatic attraction between MPs and organic compounds belong to their own physico-chemical properties (Mato et al., 2001), which are internal factors affecting the adsorption of MPs. Most compounds in the environment have antagonistic or synergistic effects. When adsorbed by MPs, there will be different adsorption capacities and competitive adsorption may occur. Hüffer and Hofmann (2016) studied the adsorption behaviours of four kinds of MPs - namely, PS, PVC, PA and medium-density $\mathrm{PE}$ - with seven kinds of aliphatic substances - namely, $n$-hexane, cyclohexane, benzene, toluene, chlorobenzene, ethyl benzoate and naphthalene - and found that the adsorption coefficient of MPs was closely related to their hydrophobicity. Similarly, studies undertaken by Seidensticker et al. (2018) reported that the adsorption of hydrophobic compounds was stronger than that of neutral substances. 
Table 4. Factors possibly affecting the affinity of heavy metals towards MPs in soils and soil-groundwater

\begin{tabular}{|c|c|c|c|c|}
\hline Attribute & Metal & MPs & MP particle size & Reference \\
\hline $\begin{array}{l}\text { MP SSA and polarity, surface } \\
\text { properties and ageing }\end{array}$ & Copper $(\mathrm{Cu})$, zinc $(\mathrm{Zn})$ & $\begin{array}{l}\text { PS beads, } \\
\text { PVC }\end{array}$ & $\begin{array}{l}\text { PS beads }(0.7-0.9 \mathrm{~mm} \text { dia.); } \\
\text { PVC }(1.6 \times 0.8 \mathrm{~mm})\end{array}$ & $\begin{array}{l}\text { Brennecke } \\
\text { et al. (2016) }\end{array}$ \\
\hline MP particle size and colour & $\begin{array}{l}\text { Aluminium, cadmium }(\mathrm{Cd}) \text {, chromium } \\
(\mathrm{Cr}) \text {, copper, iron }(\mathrm{Fe}) \text {, manganese }(\mathrm{Mn}) \text {, } \\
\text { nickel }(\mathrm{Ni}) \text {, lead }\end{array}$ & $\begin{array}{l}\text { Randomly } \\
\text { collected } \\
\text { MPs along } \\
\text { Persian Gulf }\end{array}$ & $2-5$ and $<0.25 \mathrm{~mm}$ & $\begin{array}{l}\text { Dobaradaran } \\
\text { et al. (2018) }\end{array}$ \\
\hline $\begin{array}{l}\text { MP SSA, porosity and } \\
\text { morphology, dissolved } \\
\text { organic matter, pH }\end{array}$ & $\begin{array}{l}\text { Cadmium, cobalt (Co), chromium, copper, } \\
\text { nickel, lead, zinc }\end{array}$ & $\begin{array}{l}\text { PE, PP, PS, } \\
\text { PVC }\end{array}$ & $\begin{array}{l}<5 \mathrm{~mm} \text { (shredded into fragments, } \\
\text { with irregular shapes and } \\
\text { thicknesses) }\end{array}$ & $\begin{array}{l}\text { Godoy et al. } \\
\text { (2019) }\end{array}$ \\
\hline $\begin{array}{l}\text { MP SSA, weathering, } \\
\text { formation of organic } \\
\text { complexes on surfaces }\end{array}$ & $\begin{array}{l}\text { Cadmium, cobalt, chromium, copper, } \\
\text { nickel, lead }\end{array}$ & PE pellets & $\begin{array}{l}<1 \mathrm{~mm} \text { (sieved through } 1 \mathrm{~mm} \text { nylon } \\
\text { mesh) }\end{array}$ & $\begin{array}{l}\text { Holmes et al. } \\
\text { (2014) }\end{array}$ \\
\hline $\begin{array}{l}\text { MP types, pH, duration of } \\
\text { contact, initial concentration } \\
\text { of heavy metals, } \\
\text { temperature }\end{array}$ & Aluminium, lead & $\begin{array}{l}\text { EVA granules, } \\
\text { PA, PET }\end{array}$ & $0.5-1 \mathrm{~mm}$ & $\begin{array}{l}\text { Oz et al. } \\
(2019)\end{array}$ \\
\hline $\begin{array}{l}\text { Formation of biofilm on } \\
\text { MPs }\end{array}$ & $\begin{array}{l}\text { Aluminium, barium }(\mathrm{Ba}) \text {, cobalt, caesium } \\
(\mathrm{Cs}) \text {, copper, iron, gallium }(\mathrm{Ga}) \text {, potassium } \\
(\mathrm{K}) \text {, magnesium }(\mathrm{Mg}) \text {, manganese, nickel, } \\
\text { lead, rubidium }(\mathrm{Rb}) \text {, uranium }(\mathrm{U})\end{array}$ & $\begin{array}{l}\text { Plastic pellets } \\
\text { (PLA, LDPE) }\end{array}$ & $\begin{array}{l}\text { Spherical PLA pellets ( } 4 \mathrm{~mm} \text { dia.) and } \\
\text { cylindrical LDPE ( } 3 \mathrm{~mm} \text { long, } 5 \mathrm{~mm} \\
\text { dia.) }\end{array}$ & $\begin{array}{l}\text { Richard et al. } \\
\text { (2019) }\end{array}$ \\
\hline $\begin{array}{l}\text { MP SSA, weathering and } \\
\text { formation of biofilm }\end{array}$ & $\begin{array}{l}\text { Silver }(\mathrm{Ag}) \text {, aluminium, calcium (Ca), } \\
\text { cadmium, cobalt, chromium, copper, } \\
\text { iron, mercury }(\mathrm{Hg}) \text {, manganese, nickel, } \\
\text { lead, zinc }\end{array}$ & $\begin{array}{l}\text { LDPE, HDPE, } \\
\text { PET, PP, } \\
\text { PVC }\end{array}$ & $\begin{array}{l}\text { Cylindrical PET pellets ( } 3 \mathrm{~mm} \text { long, } \\
2 \mathrm{~mm} \text { dia.) and spherical pellets of } \\
\text { LDPE, HDPE, PP and PVC ( } 3 \mathrm{~mm} \\
\text { dia.) }\end{array}$ & $\begin{array}{l}\text { Rochman } \\
\text { et al. (2014) }\end{array}$ \\
\hline $\begin{array}{l}\text { MP ageing, temperature, } \\
\mathrm{pH}\end{array}$ & Copper, zinc & PET debris & $\begin{array}{l}<5 \mathrm{~mm} \text { (secondary MPs produced by } \\
\text { decomposition of larger plastics due } \\
\text { to external forces) }\end{array}$ & $\begin{array}{l}\text { Wang et al. } \\
\text { (2019) }\end{array}$ \\
\hline MP particle size, $\mathrm{pH}$ & Cadmium & HDPE & $\begin{array}{l}48-58 \mu \mathrm{m}, 100-154 \mu \mathrm{m}, 0.6-1 \mathrm{~mm}, \\
1-2 \mathrm{~mm}\end{array}$ & $\begin{array}{l}\text { Zhang et al. } \\
\text { (2020b) }\end{array}$ \\
\hline $\begin{array}{l}\text { MP weathered surface, } \\
\text { formation of biofilm }\end{array}$ & Toxic metals & $\begin{array}{l}\text { PE, PEUR, PP, } \\
\text { PS, polymer } \\
\text { blend of } \\
\text { both PE and } \\
\text { PP }\end{array}$ & $\begin{array}{l}\text { Majority of MPs (about } 60 \% \text { ) } \\
\text { composed of particles }<1 \mathrm{~mm} \text {, with } \\
100-250 \mu \mathrm{m} \text { size fractions accounting } \\
\text { for about } 50 \% \text { of those particles }\end{array}$ & $\begin{array}{l}\text { Zhou et al. } \\
\text { (2018) }\end{array}$ \\
\hline MP SSA and hydrophobicity & $\begin{array}{l}\text { Silver, cadmium, chromium, copper, iron, } \\
\text { mercury, manganese, lead, antimony (Sb) }\end{array}$ & $\begin{array}{l}\text { PA, PE, PP, } \\
\text { PS, PVC }\end{array}$ & $\begin{array}{l}81.7 \% \text { of MPs measured in the range } \\
\text { of } 10-100 \mu \mathrm{m}\end{array}$ & $\begin{array}{l}\text { Zhou et al. } \\
\text { (2019) }\end{array}$ \\
\hline $\begin{array}{l}\text { Chemical structure and } \\
\text { electro-negativity of the } \\
\text { sorbents, crystallinity of MPs, } \\
\text { pH, electrostatic interaction }\end{array}$ & Cadmium, copper, lead & $\begin{array}{l}\text { CPE, PVC, } \\
\text { LDPE and } \\
\text { HDPE }\end{array}$ & $<5 \mathrm{~mm}$ (defined as MPs) & $\begin{array}{l}\text { Zou et al. } \\
\text { (2020) }\end{array}$ \\
\hline
\end{tabular}

$\mathrm{CPE}$, chlorinated polyethylene; EVA, ethylene vinyl acetate; HDPE, high-density polyethylene; LDPE, low-density polyethylene; PA, polyamide; PE, polyethylene; PET, poly(ethylene terephthalate); PEUR, polyether urethane; PLA, poly(lactic acid); PP, polypropylene; PS, polystyrene; PVC, poly(vinyl chloride); SSA, specific surface area

The presence of MPs in soils may make organic pollutants less available to soil biota and restrict their uptake in plants (Kleinteich et al., 2018), although long-term exposure of these MPs in the natural environment may lead to the release or desorption of their sorbates.

\section{Affinity of antibiotics towards MPs in soil}

Li et al. (2018b) investigated the adsorption of five kinds of antibiotics (sulfadiazine, amoxicillin, tetracycline, ciprofloxacin and trimethoprim) to five kinds of MPs (PE, PS, PP, PA and PVC). They found that PA had the strongest adsorption capacity for antibiotics, concluding that pore structure development and hydrogen bond formation were two main mechanisms. Studies undertaken by Zhang et al. (2017) on the adsorption mechanism of antibiotics onto MP surfaces demonstrated that $\mathrm{pH}$ value, ionic strength, temperature and other ageing factors have little effect on the adsorption capacity of tetracycline. The adsorption of antibiotics by MPs may lead to a compound effect - that is, they may interact with each other, causing greater harm to the soil ecosystem. Antibiotics in soil can also change the degradation process of MPs because antibiotics can reduce soil microbial community diversity (Kong et al., 2006).

\section{MP transport in soil}

Experimental investigations of MP transport in soil In the past few years, there has been a surge in the studies of MP and NP transport in porous media, mainly in the field of environmental science, with a systematic summary and comparison of 20 available experimental studies on this topic presented in 


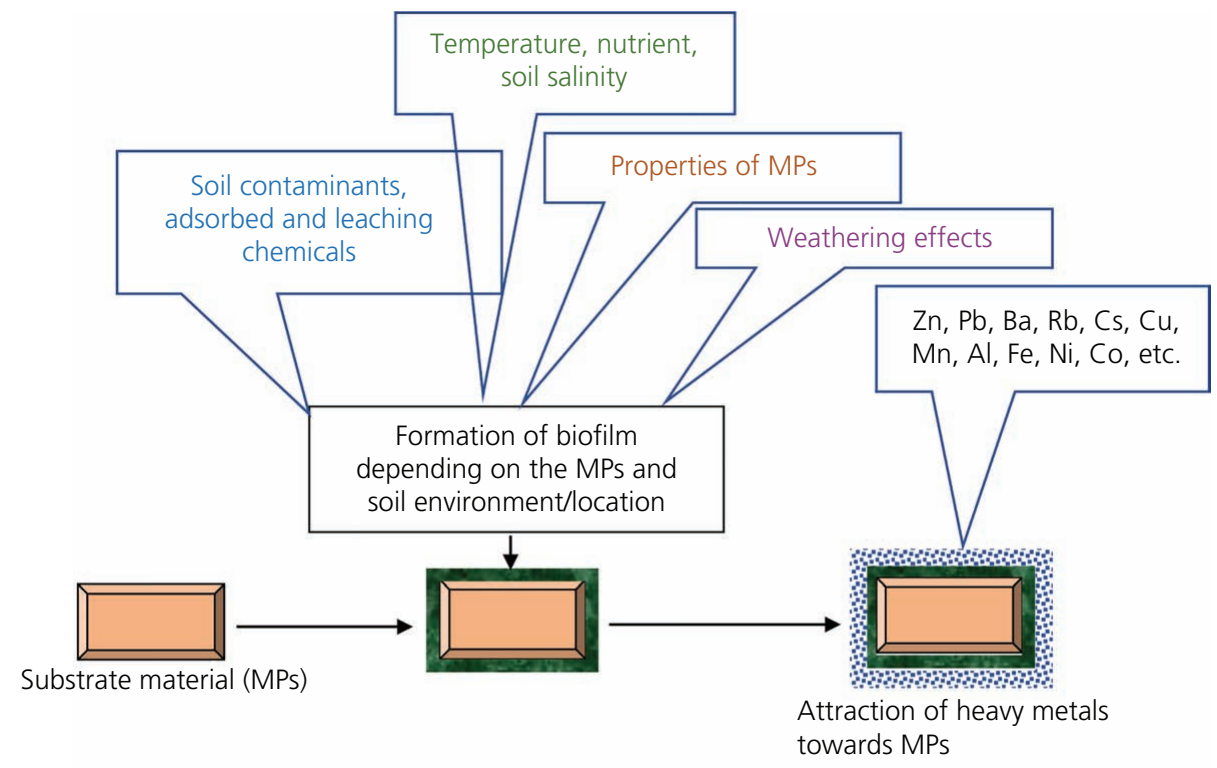

(a)

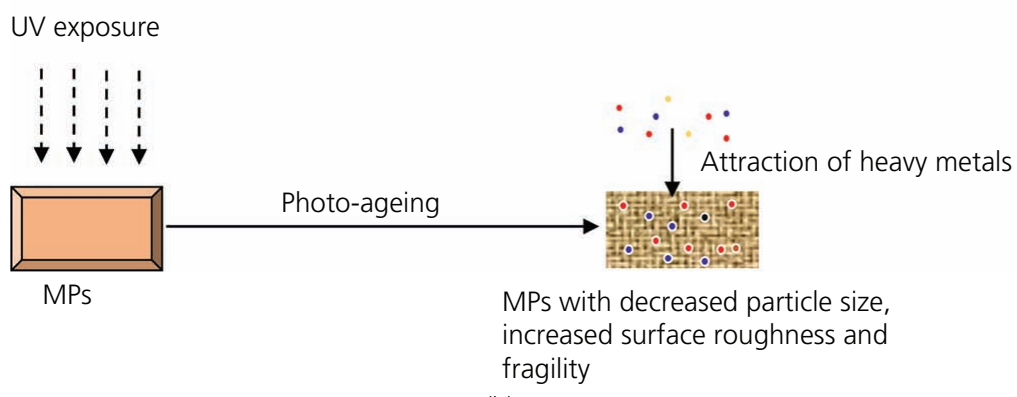

(b)

Figure 5. Accumulation of heavy metals on MP surfaces: (a) biofilm formation; (b) example of UV ageing effects

Table 5. The focuses of these studies can be categorised under the following general objectives: $(a)$ transport behaviour of MPs in clean sand and gravel; $(b)$ transport behaviour of NPs in clean sand and natural soil; $(c)$ cotransport of MPs and NPs with other microparticles in clean sand; and $(d)$ interaction between MPs, NPs and other constituents in the soil matrix. A few studies cover more than one of these objectives.

As evident from Table 5, existing studies have adopted a combination of experimental conditions selected from narrow ranges of factors and parameters. The transporting particles in these studies are typically pristine MPs and/or NPs with a few uniform sizes and arbitrary concentrations. Sometimes cotransport particles were added at concentrations that are uncommon in the natural environment. Johnson et al. (2020) reported the first set of field experimental results by releasing MPs to the clean sand and gravel sections of a constructed channel. Their measurements and data analysis techniques are similar to laboratory studies. Out of the 19 laboratory studies, only two simulated unsaturated rainwater infiltration (O'Connor et al., 2019; Waldschläger and
Schüttrumpf, 2020), while the others used saturated flow. Moreover, only one laboratory study used three types of natural soils (desert soil, black soil and red soil) containing both sand and clay (Wu et al., 2020), while the others either purchased standard clean sand or sampled local sand for washing and sieving. All the test soils were packed loosely in medium-sized columns. Among the 17 laboratory studies conducted under saturated conditions, only two studies investigated multiple flow rates (Hou et al., 2020; Zhao et al., 2020), while the other 15 studies each picked one arbitrary flow rate. The concentrations of the migrating fluid varied from freshwater to seawater, although mostly the latter. The general conclusions from the available studies are, therefore, pertinent to the impacts of the aforementioned factors and conditions on MP and NP transport in soil, while the mechanisms are mostly explained by the interaction energy using the Derjaguin-Landau-Verwey-Overbeek (DLVO) theory.

It is worth highlighting that some aspects and factors that are conventional and intuitive to geotechnical and geoenvironmental researchers have not been considered at all. Specifically, a few 
Table 5. Summary of experimental studies on the transport of MPs in soil media (continued on next page)

\begin{tabular}{|c|c|c|c|c|}
\hline Reference & $\begin{array}{l}\text { General } \\
\text { objectives }\end{array}$ & $\begin{array}{l}\text { Transporting MP } \\
\text { particles }\end{array}$ & $\begin{array}{l}\text { Soil matrix and test specimen } \\
\text { dimensions }\end{array}$ & Fluid condition \\
\hline $\begin{array}{l}\text { Johnson et al. } \\
\text { (2020) }\end{array}$ & $\begin{array}{l}\text { MP transport } \\
\text { field test }\end{array}$ & $\begin{array}{l}\text { PS, } D=0.2 \mu \mathrm{m}, \\
C=1.3 \times 10^{9} \text { particles } / \mathrm{ml} \\
D=1 \mu \mathrm{m}, \\
C=7.4 \times 10^{7} \text { particles } / \mathrm{ml} \\
\text { PMMA }, D=5.5 \mu \mathrm{m}, \\
C=1.1 \times 10^{8} \text { particles } / \mathrm{ml}\end{array}$ & $\begin{array}{l}\text { Unsaturated constructed wetland channel, } \\
12.7 \mathrm{~cm} \text { depth, } 12.7 \mathrm{~cm} \text { basal width, } \\
40.6 \mathrm{~cm} \text { surface width } \\
\text { Clean gravel, } L=19.5 \mathrm{~m}, D_{50}=4.2 \mathrm{~mm} \text {, } \\
\quad n=0.35 \\
\text { Clean sand, } L=4.9 \mathrm{~m}, D_{50}=0.42 \mathrm{~mm}, \\
n=0.25\end{array}$ & $\begin{array}{l}\text { Natural water, } 1 \text { conc., } 1 \text { pulse } \\
\text { input }\end{array}$ \\
\hline Cai et al. (2019) & $\begin{array}{r}\text { MP transport } \\
\text { cotransport }\end{array}$ & $\begin{array}{l}\mathrm{PS}, \mathrm{D}=0.2,1 \text { and } 2 \mu \mathrm{m} \\
\mathrm{C}=4 \mathrm{mg} / \mathrm{l} \\
\text { Nano-titanium dioxide } \\
\left(\mathrm{TiO}_{2}\right), \mathrm{C}=50 \mathrm{mg} / \mathrm{l}\end{array}$ & $\begin{array}{l}\text { Saturated quartz sand, } D=0.4-0.6 \mathrm{~mm} \text {, } \\
\begin{array}{l}n=0.42 \\
\phi=2 \mathrm{~cm}, L=10 \mathrm{~cm}\end{array}\end{array}$ & $\begin{array}{l}\text { Salt solution, } 3 \text { conc., } 2 \mathrm{pH}, 1 \\
\text { flow rate }\end{array}$ \\
\hline $\begin{array}{l}\text { Chu et al. } \\
\text { (2019) }\end{array}$ & MP transport & PS, $D=1.0 \mu \mathrm{m}, C=20 \mathrm{mg} / \mathrm{l}$ & $\begin{array}{l}\text { Saturated glass bead, } D=0.25-0.3 \mathrm{~mm}, \\
n=0.36 \\
\phi=3 \mathrm{~cm}, L=10 \mathrm{~cm}\end{array}$ & $\begin{array}{l}\text { Salt solution, } 4 \text { conc., } 1 \text { flow } \\
\text { rate }\end{array}$ \\
\hline $\begin{array}{l}\text { Dong et al. } \\
\text { (2018) }\end{array}$ & MP transport & $\begin{array}{l}\text { PS, } D=0.1,0.4,0.6,0.8 \\
1.5 \text { and } 2.0 \mu \mathrm{m} \\
C=30 \mathrm{mg} / \mathrm{l}\end{array}$ & $\begin{array}{l}\text { Saturated sea sand, } D_{50}=0.45 \mathrm{~mm}, n= \\
0.45 \\
\phi=1 \mathrm{~cm}, L=10 \mathrm{~cm}\end{array}$ & $\begin{array}{l}\text { Artificial seawater, } 4 \text { conc., } 1 \\
\text { flow rate }\end{array}$ \\
\hline $\begin{array}{l}\text { Hou et al. } \\
\text { (2020) }\end{array}$ & $\begin{array}{l}\text { MP transport } \\
\text { interaction }\end{array}$ & $\begin{array}{l}\mathrm{PE}, \mathrm{D}=40-48 \mu \mathrm{m}, C= \\
300,400 \text { and } 500 \mathrm{mg} / \mathrm{l}\end{array}$ & $\begin{array}{l}\text { Saturated quartz sand, } D=1-2 \text { and } \\
2-4 \mathrm{~mm}, n=0.42 \\
\phi=3 \mathrm{~cm}, L=20 \mathrm{~cm}\end{array}$ & $\begin{array}{l}\text { Salt solution with fulvic acid, } \\
5 \text { conc., } 4 \text { flow rates }\end{array}$ \\
\hline $\begin{array}{l}\text { Zhao et al. } \\
\text { (2020) }\end{array}$ & MP transport & $\begin{array}{l}\text { PS, } D=4.5 \mu \mathrm{m}, C=4.6 \times \\
10^{8} \text { particles } / \mathrm{ml}\end{array}$ & $\begin{array}{l}\text { Saturated glass bead, } D=0.5-0.6 \mathrm{~mm} \text {, } \\
\quad n=0.38 \\
\phi=1.6 \mathrm{~cm}, L=15 \mathrm{~cm} \\
\text { Plate chamber } 5 \mathrm{~cm} \times 1 \mathrm{~cm}\end{array}$ & $\begin{array}{l}\text { Salt solution, } 4 \text { conc., } 3 \text { flow } \\
\text { rates }\end{array}$ \\
\hline $\begin{array}{l}\text { O'Connor et al. } \\
\text { (2019) }\end{array}$ & MP transport & $\begin{array}{l}\mathrm{PE}, D=21,181,349 \text { and } \\
535 \mu \mathrm{m}, C=3.2 \% \text { of } \\
\text { sand by weight } \\
\mathrm{PP}, D=29 \mu \mathrm{m}, C=3.2 \% \\
\text { of sand by weight }\end{array}$ & $\begin{array}{l}\text { Unsaturated clean sand, } D_{50}=0.38 \mathrm{~mm} \text {, } \\
n=N A \\
\phi=4 \mathrm{~cm}, L=25 \mathrm{~cm}\end{array}$ & $\begin{array}{l}\text { Artificial rainwater, } 1 \text { conc., } 6 \\
\text { rainfall rates }\end{array}$ \\
\hline $\begin{array}{l}\text { Waldschläger } \\
\text { and } \\
\text { Schüttrumpf } \\
(2020)\end{array}$ & MP transport & $\begin{array}{l}\text { MP mixture consists of ten } \\
\text { pieces of the following: } \\
\text { PET, } D=1.1,1.4,1.5,2.3 \\
\text { and } 2.5 \mathrm{~mm} \\
\text { PVC, } D=1.5 \text { and } 3.2 \mathrm{~mm} \\
\text { SBR, } D=0.6 \mathrm{~mm} \\
\text { PA, } D=0.8,1.0,1.1,1.4 \\
\text { and } 2.2 \mathrm{~mm} \\
\text { PS, } D=4.8 \mathrm{~mm} \\
\text { PE, } D=1.0 \text { and } 2.2 \mathrm{~mm} \\
\text { PP, } D=1.1,1.4,3.0,3.9 \\
\text { and } 5.0 \mathrm{~mm}\end{array}$ & $\begin{array}{l}\text { Unsaturated glass bead, } D=1.5,2,3,4,6 \text {, } \\
8 \text { and } 11 \mathrm{~mm}, n=0.32-0.37 \\
\phi=19 \mathrm{~cm}, L=30 \mathrm{~cm}\end{array}$ & Pure water, 1 flow rate \\
\hline $\begin{array}{l}\text { Dong et al. } \\
\text { (2019a) }\end{array}$ & $\begin{array}{l}\text { NP transport } \\
\text { cotransport }\end{array}$ & $\begin{array}{l}\text { Nano-PS, } D=200 \mathrm{~nm} \\
C=1.5,5 \text { and } 15 \mathrm{mg} / \mathrm{l} \\
\text { Nano- } C_{60}, C=15 \mathrm{mg} / \mathrm{l}\end{array}$ & $\begin{array}{l}\text { Saturated sea sand, } D_{50}=0.45 \mathrm{~mm}, n=0.45 \\
\phi=1 \mathrm{~cm}, L=10 \mathrm{~cm}\end{array}$ & $\begin{array}{l}\text { Artificial seawater, } 3 \text { conc., } 1 \\
\text { flow rate }\end{array}$ \\
\hline $\begin{array}{l}\text { Dong et al. } \\
\text { (2019b) }\end{array}$ & NP transport & $\begin{array}{l}\text { Nano-PS, } D=200 \mathrm{~nm} \\
C=30 \mathrm{mg} / \mathrm{l}, 4 \text { surface } \\
\text { functionalities }\end{array}$ & $\begin{array}{l}\text { Saturated sea sand, } D_{50}=0.45 \mathrm{~mm}, n=0.45 \\
\phi=1 \mathrm{~cm}, L=10 \mathrm{~cm}\end{array}$ & $\begin{array}{l}\text { Artificial seawater, } 3 \text { conc., } 1 \\
\text { flow rate }\end{array}$ \\
\hline $\begin{array}{l}\text { Dong et al. } \\
(2020)\end{array}$ & $\begin{array}{l}\text { NP transport } \\
\text { interaction }\end{array}$ & $\begin{array}{l}\text { Nano-PS, } D=200,500 \text { and } \\
1000 \mathrm{~nm}, C=30 \mathrm{mg} / \mathrm{l}\end{array}$ & $\begin{array}{l}\text { Saturated sea sand, } D_{50}=0.45 \mathrm{~mm}, n=0.45 \\
\phi=1 \mathrm{~cm}, L=10 \mathrm{~cm}\end{array}$ & $\begin{array}{l}\text { Artificial seawater with } 2 \\
\text { proteins, } 9 \text { conc., } 1 \text { flow rate }\end{array}$ \\
\hline Hu et al. (2020) & $\begin{array}{l}\text { NP transport } \\
\text { interaction }\end{array}$ & $\begin{array}{l}\text { Nano-PS, } D=122 \mathrm{~nm} \\
C=10,50 \text { and } 100 \mathrm{mg} / \mathrm{l}\end{array}$ & $\begin{array}{l}\text { Saturated quartz sand, } D_{50}=0.6 \mathrm{~mm} \\
n=N A \\
\phi=2.5 \mathrm{~cm}, L=10 \mathrm{~cm}\end{array}$ & $\begin{array}{l}\text { Salt solution with naphthalene, } \\
4 \text { conc., } 1 \text { flow rate }\end{array}$ \\
\hline $\begin{array}{l}\text { Liu et al. } \\
\text { (2019b) }\end{array}$ & $\begin{array}{l}\text { NP transport } \\
\text { interaction }\end{array}$ & $\begin{array}{l}\text { Nano-PS, } D=487 \mathrm{~nm}, \\
C=15 \mathrm{mg} / \mathrm{l}, 3 \text { ages }\end{array}$ & $\begin{array}{l}\text { Saturated loamy sand, } D_{50}=0.3 \mathrm{~mm}, \\
n=0.45 \\
\phi=1 \mathrm{~cm}, L=10 \mathrm{~cm}\end{array}$ & $\begin{array}{l}\text { Salt solution with } 2 \text { non-polar } \\
\text { organic contaminants, } 8 \\
\text { conc., } 1 \text { flow rate }\end{array}$ \\
\hline $\begin{array}{l}\text { Pradel et al. } \\
(2020)\end{array}$ & NP transport & $\begin{array}{l}\text { Nano-PS, } D=200,350 \\
430 \text { and } 460 \mathrm{~nm} \\
C=5 \mathrm{mg} / \mathrm{l}\end{array}$ & $\begin{array}{l}\text { Saturated Fontainebleau sand, } \\
D_{50}=0.21 \mathrm{~mm}, n=0.4 \\
\phi=2.6 \mathrm{~cm}, L=12 \mathrm{~cm}\end{array}$ & $\begin{array}{l}\text { Salt solution, } 1 \text { conc., } 1 \text { flow } \\
\text { rate }\end{array}$ \\
\hline Wu et al. (2020) & NP transport & $\begin{array}{l}\text { Nano-PS, } D=100 \mathrm{~nm} \\
C=5 \mathrm{mg} / \mathrm{l}\end{array}$ & $\begin{array}{l}\text { Saturated natural soil, } 3 \text { types, } n=0.3, \\
0.42 \text { and } 0.45 \\
\phi=2.5 \mathrm{~cm}, L=10 \mathrm{~cm}\end{array}$ & $\begin{array}{l}\text { Salt solution, } 7 \text { conc., } 1 \text { flow } \\
\text { rate }\end{array}$ \\
\hline
\end{tabular}




\begin{tabular}{|c|c|c|c|c|}
\hline Reference & $\begin{array}{l}\text { General } \\
\text { objectives }\end{array}$ & $\begin{array}{c}\text { Transporting MP } \\
\text { particles }\end{array}$ & $\begin{array}{l}\text { Soil matrix and test specimen } \\
\text { dimensions }\end{array}$ & Fluid condition \\
\hline $\begin{array}{l}\text { He et al. } \\
\text { (2018b) }\end{array}$ & $\begin{array}{l}\text { MP and NP } \\
\text { transport } \\
\text { interaction }\end{array}$ & $\begin{array}{l}\mathrm{PS}, \mathrm{D}=0.2 \text { and } 2 \mu \mathrm{m}, \\
C=4 \mathrm{mg} / \mathrm{l} \\
\text { Nano-PS, } D=20 \mathrm{~nm}, \\
C=4 \mathrm{mg} / \mathrm{l} \\
\text { Subsequent Escherichia coli, } \\
C=1.3 \times 10^{7} \text { particles } / \mathrm{ml}\end{array}$ & $\begin{array}{l}\text { Saturated quartz sand, } D=0.3-0.43 \mathrm{~mm}, \\
\begin{aligned} n=0.42 \\
\phi=2 \mathrm{~cm}, L=10 \mathrm{~cm}\end{aligned}\end{array}$ & $\begin{array}{l}\text { Salt solution, } 4 \text { conc., } \\
1 \text { flow rate }\end{array}$ \\
\hline He et al. (2020) & $\begin{array}{l}\text { MP and NP } \\
\text { transport } \\
\text { interaction }\end{array}$ & $\begin{array}{l}\mathrm{PS}, D=0.2 \text { and } 2 \mu \mathrm{m} \\
C=4 \mathrm{mg} / \mathrm{l} \\
\text { Nano-PS, } D=20 \mathrm{~nm} \\
C=4 \mathrm{mg} / \mathrm{l}\end{array}$ & $\begin{array}{l}\text { Saturated quartz sand, } D=0.3-0.43 \mathrm{~mm} \text {, } \\
n=0.42 \text {, coated with biofilm } \\
\phi=2 \mathrm{~cm}, L=10 \mathrm{~cm}\end{array}$ & $\begin{array}{l}\text { Salt solution, } 2 \text { conc., } \\
1 \text { flow rate }\end{array}$ \\
\hline Li et al. (2019b) & $\begin{array}{l}\text { MP and NP } \\
\text { transport } \\
\text { cotransport }\end{array}$ & $\begin{array}{l}\text { PS, } D=0.2 \text { and } 2 \mu \mathrm{m}, \\
C=4 \mathrm{mg} / \mathrm{l} \\
\text { Nano-S, } D=20 \mathrm{~nm}, \\
C=4 \mathrm{mg} / \mathrm{l} \\
\text { Goethite, } C=3.5 \mathrm{mg} / \mathrm{l} \\
\text { Haematite, } C=3.5 \mathrm{mg} / \mathrm{l}\end{array}$ & $\begin{array}{l}\text { Saturated quartz sand, } D=0.3-0.43 \mathrm{~mm}, \\
\begin{aligned} n=0.42 \\
\phi=2 \mathrm{~cm}, L=10 \mathrm{~cm}\end{aligned}\end{array}$ & $\begin{array}{l}\text { Salt solution, } 2 \text { conc., } \\
1 \text { flow rate }\end{array}$ \\
\hline $\begin{array}{l}\text { Tong et al. } \\
\text { (2020a) }\end{array}$ & $\begin{array}{l}\text { MP and NP } \\
\text { transport } \\
\text { interaction }\end{array}$ & $\begin{array}{l}\text { PS, } D=0.2 \text { and } 2 \mu \mathrm{m}, \\
C=4 \mathrm{mg} / \mathrm{l} \\
\text { Nano-PS, } D=20 \mathrm{~nm} \\
C=4 \mathrm{mg} / \mathrm{l}\end{array}$ & $\begin{array}{l}\text { Saturated quartz sand, } D=0.3-0.43 \mathrm{~mm} \text {, } \\
n=0.42 \text {, mixed with two types of biochar } \\
\phi=2 \mathrm{~cm}, L=10 \mathrm{~cm}\end{array}$ & $\begin{array}{l}\text { Salt solution, } 2 \text { conc., } \\
1 \text { flow rate }\end{array}$ \\
\hline $\begin{array}{l}\text { Tong et al. } \\
\text { (2020b) }\end{array}$ & $\begin{array}{l}\text { MP and NP } \\
\text { transport } \\
\text { cotransport }\end{array}$ & $\begin{array}{l}P S, D=0.2 \text { and } 2 \mu \mathrm{m}, \\
C=4 \mathrm{mg} / \mathrm{l} \\
\text { Nano-PS, } D=20 \mathrm{~nm}, \\
C=4 \mathrm{mg} / \mathrm{l} \\
\text { Biochar, } C=100 \mathrm{mg} / \mathrm{l}\end{array}$ & $\begin{array}{l}\text { Saturated quartz sand, } D=0.3-0.43 \mathrm{~mm}, \\
\begin{aligned} n=0.42 \\
\phi=2 \mathrm{~cm}, L=10 \mathrm{~cm}\end{aligned}\end{array}$ & $\begin{array}{l}\text { Salt solution, } 2 \text { conc., } \\
1 \text { flow rate }\end{array}$ \\
\hline
\end{tabular}

conc., concentration; $D$, particle size; $D_{50}$, mean particle size; $L$, soil column length; $n$, porosity; $N A$, not available; PA, polyamide; PE, polyethylene; PET, poly (ethylene terephthalate); PMMA, poly(methyl methacrylate); PP, polypropylene; PS, polystyrene; PVC, poly(vinyl chloride); SBR, styrene-butadiene rubber; $\phi$, soil column diameter

major missing points are $(a)$ testing of natural soils with different mineral compositions and soil classifications; (b) studies with varied and realistic flow regimes, both saturated and unsaturated; (c) soil status and properties, including confining stress, temperature gradient, multiphase flows, porosity, permeability and fabric; and (d) relevant mechanistic and numerical models. Clearly, experimental complexity makes it difficult to assess the prevalence and validate models. The available studies ignored the aforementioned conditions and factors either because these are irrelevant for environmental concerns or simply for convenience. Consequently, the available results are applicable to limited situations - for example, shallow soil with a high groundwater table, coastal soil and riverine and marine sediments. Overall, there is a need for more diverse and interdisciplinary studies incorporating knowledge and objectives from geotechnics, geochemistry and hydrogeology to be conducted on this topic.

\section{Computational modelling of MP transport in soil (soil-groundwater)}

About $50 \%$ of land-based plastic wastes reach oceans through rivers alone (Atwood et al., 2019). Most of the research on MP transport is focused on the movement of MP particles in water. Less investigated are the transportation of MPs in sediments, coastal aquifers and the terrestrial subsurface more generally. Engdahl (2018) presented a numerical model for describing the transport of idealised MPs (the particle is defined solely by its size and shape) and other micro-sized fibre-like objects in saturated soil. The migrating particles are treated as discrete bead-rod chains, and the transport process is simulated as a random walk of particles in the porous media. Johnson (2020) used mechanistic pore-scale simulations and continuum-scale simulations to explain MP transport in gravel. To the authors' knowledge, these are the only available modelling works targeting specifically the transport of MPs in porous media. There are also a number of reviews that include sections on MP transport in soil, although their major focuses are diverse and environmentally oriented (de Souza Machado et al., 2018a; Guo et al., 2020; Hale et al., 2020; Li et al., 2020d; Qi et al., 2020; Wang et al., 2020; $\mathrm{Xu}$ et al., 2020b).

\section{Modelling considerations and challenges}

Modelling contaminant migration in soil requires accurate quantification of sources and sinks of MPs in soil as well as processes governing their fate, as described in the section headed 'MPs in the soil environment'. Once in soils, MP fate is driven by water flow, mechanical disturbance (ploughing, harvesting, mammalian digging), ingestion and excretion by epigean fauna, elongation of plant roots, competitive sorption and differentiation by soil aggregation, soil cracking and interaction with organic and inorganic contaminants and nutrients (Chae and An, 2018; Guo et al., 2020; Qi et al., 2020). The transport of MPs into and through subsurface environments (soil, groundwater and surface 
water) strongly depends on the MP properties (Farré et al., 2010; Geissen et al., 2010) and the environment. The challenge, overall, is to be able to characterise the relative importance of different processes mentioned earlier, under pertinent physico-chemical conditions, while taking into account the effects of plastic size, polymer type and soil structure and chemistry. Soil structure, in particular, appears to play a critical role in the distribution of MPs in soil (Zhang and Liu, 2018).

MPs are colloidal particles usually present in water as suspensions hence, models of transport must take into account colloidal interactions at micro- and nanoscales, including patterns of competitive sorption that are often difficult to capture. The DLVO theory is the most widely used framework for quantifying doublelayer electrostatic forces and van der Waals interactions between particles (Ohshima, 2012). Chu et al. (2019) used the DLVO theory and the dispersion-advection equation to simulate the transport and retention of the MPs in a saturated glass-bead column. The approach was successful in explaining the observed behaviour at small pore volumes but failed to capture non-monotonic breakthrough curves at higher pore volumes, likely due to detachment and reattachment of colloids. Extending the type of studies conducted by $\mathrm{Chu}$ et al. (2019) to actual soils and enriching transport models with other processes mentioned earlier is clearly needed. Furthermore, given that most MPs are found in topsoil, models of MP fate in it ought to consider partial saturation and capillarity.

Another challenge is to develop an understanding of the influence of hydrodynamic processes on the fate of MPs. River sediments and coastal aquifers are complex heterogeneous porous systems in which non-linear flows take place and fluctuations of the flow field typically define the smallest length scales governing the mixing. At pore scales, it is expected that molecular diffusion becomes the dominant mechanism controlling the mixing rates from pore to field scales (Meyer, 2014). Reviewing recent investigations on the effects of flow rates on the mixing, it is observed that the chemical residence time is controlled by hydrodynamics, which in turn controls the fate of MPs, not just by the advective transport but also with the non-Fickian (anomalous) mixing process (Baioni et al., 2020). Therefore, reliable modelling of the soil-MP interactions needs incorporating the effects of such complex non-Fickian mixing on the MP pollution in the coastal zone, as investigations show that an estimated value of $250 \mathrm{Mt}$ plastic components reached marine environments in 2015 (Wright and Kelly, 2017).

Another key research interest - alongside the fate of MPs - is the effect of the presence of NPs and MPs on the transport of other contaminants. Hu et al. (2020) found that naphthalene is more mobile in the presence of very small PS MPs (average size of $120 \mathrm{~nm}$ ) but that the relationship depended on the ionic strength of the solution. They also reported that, conversely, these particles have lower mobility in the presence of naphthalene. Another study, also using a glass-bead analogue, found evidence of comobility between the mobile organic fraction and very small MP particles (Keller et al., 2020). Hüffer et al. (2019) showed that PE MPs reduce the capacity of soil to sorb hydrophobic pesticides. Hence, it is clear that, while the mobility of MPs in soils remains an open question, their effects on the mobility of other contaminants of high relevance to environmental geotechnics are equally, if not more, important.

\section{Mitigation-remediation measures}

\section{Strategies for reduction and removal of MPs in the geoenvironment}

Separation of MPs from the soil has proven to be a major challenge in efforts to remediate soils contaminated with MPs. Unlike other contaminants such as heavy metals and organic pollutants, there are no 'established' techniques for remediation of MPs (Bhattacharya and Khare, 2020). However, various strategies for prevention, reduction and/or removal of MPs from the environment are being researched. These can be categorised as pre-emptive strategies, control or management strategies and remediation strategies.

\section{Pre-emptive and control/management strategies}

Pre-emptive strategies include social awareness measures, transition towards use of biodegradable plastics and regulatory measures to limit the use of plastics (McDevitt et al., 2017; Silva et al., 2018; Steensgaard et al., 2017; Wu et al., 2017). Regulatory measures, such as limiting the use of MPs in certain products; disincentivising the use of plastic items, packaging and carrier bags; and restricting the landfilling of plastics, would aid in reducing some of the sources of MPs. Reducing the amount of MPs introduced into agricultural soils through the application of composts and organic fertilisers requires a special effort. This includes avoidance of the overuse of compost and fertilisers, including sludge, and waste water irrigation, as well as better characterisation of their MP concentrations. Guidelines (standards) for the application of PMF in farm-specific conditions and practices need to be evaluated further to help farmers adopt sustainable practices. The separation of MPs at the source (e.g. plastic waste from unsegregated MSW feedstocks) is another possible measure. Such separated municipal plastic waste can be utilised as an energy source in waste-to-energy generation (Sai et al., 2018) and as construction materials for manufacturing of civil engineering composites (Goli et al., 2020). Moreover, LFMSF (also known as soil-like materials), generated during landfill mining activities, could be a potential source of MPs in agricultural soils, when they are utilised as fertilisers (Chandana et al., 2021; He et al., 2019). Hence, proper care should be taken in (a) quantification of MPs and the associated risk and (b) monitoring of the application of LFMSF in agricultural fields.

Use of biodegradable plastics has also been considered as a preemptive, more sustainable alternative (Lambert and Wagner, 2017; Rujnić-Sokele and Pilipović, 2017). However, questions have been raised about the actual degradability of 'biodegradable' plastic in real environments, as opposed to laboratory environments (Harding et al., 2017), particularly with antioxidant additives used to increase the 
design life and/or antimicrobial resistance of plastics (Harding et al., 2017; Lambert and Wagner, 2017).

Control or management strategies refer to the use of engineering or technological interventions to remove MPs from sources. These include measures implemented at WWTPs (Wu et al., 2017) and interventions to remove and reuse MPs from sediments and freshwater bodies (Eriksen et al., 2018). Carr et al. (2016) suggest that the majority of MPs are removed from the effluents of WWTPs during primary and secondary treatment stages. More effective MP removal processes generate higher MP concentration in the sludge. However, without special treatment for MP removal from WWTP effluent and relying only on standard processes of treatment, a large proportion of the MPs remain in the effluent. Various processes such as biologically active filtration (Talvitie et al., 2017b), membrane bioreactors (MBRs) (Lares et al., 2018; Talvitie et al., 2017a), dissolved air floatation, rapid sand filtration and disc filters (Talvitie et al., 2017a) have been evaluated for their efficiencies in removing MPs from the effluents of these treatment plants. While each of these techniques has been successful in reducing MPs from effluents, their level of efficiency has been shown to be highly variable, with MBRs being the most efficient and disc filters being the least (Lares et al., 2018; Talvitie et al., 2017a).

\section{Remediation strategies}

Several remediation strategies based on physical degradation, chemical degradation, catalytic degradation and biodegradation have been developed and are being adopted. Among these, bioremediation based on the microbial degradation of soil contaminated with MPs has become popular because the soil is a habitat for a wide range of microorganisms, which, as elaborated below, are sometimes quite efficient in the degradation of plastics (Pathak and Navneet, 2017). The majority of plastics have low biodegradability (Wei and Zimmermann, 2017), although a few such as PLA, polyhydroxyalkanoate and polyhydroxybutyrate are highly biodegradable. Several biodegradation mechanisms are at play (see Figure 6), but two, in particular, have been prominently investigated for degradation of complex polymers in soils: a direct action, in which the degraded plastic fragments provide a nutritional source for microbial growth, and an indirect action, in which microbial metabolic products such as enzymes degrade the plastic structure, both operating under aerobic and anaerobic conditions (Ahmed, 2018; Ghosh et al., 2013; Shah et al., 2008). Although several studies have been conducted on the microbial degradation of MPs (Guo et al., 2020; Sarker et al., 2020; Yuan et al., 2020), most are laboratory investigations. Hence, in situ investigations are needed that would better reflect the diverse and complex characteristics of different types of soils.

When microbes are introduced to MPs, they first adhere to exposed polymer surfaces, colonising them to produce enzymes (Lam et al., 2008), which prompt hydrolysis of polymers. As such, this hydrolytic division splits polymer chains by ester bond formation, which in turn causes degradation of polymers into oligomers, dimers and monomers. The degraded products are

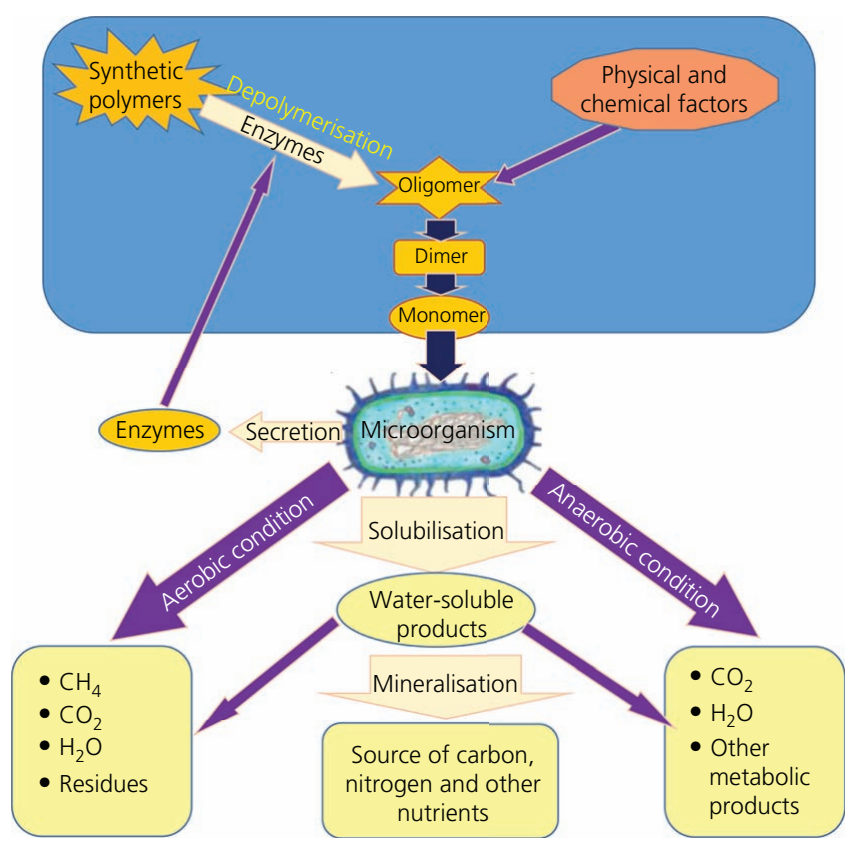

Figure 6. Mechanisms of biodegradation of plastics by microorganisms under aerobic and anaerobic conditions

taken up by microorganisms through their semipermeable membranes and are eventually converted to carbon dioxide and water by mineralisation (Tokiwa et al., 2009).

Under aerobic conditions, microbes use oxygen as an electron acceptor and produce methane $\left(\mathrm{CH}_{4}\right)$, carbon dioxide, water and other residues as end products (Priyanka and Archana, 2012). Under anaerobic conditions, polymers are degraded in the absence of oxygen by microorganisms through the catalytic activity of enzymes. Sulfate, nitrate, iron and manganese are used as electron acceptors, and carbon dioxide, water and other metabolic products are produced (Priyanka and Archana, 2012).

In the pure-culture method (ex situ approach), specific bacteria/ fungi that are isolated and cultured using different nutrient media are added to the MP-contaminated soil, which is then incubated in a reactor under optimal conditions for a specific period (Hadad et al., 2005). Samples are later retrieved and assessed for degradability of plastics. In the compost method, a known weight of dry plastic is admixed with a definite amount of mature compost and the mixture is incubated at a particular temperature and moisture. Evidence in the literature indicates that, among the different soil MP-bioremediation techniques, the pure-culture method appears to be the most effective (Shahnawaz et al., 2019).

\section{Concluding remarks and way forward}

MPs have emerged as one of the top environmental issues due to their prevalence in, and impacts on, aquatic and terrestrial ecosystems - the vast scale of which is only just becoming apparent. Impacts of MPs in soils include their entry into the food 
chain through fauna and flora capable of absorbing MPs, which is exacerbated by their slow rate of degradation under ambient in situ conditions. Lastly, MPs can influence soil bio-physicochemical properties and the mobility of other contaminants in soil, with potentially significant implications for groundwater quality.

In this paper, the authors have reviewed available evidence for, and knowledge of, MP contamination of the terrestrial subsurface and its effects on key soil ecosystem functions. Through the review, the authors have identified five key research gaps in the literature (presented below in no particular order of importance), with particular emphasis on aspects of soil and groundwater behaviour of interest to environmental geotechnics:

(a) better analytical characterisation of MPs and NPs in the soil

(b) mapping of MP prevalence in soils and groundwater and its effects on soil physical, chemical and biological conditions and properties

(c) better understanding and quantification of the fate of MPs in soils, including their effects on the mobility of other soil contaminants

(d) better understanding and quantification of MP fate in landfills and their environments

(e) better remediation strategies for MP pollution in soils.

The above research goals require concerted, multidisciplinary effort. Nevertheless, with the exception of goal (a), they are ones in which geotechnical and geoenvironmental concepts, approaches and protocols - theoretical, experimental and computational - are paramount.

\section{Analytical characterisation of MPs and NPs}

The lack of established analytical protocols for measuring concentrations of NPs and smaller-sized MPs is a serious obstacle. Analytical methods used in most studies found in the literature are capable of detecting only those particle sizes greater than typically $1 \mu \mathrm{m}$, such that the extent of the prevalence of NPs and smaller-sized MPs in the environment is not known. The ability to detect NPs and smaller MPs is, therefore, clearly an important methodological gap and a research priority. As shown in this paper, the lack of protocol for result reporting is an obstacle to the comparability of studies, which hampers scientific progress on MPs. The precise detection and quantification of the types and extents of MPs present in soils using standardised tools/techniques is required not only to understand the level of contamination but also to inform the adoption of suitable remediation strategies. The combined application of visual inspection and chemical detection methods seems a better choice for MP research, although the balance of cost, accuracy and time must be taken into consideration. The proposed standard analytical protocol of MP detection in soil media, elaborated earlier in the paper, provides focused direction for the research community in this regard.

\section{MP prevalence and effects in soils}

Many studies mention groundwater as a potential receptor of MP fibres and fragments, but only a very limited number address their presence in aquifers. The development of accurate and groundwater-specific MP detection and quantification standards will boost research efforts, minimise biases and increase understanding of MP existence in aquifers. To that end, including MPs in existing emerging contaminant-monitoring programmes would be vital for the development of this new research area. Further, it is recommended that local, regional and global pollution maps be generated highlighting land use-land change patterns and showing the extent of MP contamination. This is essential as part of an environmental risk assessment framework required to manage this new anthropogenic pollutant.

To the best of the authors' knowledge, no attempt has been made at studying the effect of MPs on soil mechanical properties and slope stability, and given the widespread prevalence of MPs, there is a need, from an environmental geotechnics perspective, to characterise better the effects of MPs on the mechanical and hydraulic properties of soils. From a biological point of view, the role of MPs in transforming soil-microbial ecology and, hence, its implications for geoenvironmental physico-chemical processes have not been investigated either. Such changes can affect soil-plant interactions and soil biodiversity, which have far-reaching consequences on all living species. Of particular interest is the exposure of soil biota to different levels of MP contamination in soil, considering the coexistence of other contaminants and, given the persistence of MPs, transgenerational effects.

\section{Fate of MPs in soils}

Understanding and quantifying transport mechanisms, degradation and transformation processes governing MPs in soil and groundwater environments are urgently required. Equally important is an understanding of the role of MPs as contaminant carriers and their long-term cumulative and synergistic pollution effects on soil ecosystem functions, including biodiversity at different scales and subsurface water quality. This includes efforts to understand the direct and indirect influence of the MP shape, size, composition and concentration on the key processes of soil aggregation and soil physico-chemical and hydromechanical properties.

There is ample evidence of sorption of heavy metals onto MPs, which can then act as pollutant carriers. However, far more work is needed in this area, as well as a better understanding of the interaction of MPs with organic contaminants and the effect of MPs on the mobility of organic and inorganic soil contaminants through ways other than direct carrying. For example, it is still not clear whether the characteristics of MPs or environmental conditions play a more important role in heavy metal sorption on MPs. Based on such knowledge, it may be possible to modify sources of MPs during the manufacturing process so as to reduce future heavy metal mobility in soil.

Interdisciplinary studies incorporating knowledge and objectives from geotechnics, geochemistry and hydrogeology are required in this regard. Computational modelling frameworks of MP transport in soil need to be developed, extended and calibrated to consider 
complex interactions between MPs and other chemicals under complex environmental conditions pertinent to specific field scenarios.

\section{MPs in landfill environments}

The number of studies of MPs in municipal waste landfills is still limited but already strongly indicates that they constitute major sinks for MPs and potentially major sources of MP pollution in soils. This is unsurprising given the amount of plastic of different sizes and of SS received by landfills. To the best of the authors' knowledge, not a single study can be found in the literature investigating the extent to which MP's pollution has affected environments adjacent to municipal waste landfills (base liners, soil buffers, aquifers and neighbouring sites). Quantification of the fluxes of MPs in landfill waste (input, discharge by leachate treatment, escape into the wider environment) is urgently required, as well as an understanding of the capacity of conventional base liners to prevent MP contamination of the subsurface.

\section{New treatments}

To address the MP terrestrial pollution problem, concentrated efforts are required in developing comprehensive pre-emptive strategies (e.g. transiting towards the use of biodegradable plastics), control or management strategies (including use of engineering or technological interventions to remove MPs from sources that contribute these pollutants into the geoenvironment) and green and sustainable remediation strategies. New treatment and/or methods for removing or reducing MP contamination at the source or within the soil are therefore needed. For example, given the poor efficacy and slow degradation rate of many plastics, there is a great need for the evolution of new microbes, enzymes and degradation pathways that can convert recalcitrant plastics into harmless monomers with a focus on beneficial end products. Use of 'active microbial consortia', 'Blue Technology' and 'plastisphere' seem to have greater potential for natural bioremediation processes. Another example is research and development of biodegradable PMF and multifunctional mulch recovery machinery that can help promote effective management and control of residual mulch pollution.

This is, however, a rapidly changing field, and the paper is intended for providing guidance to researchers and policymakers with interest in this field. It is a contribution to a mounting worldwide effort at tackling a widespread environmental problem that threatens lives and livelihoods.

\section{REFERENCES}

Ahmed T (2018) Biodegradation of plastics: current scenario and future prospects for environmental safety. Environmental Science and Pollution Research 25(8): 7287-7298, https://doi.org/10.1007/s11356-018-1234-9. Al-Malack MH (2001) Migration of lead from unplasticized polyvinyl chloride pipes. Hazardous Materials 82(3): 263-274, https://doi.org/ 10.1016/S0304-3894(00)00366-6.

Albertsson AC (1980) The shape of the biodegradation curve for low and high density polyethenes in prolonged series of experiments. European Polymer Journal 16(7): 623-630, https://doi.org/10.1016/0014-3057(80)90100-7.
Alimi OS, Budarz JF, Hernandez LM and Tufenkji N (2018) Microplastics and nanoplastics in aquatic environments: aggregation, deposition, and enhanced contaminant transport. Environmental Science \& Technology 52(4): 1704-1724, https://doi.org/10.1021/acs.est.7b05559.

Alomar C, Sureda A, Capó X et al. (2017) Microplastic ingestion by Mullus surmuletus Linnaeus, 1758 fish and its potential for causing oxidative stress. Environmental Research 159: 135-142, https://doi. org/10.1016/j.envres.2017.07.043.

Andrady AL (2011) Microplastics in the marine environment. Marine Pollution Bulletin 62(8): 1596-1605, https://doi.org/10.1016/j. marpolbul.2011.05.030.

Araujo CF, Nolasco MM, Ribeiro AM and Riberio-Claro PJ (2018) Identification of microplastics using Raman spectroscopy: latest developments and future prospects. Water Research 142: 426-440, https://doi.org/10.1016/j.watres.2018.05.060.

Arkatkar A, Arutchelvi J, Bhaduri S, Uppara PV and Doble M (2009) Degradation of unpretreated and thermally pretreated polypropylene by soil consortia. International Biodeterioration and Biodegradation 63(1): 106-111, https://doi.org/10.1016/j.ibiod.2008.06.005.

Atwood EC, Falcieri FM, Piehl S et al. (2019) Coastal accumulation of microplastic particles emitted from the Po River, Northern Italy: comparing remote sensing and hydrodynamic modelling with in situ sample collections. Marine Pollution Bulletin 138: 561-574, https:// doi.org/10.1016/j.marpolbul.2018.11.045.

Baioni E, Porta GM, Mousavi Nezhad M and Guadagnini A (2020) Assessment of turbulence effects on effective solute diffusivity close to a sediment-free fluid interface. Stochastic Environmental Research and Risk Assessment 34(12): 2211-2228, https://doi.org/10.1007/ s00477-020-01877-y.

Bandow N, Will V, Wachtendorf V and Simon FG (2017) Contaminant release from aged microplastic. Environmental Chemistry 14(6): 394-405, https://doi.org/10.1071/EN17064.

Barnes DKA, Galgani F, Thompson RC and Barlaz M (2009) Accumulation and fragmentation of plastic debris in global environments. Philosophical Transactions of the Royal Society B: Biological Sciences 364(1526): 1985-1998, https://doi.org/10.1098/rstb.2008. 0205 .

Beckingham B and Ghosh U (2017) Differential bioavailability of polychlorinated biphenyls associated with environmental particles: microplastic in comparison to wood, coal and biochar. Environmental Pollution 220(Part A): 150-158, https://doi.org/10.1016/j.envpol. 2016.09.033.

Bergmann M, Wirzberger V, Krumpen T et al. (2017) High quantities of microplastic in arctic deep-sea sediments from the Hausgarten observatory. Environmental Science \& Technology 51(19): 11000-11010, https://doi.org/10.1021/acs.est.7b03331.

Bhattacharya A and Khare SK (2020) Ecological and toxicological manifestations of microplastics: current scenario, research gaps, and possible alleviation measures. Environmental Science and Health, Part C 38(1): 1-20, https://doi.org/10.1080/10590501.2019.1699379.

Bläsing M and Amelung W (2018) Plastics in soil: analytical methods and possible sources. Science of the Total Environment 612: 422-435, https://doi.org/10.1016/j.scitotenv.2017.08.086.

Boots B, Russell CW and Green DS (2019) Effects of microplastics in soil ecosystems: above and below ground. Environmental Science \& Technology 53(19): 11496-11506, https://doi.org/10.1021/acs.est. $9 \mathrm{~b} 03304$.

Bosker T, Bouwman LJ, Brun NR, Behrens P and Vijver MG (2019) Microplastics accumulate on pores in seed capsule and delay germination and root growth of the terrestrial vascular plant Lepidium sativum. Chemosphere 226: 774-781, https://doi.org/10.1016/j. chemosphere.2019.03.163.

Bouwman H, Minnaar K, Bezuidenhout C and Verster C (2018) Microplastics in Freshwater Water Environments: A Scoping Study. Water Research Commission, Pretoria, South Africa, WRC Report No. 
2610/1/18. See http://www.wrc.org.za/wp-content/uploads/mdocs/ 2610-1-18.pdf (accessed 26/03/2021).

Brennecke D, Duarte B, Paiva F, Caçador I and Canning-Clode J (2016) Microplastics as vector for heavy metal contamination from the marine environment. Estuarine, Coastal and Shelf Science 178: 189-195, https://doi.org/10.1016/j.ecss.2015.12.003.

Briassoulis D and Giannoulis A (2018) Evaluation of the functionality of bio-based plastic mulching films. Polymer Testing 67: 99-109, https:// doi.org/10.1016/j.polymertesting.2018.02.019.

Briassoulis D, Babou E, Hiskakis M and Kyrikou I (2015) Analysis of longterm degradation behaviour of polyethylene mulching films with prooxidants under real cultivation and soil burial conditions.

Environmental Science and Pollution Research 22: 2584-2598, https:// doi.org/10.1007/s11356-014-3464-9.

Cai L, He L, Peng S, Li M and Tong M (2019) Influence of titanium dioxide nanoparticles on the transport and deposition of microplastics in quartz sand. Environmental Pollution 253: 351-357, https://doi.org/10.1016/j. envpol.2019.07.006

Campanale C, Stock F, Massarelli C et al. (2020) Microplastics and their possible sources: the example of Ofanto River in southeast Italy. Environmental Pollution 258: article 113284, https://doi.org/10.1016/j. envpol.2019.113284.

Cao D, Wang X, Luo X, Liu G and Zheng H (2017) Effects of polystyrene microplastics on the fitness of earthworms in an agricultural soil. IOP Conference Series: Earth and Environmental Science 61: article 012148, https://doi.org/10.1088/1755-1315/61/1/012148.

Carr SA, Liu J and Tesoro AG (2016) Transport and fate of microplastic particles in wastewater treatment plants. Water Research 91: 174-182, https://doi.org/10.1016/j.watres.2016.01.002

Cartes J, Neumann P, Hospido A and Vidal G (2018) Life cycle assessment of management alternatives for sludge from sewage treatment plants in Chile: does advanced anaerobic digestion improve environmental performance compared to current practices? Journal of Material Cycles and Waste Management 20(3): 1530-1540, https:// doi.org/10.1007/s10163-018-0714-9.

CCME (Canadian Council of Ministers of the Environment) (2012) Canada-wide Approach for the Management of Wastewater Biosolids. CCME, Winnipeg, MB, Canada. See https:/www.ccme.ca/files/ Resources/waste/biosolids/pn 1477 biosolids cw approach e.pdf (accessed 06/07/2020).

Chae Y and An YJ (2018) Current research trends on plastic pollution and ecological impacts on the soil ecosystem: a review. Environmental Pollution 240: 387-395, https://doi.org/10.1016/j.envpol.2018.05.008.

Chandana N, Goli VSNS, Mohammad A and Singh DN (2021) Characterization and utilization of landfill-mined-soil-like-fractions (LFMSF) for sustainable development: a critical appraisal. Waste and Biomass Valorization 12(2): 641-662, https://doi.org/10.1007/s12649020-01052-y.

Chen Y, Wen D, Pei J et al. (2020) Identification and quantification of microplastics using Fourier-transform infrared spectroscopy: current status and future prospects. Current Opinion in Environmental Science \& Health 18: 14-19, https://doi.org/10.1016/j.coesh.2020.05.004

Chu X, Li T, Li Z, Yan A and Shen C (2019) Transport of microplastic particles in saturated porous media. Water 11(12): article 2474, https:// doi.org/10.3390/w11122474

Conley K, Clum A, Deepe J, Lane H and Beckingham B (2019) Wastewater treatment plants as a source of microplastics to an urban estuary: removal efficiencies and loading per capita over one year. Water Research $X \mathbf{3}$ : article 100030, https://doi.org/10.1016/j.wroa.2019.100030.

Cook HF, Valdes GSB and Lee HC (2006) Mulch effects on rainfall interception, soil physical characteristics and temperature under Zea mays L. Soil Tillage Research 91(1-2): 227-235, https://doi.org/10. 1016/j.still.2005.12.007.

Cook S, Chan HL, Abolfathi S et al. (2020) Longitudinal dispersion of microplastics in aquatic flows using fluorometric techniques. Water
Research 170: article 115337, https://doi.org/10.1016/j.watres.2019. 115337.

Cooper DA and Corcoran PL (2010) Effects of mechanical and chemical processes on the degradation of plastic beach debris on the island of Kauai, Hawaii. Marine Pollution Bulletin 60(5): 650-654, https://doi. org/10.1016/j.marpolbul.2009.12.026

Corradini F, Meza P, Eguiluz R et al. (2019a) Evidence of microplastic accumulation in agricultural soils from sewage sludge disposal. Science of the Total Environment 671: 411-420, https://doi.org/10. 1016/j.scitotenv.2019.03.368.

Corradini F, Bartholomeus H, Lwanga EH, Gertsen H and Geissen V (2019b) Predicting soil microplastic concentration using vis-NIR spectroscopy. Science of the Total Environment 650(Part 1): 922-932, https://doi.org/10.1016/j.scitotenv.2018.09.101.

Corti A, Vallini G, Pera A et al. (1992) Composting microbial ecosystem for testing biodegradability of starch filled polyethylene films. In Proceedings of the 2nd International Scientific Workshop on Biodegradable Polymers and Plastics, Montpellier, France (Vert M, Feijen J, Albertsson A, Scott G and Chiellini E (eds)). Royal Society of Chemistry, Cambridge, UK, Special Publication 109, pp. 245-248.

Crossman J, Hurley RR, Futter M and Nizzetto L (2020) Transfer and transport of microplastics from biosolids to agricultural soils and the wider environment. Science of the Total Environment 724: article 138334, https://doi.org/10.1016/j.scitotenv.2020.138334.

de Souza Machado AA, Kloas W, Zarfl C, Hempel S and Rillig MC (2018a) Microplastics as an emerging threat to terrestrial ecosystems. Global Change Biology 24(4): 1405-1416, https://doi.org/10.1111/gcb.14020.

de Souza Machado AA, Lau CW, Till J et al. (2018b) Impacts of microplastics on the soil biophysical environment. Environmental Science \& Technology 52(17): 9656-9665, https://doi.org/10.1021/acs.est.8b02212.

de Souza Machado AA, Lau CW, Kloas W et al. (2019) Microplastics can change soil properties and affect plant performance. Environmental Science \& Technology 53(10): 6044-6052, https://doi.org/10.1021/acs. est.9b01339.

Dehghani S, Moore F and Akhbarizadeh R (2017) Microplastic pollution in deposited urban dust, Tehran metropolis, Iran. Environmental Science and Pollution Research 24(25): 20360-20371, https://doi.org/ 10.1007/s11356-017-9674-1.

Dobaradaran S, Schmidt TC, Nabipour I et al. (2018) Characterization of plastic debris and association of metals with microplastics in coastline sediment along the Persian Gulf. Waste Management 78: 649-658, https://doi.org/10.1016/j.wasman.2018.06.037.

Dong Z, Qiu Y, Zhang W, Yang Z and Wei L (2018) Size-dependent transport and retention of micron-sized plastic spheres in natural sand saturated with seawater. Water Research 143: 518-526, https://doi.org/ 10.1016/j.watres.2018.07.007.

Dong Z, Zhang W, Qiu Y et al. (2019a) Cotransport of nanoplastics (NPs) with fullerene $\left(\mathrm{C}_{60}\right)$ in saturated sand: effect of $\mathrm{NPs} / \mathrm{C}_{60}$ ratio and seawater salinity. Water Research 148: 469-478, https://doi.org/10. 1016/j.watres.2018.10.071.

Dong Z, Zhu L, Zhang W et al. (2019b) Role of surface functionalities of nanoplastics on their transport in seawater-saturated sea sand. Environmental Pollution 255(Part 1): article 113177, https://doi.org/ 10.1016/j.envpol.2019.113177.

Dong Z, Hou Y, Han W et al. (2020) Protein corona-mediated transport of nanoplastics in seawater-saturated porous media. Water Research 182: article 115978, https://doi.org/10.1016/j.watres.2020.115978.

Doyle MJ, Watson W, Bowlin NM and Sheavly SB (2011) Plastic particles in coastal pelagic ecosystems of the Northeast Pacific ocean. Marine Environmental Research 71(1): 41-52, https://doi.org/10.1016/j. marenvres.2010.10.001

Dümichen E, Eisentraut P, Bannick CG et al. (2017) Fast identification of microplastics in complex environmental samples by a thermal degradation method. Chemosphere 174: 572-584, https://doi.org/10. 1016/j.chemosphere.2017.02.010. 
Ebere EC, Wirnkor VA and Ngozi VE (2019) Uptake of microplastics by plant: a reason to worry or to be happy? World Scientific News 131: 256-267.

Edo C, González-Pleiter M, Leganés F, Fernández-Piñas F and Rosal R (2020) Fate of microplastics in wastewater treatment plants and their environmental dispersion with effluent and sludge. Environmental Pollution 259: article 113837, https://doi.org/10.1016/j.envpol.2019. 113837.

Egley GH (1983) Weed seed and seedling reductions by soil solarization with transparent polyethylene sheets. Weed Science 31(3): 404-409, https://doi.org/10.1017/S0043174500069253.

Enfrin M, Dumée LF and Lee J (2019) Nano/microplastics in water and wastewater treatment processes - origin, impact and potential solutions. Water Research 161: 621-638, https://doi.org/10.1016/j. watres.2019.06.049.

Engdahl NB (2018) Simulating the mobility of micro-plastics and other fiber-like objects in saturated porous media using constrained random walks. Advances in Water Resources 121: 277-284, https://doi.org/10 1016/j.advwatres.2018.08.011.

Eriksen M, Thiel M, Prindiville M and Kiessling T (2018) Microplastic: what are the solutions? In Freshwater Microplastics - Emerging Environmental Contaminants? (Wagner M and Lambert S (eds)). Springer, Cham, Switzerland, pp. 273-298.

Espí E, Salmerón A, Fontecha A, García Y and Real Al (2006) Plastic films for agricultural applications. Plastic Film \& Sheeting 22(2): 85-102, https://doi.org/10.1177/8756087906064220.

Eurostat (2020) Sewage Sludge Production and Disposal. Eurostat, Luxembourg, Luxembourg. See https://ec.europa.eu/eurostat/web/ products-datasets/product?code=env_ww_spd (accessed 26/03/2021).

Farré M, Pérez S, Gajda-Schrantz K et al. (2010) First determination of $\mathrm{C}_{60}$ and $\mathrm{C}_{70}$ fullerenes and $\mathrm{N}$-methylfulleropyrrolidine $\mathrm{C}_{60}$ on the suspended material of wastewater effluents by liquid chromatography hybrid quadrupole linear ion trap tandem mass spectrometry. Journal of Hydrology 383(1-2): 44-51, https://doi.org/10.1016/j.jhydrol.2009. 08.016.

Farrell P and Nelson K (2013) Trophic level transfer of microplastic: Mytilus edulis (L.) to Carcinus maenas (L.). Environmental Pollution 177: 1-3, https://doi.org/10.1016/j.envpol.2013.01.046.

Fernandes A, Rose M and Charlton C (2008) 4-Nonylphenol (NP) in foodcontact materials: analytical methodology and occurrence. Food Additives \& Contaminants: Part A 25(3): 364-372, https://doi.org/10. 1080/02652030701564548.

Fuller S and Gautam AA (2016) A procedure for measuring microplastics using pressurized fluid extraction. Environmental Science \& Technology 50(11): 5774-5780, https://doi.org/10.1021/acs.est. $6 \mathrm{~b} 00816$.

Galgani F, Hanke G, Werner S and De Vrees L (2013) Marine litter within the European Marine Strategy Framework Directive. ICES Journal of Marine Science 70(6): 1055-1064, https://doi.org/10.1093/icesjms/ fst122.

Galloway TS, Cole M and Lewis C (2017) Interactions of microplastic debris throughout the marine ecosystem. Nature Ecology \& Evolution 1: article 0116, https://doi.org/10.1038/s41559-017-0116.

Gaylor MO, Harvey E and Hale RC (2013) Polybrominated diphenyl ether (PBDE) accumulation by earthworms (Eisenia fetida) exposed to biosolids-, polyurethane foam microparticle-, and Penta-BDE-amended soils. Environmental Science \& Technology 47(23): 13831-13839, https://doi.org/10.1021/es403750a.

Geissen V, Ramos F, Bastidas-Bastidas PJ et al. (2010) Soil and water pollution in a banana production region in Tropical Mexico. Bulletin of Environmental Contamination and Toxicology 85(4): 407-413, https://doi.org/10.1007/s00128-010-0077-y.

Gesamp (Joint Group of Experts on the Scientific Aspects of Marine Environmental Protection) (2019) Guidelines or the Monitoring and Assessment of Plastic Litter and Microplastics in the Ocean (Kershaw
PJ, Turra A and Galgani F (eds)). IMO/FAO/UNESCO-IOC/UNIDO/ WMO/IAEA/UN/UNEP/UNDP/ISA Gesamp, Gesamp Reports and Studies No. 99, United Nations Office, Nairobi, Kenya.

Ghosh SK, Pal S and Ray S (2013) Study of microbes having potentiality for biodegradation of plastics. Environmental Science and Pollution Research 20: 4339-4355, https://doi.org/10.1007/s11356013-1706-x.

Gies EA, Lenoble JL, Noël M et al. (2018) Retention of microplastics in a major secondary wastewater treatment plant in Vancouver, Canada. Marine Pollution Bulletin 133: 553-561, https://doi.org/10.1016/j. marpolbul.2018.06.006.

Godoy V, Blázquez G, Calero M, Quesada L and Martín-Lara MA (2019) The potential of microplastics as carriers of metals. Environmental Pollution 255(Part 3): article 113363, https://doi.org/10.1016/j.envpol. 2019.113363.

Goli VSNS, Mohammad A and Singh DN (2020) Application of municipal plastic waste as a manmade neo-construction material: issues \& wayforward. Resources, Conservation and Recycling 161: article 105008, https://doi.org/10.1016/j.resconrec.2020.105008.

Guo JJ, Huang XP, Xiang L et al. (2020) Source, migration and toxicology of microplastics in soil. Environment International 137: article 105263, https://doi.org/10.1016/j.envint.2019.105263.

Hadad D, Geresh S and Sivan A (2005) Biodegradation of polyethylene by the thermophilic bacterium Brevibacillus borstelensis. Applied Microbiology 98(5): 1093-1100, https://doi.org/10.1111/j.1365-2672. 2005.02553.x.

Hale RC, Seeley ME, La Guardia MJ, Mai L and Zeng EY (2020) A global perspective on microplastics. Geophysical Research: Oceans 125(1): article e2018JC014719.

Halley P, Rutgers R, Coombs S et al. (2001) Developing biodegradable mulch films from starch-based polymers. Starch 53(8): 362-367, https://doi.org/10.1002/1521-379X(200108).

Hansen E, Nillson N, Lithner D and Lassen C (2013) Hazardous Substances in Plastic Materials. COWI and Danish Technological Institute.

Harding KG, Gounden T and Pretorius S (2017) "Biodegradable" plastics: a myth of marketing? Procedia Manufacturing 7: 106-110, https://doi. org/10.1016/j.promfg.2016.12.027.

Hartmann NB, Rist S, Bodin J et al. (2017) Microplastics as vectors for environmental contaminants: exploring sorption, desorption, and transfer to biota. Integrated Environmental Assessment and Management 13(3): 488-493, https://doi.org/10.1002/ieam.1904.

Hartmann NB, Hüffer T, Thompson RC et al. (2019) Are we speaking the same language? Recommendations for a definition and categorization framework for plastic debris. Environmental Science \& Technology 53(3): 1039-1047, https://doi.org/10.1021/acs.est.8b05297.

He D, Luo Y, Lu S et al. (2018a) Microplastics in soils: analytical methods, pollution characteristics and ecological risks. TrAC Trends in Analytical Chemistry 109: 163-172, https://doi.org/10.1016/j.trac. 2018.10.006.

He L, Wu D, Rong H et al. (2018b) Influence of nano- and microplastic particles on the transport and deposition behaviors of bacteria in quartz sand. Environmental Science \& Technology 52(20): 11555-11563, https://doi.org/10.1021/acs.est.8b01673.

He P, Chen L, Shao L, Zhang H and Lü F (2019) Municipal solid waste (MSW) landfill: a source of microplastics? - Evidence of microplastics in landfill leachate. Water Research 159: 38-45, https://doi.org/10. 1016/j.watres.2019.04.060.

He L, Rong H, Wu D et al. (2020) Influence of biofilm on the transport and deposition behaviors of nano-and micro-plastic particles in quartz sand. Water Research 178: article 115808, https://doi.org/10.1016/j. watres.2020.115808.

Helcoski R, Yonkos LT, Sanchez A and Baldwin AH (2020) Wetland soil microplastics are negatively related to vegetation cover and stem density. Environmental Pollution 256: article 113391, https://doi.org/ 10.1016/j.envpol.2019.113391. 
Helmberger MS, Tiemann LK and Grieshop MJ (2020) Towards an ecology of soil microplastics. Functional Ecology 34(3): 550-560, https://doi.org/10.1111/1365-2435.13495.

Hennesuse-Boxus C and Pacary T (2003) Emissions from Plastics. Rapra Technology Limited, Shrewsbury, UK, Rapra Review Report 161, vol. 14, no. 5 .

Hernandez LM, Xu EG, Larsson HCE et al. (2019) Plastic teabags release billions of microparticles and nanoparticles into tea. Environmental Science \& Technology 53(21): 12300-12310, https://doi.org/10.1021/ acs.est.9b02540

Hodson ME, Duffus-Hodson CA, Clark A, Prendergast-Miller MT and Thorpe KL (2017) Plastic bag derived-microplastics as a vector for metal exposure in terrestrial invertebrates. Environmental Science \& Technology 51(8): 4714-4721, https://doi.org/10.1021/acs.est.7b00635.

Holmes LA, Turner A and Thompson RC (2012) Adsorption of trace metals to plastic resin pellets in the marine environment. Environmental Pollution 160: 42-48, https://doi.org/10.1016/j.envpol.2011.08.052.

Holmes LA, Turner A and Thompson RC (2014) Interactions between trace metals and plastic production pellets under estuarine conditions. Marine Chemistry 167: 25-32, https://doi.org/10.1016/j.marchem. 2014.06.001.

Horton AA, Walton A, Spurgeon DJ, Lahive E and Svendsen C (2017) Microplastics in freshwater and terrestrial environments: evaluating the current understanding to identify the knowledge gaps and future research priorities. Science of the Total Environment 586: 127-141, https://doi.org/10.1016/j.scitotenv.2017.01.190.

Hou J, Xu X, Lan L et al. (2020) Transport behavior of micro polyethylene particles in saturated quartz sand: impacts of input concentration and physicochemical factors. Environmental Pollution 263(Part B): article 114499, https://doi.org/10.1016/j.envpol.2020.114499.

Hu E, Shang S, Fu Z et al. (2020) Cotransport of naphthalene with polystyrene nanoplastics (PSNP) in saturated porous media: effects of $\mathrm{PSNP} /$ naphthalene ratio and ionic strength. Chemosphere 245: article 125602, https://doi.org/10.1016/j.chemosphere.2019.125602.

Huang Y, Zhao Y, Wang J et al. (2019) LDPE microplastic films alter microbial community composition and enzymatic activities in soil. Environmental Pollution 254(Part A): article 112983, https://doi.org/ 10.1016/j.envpol.2019.112983.

Huerta Lwanga E, Gertsen H, Gooren H et al. (2016) Microplastics in the terrestrial ecosystem: implications for Lumbricus terrestris (Oligochaeta, Lumbricidae). Environmental Science \& Technology 50(5): 2685-2691, https://doi.org/10.1021/acs.est.5b05478.

Huerta Lwanga E, Mendoza Vega J, Ku Quej V et al. (2017a) Field evidence for transfer of plastic debris along a terrestrial food chain. Scientific Reports 7: article 14071, https://doi.org/10.1038/s41598-01714588-2.

Huerta Lwanga E, Gertsen H, Gooren H et al. (2017b) Incorporation of microplastics from litter into burrows of Lumbricus terrestris. Environmental Pollution 220(Part A): 523-531, https://doi.org/10. 1016/j.envpol.2016.09.096.

Huerta Lwanga E, Thapa B, Yang X et al. (2018) Decay of low-density polyethylene by bacteria extracted from earthworm's guts: a potential for soil restoration. Science of the Total Environment 624: 753-757, https://doi.org/10.1016/j.scitotenv.2017.12.144.

Hüffer T and Hofmann T (2016) Sorption of non-polar organic compounds by micro-sized plastic particles in aqueous solution. Environmental Pollution 214: 194-201, https://doi.org/10.1016/j. envpol.2016.04.018.

Hüffer T, Metzelder F, Sigmund G et al. (2019) Polyethylene microplastics influence the transport of organic contaminants in soil. Science of the Total Environment 657: 242-247, https://doi.org/10. 1016/j.scitotenv.2018.12.047.

Hurley RR and Nizzetto L (2018) Fate and occurrence of micro(nano)plastics in soils: knowledge gaps and possible risks.
Current Opinion in Environmental Science \& Health 1: 6-11, https:// doi.org/10.1016/j.coesh.2017.10.006.

Imhof HK, Ivleva NP, Schmid J, Niessner R and Laforsch C (2013) Contamination of beach sediments of a subalpine lake with microplastic particles. Current Biology 23(19): 867-868, https://doi. org/10.1016/j.cub.2013.09.001.

Jahnke A, Arp HPH, Escher BI et al. (2017) Reducing uncertainty and confronting ignorance about the possible impacts of weathering plastic in the marine environment. Environmental Science \& Technology Letters 4(3): 85-90, https://doi.org/10.1021/acs.estlett.7b00008.

Jiang $\mathrm{X}$, Chen H, Liao Y et al. (2019) Ecotoxicity and genotoxicity of polystyrene microplastics on higher plant Vicia faba. Environmental Pollution 250: 831-838, https://doi.org/10.1016/j.envpol.2019.04.055.

Johnson WP (2020) Quantitative linking of nanoscale interactions to continuum-scale nanoparticle and microplastic transport in environmental granular media. Environmental Science \& Technology 54(13): 8032-8042, https://doi.org/10.1021/acs.est.0c01172.

Johnson WP, Rasmuson A, Ron C et al. (2020) Anionic nanoparticle and microplastic non-exponential distributions from source scale with grain size in environmental granular media. Water Research 182: article 116012, https://doi.org/10.1016/j.watres.2020.116012.

Kane IA, Clare MA, Miramontes E et al. (2020) Seafloor microplastic

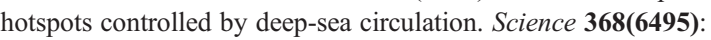
1140-1145, https://doi.org/10.1126/science.aba5899.

Kangas A (2017) Sewage sludge treatment and utilization in Finland. Proceedings of HELCOM Workshop on Sewage Sludge Handling, Vilnius, Lithuania. See https://portal.helcom.fi/meetings/SEWAGE\% 20SLUDGE\%20HANDLING\%20WS\%201-2017-495/Related\% 20Information/Sewage $\% 20$ sludge $\% 20$ treatment $\% 20$ and $\% 20$ utilization $\% 20$ in $\% 20$ Finland.pdf (accessed 26/03/2021).

Käppler A, Fischer D, Oberbeckmann S et al. (2016) Analysis of environmental microplastics by vibrational microspectroscopy: FTIR, Raman or both? Analytical and Bioanalytical Chemistry 408: 8377-8391, https://doi.org/10.1007/s00216-016-9956-3.

Kasirajan S and Ngouajio M (2012) Polyethylene and biodegradable mulches for agricultural applications: a review. Agronomy for Sustainable Development 32: 501-529, https://doi.org/10.1007/ s13593-011-0068-3.

Keller AS, Jimenez-Martinez J and Mitrano DM (2020) Transport of nanoand microplastic through unsaturated porous media from sewage sludge application. Environmental Science \& Technology 54(2): 911-920, https://doi.org/10.1021/acs.est.9b06483.

Kijchavengkul T and Auras R (2008) Compostability of polymers. Polymer International 57(6): 793-804, https://doi.org/10.1002/pi.2420.

Kim YJ, Osako M and Sakai SI (2006) Leaching characteristics of polybrominated diphenyl ethers (PBDEs) from flame-retardant plastics. Chemosphere 65(3): 506-513, https://doi.org/10.1016/j. chemosphere.2006.01.019.

Kirstein IV, Kirmizi S, Wichels A et al. (2016) Dangerous hitchhikers? Evidence for potentially pathogenic Vibrio spp. on microplastic particles. Marine Environmental Research 120: 1-8, https://doi.org/10. 1016/j.marenvres.2016.07.004.

Kiyama Y, Miyahara K and Ohshima Y (2012) Active uptake of artificial particles in the nematode Caenorhabditis elegans. Journal of Experimental Biology 215(7): 1178-1183, https://doi.org/10.1242/jeb.067199.

Kleinteich J, Seidensticker S, Marggrander N and Zarfl C (2018) Microplastics reduce short-term effects of environmental contaminants. Part II: polyethylene particles decrease the effect of polycyclic aromatic hydrocarbons on microorganisms. Environmental Research and Public Health 15(2): article 287, https://doi.org/10.3390/ ijerph15020287.

Koelmans AA, Nor NHM, Hermsen E et al. (2019) Microplastics in freshwaters and drinking water: critical review and assessment of data quality. Water Research 155: 410-422. 
Kokalj AJ, Horvat P, Skalar T and Kržan A (2018) Plastic bag and facial cleanser derived microplastic do not affect feeding behaviour and energy reserves of terrestrial isopods. Science of the Total Environment 615: 761-766, https://doi.org/10.1016/j.scitotenv.2017.10.020.

Kong WD, Zhu YG, Fu BJ, Marschner P and He JZ (2006) The veterinary antibiotic oxytetracycline and $\mathrm{Cu}$ influence functional diversity of the soil microbial community. Environmental Pollution 143(1): 129-137, https://doi.org/10.1016/j.envpol.2005.11.003.

Krueger MC, Harms H and Schlosser D (2015) Prospects for microbiological solutions to environmental pollution with plastics. Applied Microbiology and Biotechnology 99(21): 8857-8874, https:// doi.org/10.1007/s00253-015-6879-4.

Kyrikou I and Briassoulis D (2007) Biodegradation of agricultural plastic films: a critical review. Journal of Polymer and Environment 15(2): 125-50, https://doi.org/10.1007/s10924-007-0053-8.

Lam CXF, Hutmacher DW, Schantz JT, Woodruff MA and Teoh SH (2008) Evaluation of polycaprolactone scaffold degradation for 6 months in vitro and in vivo. Journal of Biomedical Materials Research Part A 90A(3): 906-919, https://doi.org/10.1002/jbm.a.32052.

Lambert S and Wagner M (2017) Environmental performance of biobased and biodegradable plastics: the road ahead. Chemical Society Reviews 46(22): 6855-6871, https://doi.org/10.1039/C7CS00149E.

Lang M, Yu X, Liu J et al. (2020) Fenton aging significantly affects the heavy metal adsorption capacity of polystyrene microplastics. Science of the Total Environment 722: article 137762, https://doi.org/10.1016/j. scitotenv.2020.137762.

Lares M, Ncibi MC, Sillanpää M and Sillanpää M (2018) Occurrence, identification and removal of microplastic particles and fibers in conventional activated sludge process and advanced MBR technology Water Research 133: 236-246, https://doi.org/10.1016/j.watres.2018. 01.049 .

Lee KW, Shim WJ, Kwon OY and Kang JH (2013) Size-dependent effects of micro polystyrene particles in the marine copepod Tigriopus japonicus. Environmental Science \& Technology 47(19): 11278-11283, https://doi.org/10.1021/es401932b.

Lei L, Liu M, Song Y et al. (2018) Polystyrene (nano)microplastics cause size-dependent neurotoxicity, oxidative damage and other adverse effects in Caenorhabditis elegans. Environmental Science: Nano 5(8): 2009-2020, https://doi.org/10.1039/C8EN00412A.

Levis JW, Weisbrod A, van Hoof G and Barlaz MA (2017) A review of the airborne and waterborne emissions from uncontrolled solid waste disposal sites. Critical Reviews in Environmental Science \& Technology 47(12): 1003-1041, https://doi.org/10.1080/10643389. 2017.1342513

Li X, Chen L, Mei Q et al. (2018a) Microplastics in sewage sludge from the wastewater treatment plants in China. Water Research 142: 75-85, https://doi.org/10.1016/j.watres.2018.05.034.

Li J, Zhang K and Zhang H (2018b) Adsorption of antibiotics on microplastics. Environmental Pollution 237: 460-467, https://doi.org/ 10.1016/j.envpol.2018.02.050.

Li L, Zhou Q, Yin N, Tu C and Luo Y (2019a) Uptake and accumulation of microplastics in an edible plant. Kexue Tongbao/Chinese Science Bulletin 64(9): 928-934, https://doi.org/10.1360/N972018-00845.

Li M, He L, Zhang M et al. (2019b) Cotransport and deposition of iron oxides with different-sized plastic particles in saturated quartz sand. Environmental Science \& Technology 53(7): 3547-3557, https://doi. org/10.1021/acs.est.8b06904.

Li Z, Li Q, Li R et al. (2020a) Physiological responses of lettuce (Lactuca sativa L.) to microplastic pollution. Environmental Science and Pollution Research 27(24): 30306-30314, https://doi.org/10.1007/ s11356-020-09349-0.

Li L, Yang J, Zhou Q, Peijnenburg WJGM and Luo Y (2020b) Uptake of microplastics and their effects on plants. In Microplastics in Terrestrial Environments (He D and Luo Y (eds)). Springer, Cham, Switzerland, pp. 279-298.
Li D, Shi Y, Yang L et al. (2020c) Microplastic release from the degradation of polypropylene feeding bottles during infant formula preparation. Nature Food 1: 746-754, https://doi.org/10.1038/s43016020-00171-y.

Li J, Song Y and Cai Y (2020d) Focus topics on microplastics in soil: analytical methods, occurrence, transport, and ecological risks. Environmental Pollution 257: article 113570, https://doi.org/10.1016/j. envpol.2019.113570.

Liu H, Yang X, Liu G et al. (2017) Response of soil dissolved organic matter to microplastic addition in Chinese loess soil. Chemosphere 185: 907-917, https://doi.org/10.1016/j.chemosphere.2017.07.064.

Liu M, Lu S, Song Y et al. (2018) Microplastic and mesoplastic pollution in farmland soils in suburbs of Shanghai, China. Environmental Pollution 242(Part A): 855-862, https://doi.org/10.1016/j.envpol. 2018.07.051.

Liu X, Yuan W, Di M, Li Z and Wang J (2019a) Transfer and fate of microplastics during the conventional activated sludge process in one wastewater treatment plant of China. Chemical Engineering Journal 362: 176-182, https://doi.org/10.1016/j.cej.2019.01.033.

Liu J, Zhang T, Tian L et al. (2019b) Aging significantly affects mobility and contaminant-mobilizing ability of nanoplastics in saturated loamy sand. Environmental Science \& Technology 53(10): 5805-5815, https://doi.org/10.1021/acs.est.9b00787.

Loyo-Rosales JE, Rosales-Rivera GC, Lynch AM, Rice CP and Torrents A (2004) Migration of nonylphenol from plastic containers to water and a milk surrogate. Journal of Agricultural and Food Chemistry 52(7): 2016-2020, https://doi.org/10.1021/jf0345696.

Lusher AL, Hurley R, Vogelsang C, Nizzetto L and Olsen M (2017) Mapping Microplastics in Sludge. Norwegian Institute for Water Research, Oslo, Norway, Report No. 7215-2017. See https://niva. brage.unit.no/niva-xmlui/bitstream/handle/11250/2493527/7215-2017. pdf? sequence=1 (accessed 26/03/2021).

Lv W, Zhou W, Lu S et al. (2019) Microplastic pollution in rice-fish coculture system: a report of three farmland stations in Shanghai, China Science of the Total Environment 652: 1209-1218, https://doi.org/10. 1016/j.scitotenv.2018.10.321.

Magni S, Binelli A, Pittura L et al. (2019) The fate of microplastics in an Italian wastewater treatment plant. Science of the Total Environment 652: 602-610, https://doi.org/10.1016/j.scitotenv.2018.10.269.

Magnusson K and Norén F (2014) Screening of Microplastic Particles in and Down-stream a Wastewater Treatment Plant. Swedish Environmental Research Institute, Stockholm, Sweden, Report No. C55. IVL. See https:/www.diva-portal.org/smash/get/diva2:773505/ FULLTEXT01.pdf (accessed 26/03/2021).

Mahon AM, O'Connell B, Healy MG et al. (2017) Microplastics in sewage sludge: effects of treatment. Environmental Science \& Technology 51(2): 810-818, https://doi.org/10.1021/acs.est.6b04048.

Mammo FK, Amoah ID, Gani KM et al. (2020) Microplastics in the environment: interactions with microbes and chemical contaminants. Science of the Total Environment 743: article 140518, https://doi.org/ 10.1016/j.scitotenv.2020.140518.

Mason SA, Garneau D, Sutton R et al. (2016) Microplastic pollution is widely detected in US municipal wastewater treatment plant effluent. Environmental Pollution 218: 1045-54, https://doi.org/10.1016/j. envpol.2016.08.056.

Massos A and Turner A (2017) Cadmium, lead and bromine in beached microplastics. Environmental Pollution 227: 139-145, https://doi.org/ 10.1016/j.envpol.2017.04.034.

Masura J, Baker J, Foster G and Arthur C (2015) Methods for the analysis of microplastics in water samples. In Laboratory Methods for the Analysis of Microplastics in the Marine Environment: Recommendations for Quantifying Synthetic Particles in Waters and Sediments. NOAA Marine Debris Program, National Oceanic and Atmospheric Administration, Silver Spring, MD, USA, NOAA Technical Memorandum NOS-OR\&R-48, pp. 3-12. 
Mato Y, Isobe T, Takada $\mathrm{H}$ et al. (2001) Plastic resin pellets as a transport medium for toxic chemicals in the marine environment. Environmental Science \& Technology 35(2): 318-324, https://doi.org/10.1021/ es0010498.

McDevitt JP, Criddle CS, Morse M et al. (2017) Addressing the issue of microplastics in the wake of the microbead-free waters act - a new standard can facilitate improved policy. Environmental Science \& Technology 51(12): 6611-6617, https://doi.org/10.1021/acs.est. $6 \mathrm{~b} 05812$.

Meyer DW (2014) Stochastic Models of Particle Dynamics in Turbulent and Subsurface Flows. PhD thesis, ETH Zürich, Zurich, Switzerland.

Mintenig SM, Int-Veen I, Löder MGJ, Primpke S and Gerdts G (2017) Identification of microplastic in effluents of waste water treatment plants using focal plane array-based micro-Fourier-transform infrared imaging. Water Research 108: 365-372, https://doi.org/10.1016/j. watres.2016.11.015

Mintenig SM, Löder MGJ, Primpke S and Gerdts G (2019) Low numbers of microplastics detected in drinking water from ground water sources. Science of the Total Environment 648: 631-635, https://doi.org/10. 1016/j.scitotenv.2018.08.178.

Murphy F, Ewins C, Carbonnier F and Quinn B (2016) Wastewater treatment works (WwTW) as a source of microplastics in the aquatic environment. Environmental Science \& Technology 50(11) 5800-5808, https://doi.org/10.1021/acs.est.5b05416.

Mutsuga M, Kawamura Y, Sugita-Konishi Y et al. (2006) Migration of formaldehyde and acetaldehyde into mineral water in polyethylene terephthalate (PET) bottles. Food Additives \& Contaminants 23(2) 212-218, https://doi.org/10.1080/02652030500398361.

$\mathrm{Ng} \mathrm{EL}$, Huerta Lwanga E, Eldridge SM et al. (2018) An overview of microplastic and nanoplastic pollution in agroecosystems. Science of the Total Environment 627: 1377-1388, https://doi.org/10.1016/j. scitotenv.2018.01.341.

Ng W, Minasny B and McBratney A (2020) Convolutional neural network for soil microplastic contamination screening using infrared spectroscopy. Science of the Total Environment 702: article 134723, https://doi.org/10.1016/j.scitotenv.2019.134723.

Nizzetto L, Futter M and Langaas S (2016) Are agricultural soils dumps for microplastics of urban origin? Environmental Science \& Technology 50(20): 10777-10779, https://doi.org/10.1021/acs.est.6b04140.

O'Brine T and Thompson RC (2010) Degradation of plastic carrier bags in the marine environment. Marine Pollution Bulletin 60(12): 2279-2283, https://doi.org/10.1016/j.marpolbul.2010.08.005.

O'Connor D, Pan S, Shen Z et al. (2019) Microplastics undergo accelerated vertical migration in sand soil due to small size and wet-dry cycles. Environmental Pollution 249: 527-534, https://doi.org/10.1016/j. envpol.2019.03.092.

Ohshima H (2012) Chapter 3: The Derjaguin-Landau-Verwey-Overbeek (DLVO) theory of colloid stability. In Electrical Phenomena at Interfaces and Biointerfaces: Fundamentals and Applications in Nano-, Bio-, and Environmental Sciences (Ohshima H (ed.)). Wiley, Hoboken, NJ, USA, pp. 27-34.

Olea N, Pulgar R, Pérez P et al. (1996) Estrogenicity of resin-based composites and sealants used in dentistry. Environmental Health Perspectives 104(3): 298-305, https://doi.org/10.1289/ehp.96104298.

Oßmann BE, Sarau G, Schmitt SW et al. (2017) Development of an optimal filter substrate for the identification of small microplastic particles in food by micro-Raman spectroscopy. Analytical and Bioanalytical Chemistry 409(16): 4099-4109, https://doi.org/10.1007/ s00216-017-0358-y.

Otake Y, Kobayashi T, Ashabe H, Murakami N and Ono K (1995) Biodegradation of low-density polyethylene, polystyrene, polyvinyl chloride, and urea formaldehyde resin buried under soil for over 32 years. Journal of Applied Polymer Science 56(13): 1789-1796, https:// doi.org/10.1002/app.1995.070561309.
Oz N, Kadizade G and Yurtsever M (2019) Investigation of heavy metal adsorption on microplastics. Applied Ecology and Environmental Research 17(4): 7301-7310, https://doi.org/10.15666/aeer/ 1704_73017310.

Panno SV, Kelly WR, Scott J et al. (2019) Microplastic contamination in karst groundwater systems. Groundwater 57(2): 189-196, https://doi. org/10.1111/gwat.12862.

Pathak VM and Navneet (2017) Review on the current status of polymer degradation: a microbial approach. Bioresources and Bioprocessing 4: article 15, https://doi.org/10.1186/s40643-017-0145-9.

Paul A, Wander L, Becker R, Goedecke C and Braun U (2019) Highthroughput NIR spectroscopic (NIRS) detection of microplastics in soil. Environmental Science and Pollution Research 26(8): 7364-7374, https://doi.org/10.1007/s11356-018-2180-2.

Peng X, Chen M, Chen S et al. (2018) Microplastics contaminate the deepest part of the world's ocean. Geochemical Perspectives Letters 9: 1-5, https://doi.org/10.7185/geochemlet.1829.

Piehl S, Leibner A, Löder MGJ et al. (2018) Identification and quantification of macro- and microplastics on an agricultural farmland. Scientific Reports 8: article 17950, https://doi.org/10.1038/s41598-018-36172-y.

Pohl F, Eggenhuisen JT, Kane IA and Clare MA (2020) Transport and burial of microplastics in deep-marine sediments by turbidity currents. Environmental Science \& Technology 54(7): 4180-4189, https://doi. org/10.1021/acs.est.9b07527.

Połeć M, Aleksander-Kwaterczak U, Wątor K and Kmiecik E (2018) The occurrence of microplastics in freshwater systems - preliminary results from Krakow (Poland). Geology, Geophysics and Environment 44(4): 391-400, https://doi.org/10.7494/geol.2018.44.4.391.

Pradel A, El Hadri H, Desmet C et al. (2020) Deposition of environmentally relevant nanoplastic models in sand during transport experiments. Chemosphere 255: article 126912, https://doi.org/10. 1016/j.chemosphere.2020.126912.

Priyanka N and Archana T (2012) Biodegradability of polythene and plastic by the help of microorganism: a way for brighter future. Journal of Environmental \& Analytical Toxicology 1(4): article 1000111, https://doi.org/10.4172/2161-0525.1000111.

Qi Y, Yang X, Pelaez AM et al. (2018) Macro- and micro-plastics in soil-plant system: effects of plastic mulch film residues on wheat (Triticum aestivum) growth. Science of the Total Environment 645 : 1048-1056, https://doi.org/10.1016/j.scitotenv.2018.07.229.

Qi R, Jones DL, Li Z, Liu Q and Yan C (2020) Behavior of microplastics and plastic film residues in the soil environment: a critical review. Science of the Total Environment 703: article 134722, https://doi.org/ 10.1016/j.scitotenv.2019.134722.

Re V (2019) Shedding light on the invisible: addressing the potential for groundwater contamination by plastic microfibers. Hydrogeology Journal 27(7): 2719-2727, https://doi.org/10.1007/s10040-019-01998-x.

Reis PIN (2019) Microplastic Contamination in Argentina: Insights about a Source (Wastewater Treatment Plant) and a Sink (Beach): 2 Case Studies. Master's thesis, Universidade de Lisboa, Lisbon, Portugal. See https://www.repository.utl.pt/handle/10400.5/19528 (accessed 27/ 03/2021).

Renner G, Schmidt TC and Schram J (2020) Automated rapid \& intelligent microplastics mapping by FTIR microscopy: a Python-based workflow. MethodsX 7: article 100742, https://doi.org/10.1016/j.mex. 2019.11.015

Rezaei M, Riksen MJPM, Sirjani E, Sameni A and Geissen V (2019) Wind erosion as a driver for transport of light density microplastics. Science of the Total Environment 669: 273-281, https://doi.org/10.1016/j. scitotenv.2019.02.382.

Richard H, Carpenter EJ, Komada T, Palmer PT and Rochman CM (2019) Biofilm facilitates metal accumulation onto microplastics in estuarine waters. Science of the Total Environment 683: 600-608, https://doi. org/10.1016/j.scitotenv.2019.04.331. 
Rijk R and Ehlert K (2001) Migration of Phthalate Plasticizers from Soft PVC Toys and Child Care Articles. TNO Nutrition and Food Research Institute, Zeist, the Netherlands, TNO Report V3932.

Rillig MC (2012) Microplastic in terrestrial ecosystems and the soil? Environmental Science \& Technology 46(12): 6453-6454, https://doi. org/10.1021/es302011r.

Rillig MC, Ingraffia R and de Souza Machado AA (2017a) Microplastic incorporation into soil in agroecosystems. Frontiers in Plant Science 8: article 1805, https://doi.org/10.3389/fpls.2017.01805.

Rillig MC, Ziersch L and Hempel S (2017b) Microplastic transport in soil by earthworms. Scientific Reports 7: article 1362, https://doi.org/10. 1038/s41598-017-01594-7.

Rillig MC, de Souza Machado AA, Lehmann A and Klümper U (2019) Evolutionary implications of microplastics for soil biota. Environmental Chemistry 16(1): 3-7, https://doi.org/10.1071/EN18118.

Rochman CM, Hoh E, Hentschel BT and Kaye S (2013) Long-term field measurement of sorption of organic contaminants to five types of plastic pellets: implications for plastic marine debris. Environmental Science \& Technology 47(3): 1646-1654, https://doi.org/10.1021/es303700s.

Rochman CM, Hentschel BT and Teh SJ (2014) Long-term sorption of metals is similar among plastic types: implications for plastic debris in aquatic environments. PLOS ONE 9(1): article e85433, https://doi.org/ 10.1371/journal.pone.0085433.

Rujnić-Sokele M and Pilipović A (2017) Challenges and opportunities of biodegradable plastics: a mini review. Waste Management and Research 35(2): 132-140, https://doi.org/10.1177/0734242X16683272.

Rummel CD, Jahnke A, Gorokhova E, Kühnel D and Schmitt-Jansen M (2017) Impacts of biofilm formation on the fate and potential effects of microplastic in the aquatic environment. Environmental Science \& Technology Letters 4(7): 258-267, https://doi.org/10.1021/acs.estlett. $7 \mathrm{~b} 00164$.

Ryerson University (2015) Risks Associated with Application of Municipal Biosolids to Agricultural Lands in a Canadian Context. Ryerson University, Toronto, ON, Canada. See https:/cwn-rce.ca/wp-content/ uploads/2015/08/McCarthy-Risks-Biosolids-2015.pdf (accessed 27/03/ 2021).

Sai GVSN, Pundlik RC, Rao PV and Kale GR (2018) Chemical looping combustion of biomass for renewable \& non- $\mathrm{CO}_{2}$ emissions energy status and review. International Journal of Engineering and Technology 7(2.1): 6-10, https://doi.org/10.14419/ijet.v7i2.1.9872.

Sarker A, Deepo DM, Nandi R et al. (2020) A review of microplastics pollution in the soil and terrestrial ecosystems: a global and Bangladesh perspective. Science of The Total Environment 733: article 139296, https://doi.org/10.1016/j.scitotenv.2020.139296.

Sarris TS, Scott DM, Close ME et al. (2019) The effects of denitrification parameterization and potential benefits of spatially targeted regulation for the reduction of $\mathrm{N}$-discharges from agriculture. Journal of Environmental Management 247: 299-312, https://doi.org/10.1016/j jenvman.2019.06.074.

Scheurer M and Bigalke M (2018) Microplastics in Swiss floodplain soils Environmental Science \& Technology 52(6): 3591-3598, https://doi. org/10.1021/acs.est.7b06003.

Schmid O and Stoeger T (2016) Surface area is the biologically most effective dose metric for acute nanoparticle toxicity in the lung. Aerosol Science 99: 133-143, https://doi.org/10.1016/j.jaerosci.2015.12.006.

Schwaferts C, Niessner R, Elsner M and Ivleva NP (2019) Methods for the analysis of submicrometer- and nanoplastic particles in the environment. TrAC Trends in Analytical Chemistry 112: 52-65, https:// doi.org/10.1016/j.trac.2018.12.014

Schymanski D, Goldbeck C, Humpf HU and Fürst P (2018) Analysis of microplastics in water by micro-Raman spectroscopy: release of plastic particles from different packaging into mineral water. Water Research 129: 154-162, https://doi.org/10.1016/j.watres.2017.11.011.

Seidensticker S, Grathwohl P, Lamprecht J and Zarfl C (2018) A combined experimental and modeling study to evaluate $\mathrm{pH}$-dependent sorption of polar and non-polar compounds to polyethylene and polystyrene microplastics. Environmental Sciences Europe 30: article 30, https:// doi.org/10.1186/s12302-018-0155-z.

Shah AA, Hasan F, Hameed A and Ahmed S (2008) Biological degradation of plastics: a comprehensive review. Biotechnology Advances 26(3): 246-265, https://doi.org/10.1016/j.biotechadv.2007.12.005.

Shahnawaz M, Sangale MK and Ade AB (2019) Bioremediation Technologies for Plastics Wastes. Springer, Singapore.

Shan J, Zhao J, Liu L et al. (2018) A novel way to rapidly monitor microplastics in soil by hyperspectral imaging technology and chemometrics. Environmental Pollution 238: 121-129, https://doi.org/ 10.1016/j.envpol.2018.03.026

Shashank BS, Kuntikana G, Jiang NJ and Singh DN (2020) Investigations on biosorption and biogenic calcite precipitation in sands. Soil Use and Management, https://doi.org/10.1111/sum.12611.

Shim WJ, Hong SH and Eo SE (2017) Identification methods in microplastic analysis: a review. Analytical Methods 2017(9): 1384-1391, https://doi.org/10.1039/C6AY02558G.

Silva AB, Costa MF and Duarte AC (2018) Biotechnology advances for dealing with environmental pollution by micro(nano) plastics: lessons on theory and practices. Current Opinion in Environmental Science \& Health 1: 30-35, https://doi.org/10.1016/j.coesh.2017.10.005.

Singh B and Sharma N (2008) Mechanistic implications of plastic degradation. Polymer Degradation and Stability 93(3): 561-584, https://doi.org/10.1016/j.polymdegradstab.2007.11.008.

Skjevrak I, Due A, Gjerstad KO and Herikstad H (2003) Volatile organic components migrating from plastic pipes (HDPE, PEX and PVC) into drinking water. Water Research 37(8): 1912-1920, https://doi.org/10. 1016/S0043-1354(02)00576-6.

Steensgaard IM, Syberg K, Rist S et al. (2017) From macro- to microplastics - analysis of EU regulation along the life cycle of plastic bags. Environmental Pollution 224: 289-299, https://doi.org/10.1016/j. envpol.2017.02.007.

Su Y, Zhang Z, Wu D et al. (2019) Occurrence of microplastics in landfill systems and their fate with landfill age. Water Research 164: article 114968, https://doi.org/10.1016/j.watres.2019.114968.

Sun J, Dai X, Wang Q, van Loosdrecht MCM and Ni BJ (2019) Microplastics in wastewater treatment plants: detection, occurrence and removal. Water Research 152: 21-37, https://doi.org/10.1016/j. watres.2018.12.050

Tagg AS, Sapp M, Harrison JP and Ojeda JJ (2015) Identification and quantification of microplastics in wastewater using focal plane arraybased reflectance micro-FT-IR imaging. Analytical Chemistry 87(12): 6032-6040, https://doi.org/10.1021/acs.analchem.5b00495.

Talvitie J, Mikola A, Koistinen A and Setälä O (2017a) Solutions to microplastic pollution - removal of microplastics from wastewater effluent with advanced wastewater treatment technologies. Water Research 123: 401-407, https://doi.org/10.1016/j.watres.2017. 07.005 .

Talvitie J, Mikola A, Setälä O, Heinonen M and Koistinen A (2017b) How well is microlitter purified from wastewater? - A detailed study on the stepwise removal of microlitter in a tertiary level wastewater treatment plant. Water Research 109: 164-172, https://doi.org/10.1016/j.watres. 2016.11.046.

Tang G, Liu M, Zhou Q et al. (2018) Microplastics and polycyclic aromatic hydrocarbons (PAHs) in Xiamen coastal areas: implications for anthropogenic impacts. Science of the Total Environment 634: 811-820, https://doi.org/10.1016/j.scitotenv.2018.03.336.

Taylor SE, Pearce Cl, Sanguinet KA et al. (2020) Polystyrene nano- and microplastic accumulation at Arabidopsis and wheat root cap cells, but no evidence for uptake into roots. Environmental Science: Nano 2020(7): 1942-1953, https://doi.org/10.1039/d0en00309c

Teuten EL, Saquing JM, Knappe DRU et al. (2009) Transport and release of chemicals from plastics to the environment and to wildlife. Philosophical Transactions of the Royal Society B: Biological 
Sciences 364(1526): 2027-2045, https://doi.org/10.1098/rstb.2008. 0284

Thompson RC, Olsen Y, Mitchell RP et al. (2004) Lost at sea: where is all the plastic? Science 304(5672): 838, https://doi.org/10.1126/science.1094559.

Tokiwa Y, Calabia BP, Ugwu CU and Aiba S (2009) Biodegradability of plastics. Molecular Sciences 10(9): 3722-3742, https://doi.org/10. 3390/ijms 10093722 .

Tong M, He L, Rong H, Li M and Kim H (2020a) Transport behaviors of plastic particles in saturated quartz sand without and with biochar/ $\mathrm{Fe}_{3} \mathrm{O}_{4}$-biochar amendment. Water Research 169: article 115284, https://doi.org/10.1016/j.watres.2019.115284.

Tong M, Li T, Li M, He L and Ma Z (2020b) Cotransport and deposition of biochar with different sized-plastic particles in saturated porous media. Science of the Total Environment 713: article 136387, https://doi.org/ 10.1016/j.scitotenv.2019.136387.

Tønning K, Jacobsen E, Pedersen E and Nilsson NH (2010) Phthalates in Products That Children Are in Direct Contact with. Danish Environmental Protection Agency, Copenhagen, Denmark, Survey of Chemical Substances in Consumer Products Report No. 109. See https://www2.mst.dk/udgiv/publications/2010/978-87-92708-75-5/pdf/ 978-87-92708-74-8.pdf (accessed 27/03/2021).

Ujang Z and Henze M (2006) Municipal Wastewater Management in Developing Countries. IWA Publishing, London, UK.

UNEP (UN Environmental Programme) (2014) UNEP Year Book 2014 Emerging Issues Update. Air Pollution: World's Worst Environmental Health Risk. UNEP, Nairobi, Kenya.

Unice KM, Weeber MP, Abramson MM et al. (2019) Characterizing export of land-based microplastics to the estuary - Part I: application of integrated geospatial microplastic transport models to assess tire and road wear particles in the Seine watershed. Science of the Total Environment 646: 1639-1649, https://doi.org/10.1016/j.scitotenv.2018.07.368.

Van Cauwenberghe L, Vanreusel A, Mees J and Janssen CR (2013) Microplastic pollution in deep-sea sediments. Environment Pollution 182: 495-499, https://doi.org/10.1016/j.envpol.2013.08.013.

van den Berg P, Huerta-Lwanga E, Corradini F and Geissen V (2020) Sewage sludge application as a vehicle for microplastics in eastern Spanish agricultural soils. Environmental Pollution 261: article 114198, https://doi.org/10.1016/j.envpol.2020.114198.

van Praagh M, Hartman C and Brandmyr E (2018) Microplastics in Landfill Leachates in the Nordic Countries. Nordisk Ministerråd, Copenhagen, Denmark, TemaNord 2018:557.

von Moos N, Burkhardt-Holm P and Köhler A (2012) Uptake and effects of microplastics on cells and tissue of the blue mussel Mytilus edulis L. after an experimental exposure. Environmental Science \& Technology 46(20): 11327-11335, https://doi.org/10.1021/es302332w.

Waldschläger K and Schüttrumpf H (2020) Infiltration behavior of microplastic particles with different densities, sizes, and shapes - from glass spheres to natural sediments. Environmental Science \& Technology 54(15): 9366-9373, https://doi.org/10.1021/acs.est.0c01722.

Waldschläger K, Lechthaler S, Stauch G and Schüttrumpf H (2020) The way of microplastic through the environment - application of the source-pathway-receptor model (review). Science of the Total Environment 713: article 136584, https://doi.org/10.1016/j.scitotenv. 2020.136584

Wan Y, Wu C, Xue Q and Hui X (2019) Effects of plastic contamination on water evaporation and desiccation cracking in soil. Science of the Total Environment 654: 576-582, https://doi.org/10.1016/j.scitotenv. 2018.11.123.

Wang J, Peng J, Tan Z et al. (2017) Microplastics in the surface sediments from the Beijiang River littoral zone: composition, abundance, surface textures and interaction with heavy metals. Chemosphere 171: 248-258, https://doi.org/10.1016/j.chemosphere.2016.12.074.

Wang F, Wong CS, Chen D et al. (2018) Interaction of toxic chemicals with microplastics: a critical review. Water Research 139: 208-219, https://doi.org/10.1016/j.watres.2018.04.003.
Wang HT, Ding J, Xiong C et al. (2019) Exposure to microplastics lowers arsenic accumulation and alters gut bacterial communities of earthworm Metaphire californica. Environmental Pollution 251: 110-116, https://doi.org/10.1016/j.envpol.2019.04.054.

Wang W, Ge J, Yu X and Li H (2020) Environmental fate and impacts of microplastics in soil ecosystems: progress and perspective. Science of the Total Environment 708: article 134841, https://doi.org/10.1016/j. scitotenv.2019.134841.

Watteau F, Dignac MF, Bouchard A, Revallier A and Houot S (2018) Microplastic detection in soil amended with municipal solid waste composts as revealed by transmission electronic microscopy and pyrolysis/GC/MS. Frontiers in Sustainable Food Systems 2: article 81, https://doi.org/10.3389/fsufs.2018.00081.

Wei R and Zimmermann W (2017) Microbial enzymes for the recycling of recalcitrant petroleum-based plastics: how far are we? Microbial Biotechnology 10(6): 1308-1322, https://doi.org/10.1111/1751-7915. 12710.

Weinstein JE, Crocker BK and Gray AD (2016) From macroplastic to microplastic: degradation of high-density polyethylene, polypropylene, and polystyrene in a salt marsh habitat. Environmental Toxicology and Chemistry 35(7): 1632-1640, https://doi.org/10.1002/etc.3432.

Weithmann N, Möller JN, Löder MGJ et al. (2018) Organic fertilizer as a vehicle for the entry of microplastic into the environment. Science Advances 4(4): article eaap8060, https://doi.org/10.1126/sciadv. aap8060.

Wilson SR, Close ME, Abraham P et al. (2020) Achieving unbiased predictions of national-scale groundwater redox conditions via data oversampling and statistical learning. Science of the Total Environment 705: article 135877, https://doi.org/10.1016/j.scitotenv.2019.135877.

Wirnkor VA, Ebere EC and Ngozi VE (2019) Microplastics, an emerging concern: a review of analytical techniques for detecting and quantifying microplastics. Analytical Methods in Environmental Chemistry 2(2): 13-30, https://doi.org/10.24200/amecj.v2.i2.57.

Woodall LC, Sanchez-Vidal A, Canals M et al. (2014) The deep sea is a major sink for microplastic debris. Royal Society Open Science 1(4) article 140317, https://doi.org/10.1098/rsos.140317.

Wright SL and Kelly FJ (2017) Plastic and human health: a micro issue? Environmental Science \& Technology 51(12): 6634-6647, https://doi. org/10.1021/acs.est.7b00423.

Wright SL, Rowe D, Thompson RC and Galloway TS (2013a) Microplastic ingestion decreases energy reserves in marine worms. Current Biology 23(23): 1031-1033, https://doi.org/10.1016/j.cub.2013.10.068.

Wright SL, Thompson RC and Galloway TS (2013b) The physical impacts of microplastics on marine organisms: a review. Environmental Pollution 178: 483-492, https://doi.org/10.1016/j.envpol.2013.02.031.

Wu WM, Yang J and Criddle CS (2017) Microplastics pollution and reduction strategies. Frontiers of Environmental Science \& Engineering 11: article 6, https://doi.org/10.1007/s11783-0170897-7.

Wu X, Lyu X, Li Z et al. (2020) Transport of polystyrene nanoplastics in natural soils: effect of soil properties, ionic strength and cation type. Science of the Total Environment 707: article 136065, https://doi.org/ 10.1016/j.scitotenv.2019.136065.

Xu Q, Gao Y, Xu L et al. (2020a) Investigation of the microplastics profile in sludge from China's largest water reclamation plant using a feasible isolation device. Hazardous Materials 388: article 122067, https://doi. org/10.1016/j.jhazmat.2020.122067.

Xu B, Liu F, Cryder Z et al. (2020b) Microplastics in the soil environment: occurrence, risks, interactions and fate - a review. Critical Reviews in Environmental Science \& Technology 50(21): 2175-2222, https://doi. org/10.1080/10643389.2019.1694822.

Yadav V, Sherly MA, Ranjan P et al. (2020) Framework for quantifying environmental losses of plastics from landfills. Resources, Conservation and Recycling 161: article 104914, https://doi.org/10. 1016/j.resconrec.2020.104914. 
Yang G, Zhang G and Wang H (2015) Current state of sludge production, management, treatment and disposal in China. Water Research $\mathbf{7 8}$ 60-73, https://doi.org/10.1016/j.watres.2015.04.002.

Yoshida S, Hiraga K, Takehana T et al. (2016) A bacterium that degrades and assimilates poly(ethylene terephthalate). Science 351(6278): 1196-1199, https://doi.org/10.1126/science.aad6359.

Yu F, Yang C, Zhu Z, Bai X and Ma J (2019) Adsorption behavior of organic pollutants and metals on micro/nanoplastics in the aquatic environment. Science of the Total Environment 694: article 133643 https://doi.org/10.1016/j.scitotenv.2019.133643.

Yu H, Hou J, Dang Q et al. (2020) Decrease in bioavailability of soil heavy metals caused by the presence of microplastics varies across aggregate levels. Hazardous Materials 395: article 122690, https://doi. org/10.1016/j.jhazmat.2020.122690.

Yuan J, Ma J, Sun Y et al. (2020) Microbial degradation and other environmental aspects of microplastics/plastics. Science of the Total Environment 715: article 136968, https://doi.org/10.1016/j.scitotenv. 2020.136968.

Zhang GS and Liu YF (2018) The distribution of microplastics in soil aggregate fractions in southwestern China. Science of the Total Environment 642: 12-20, https://doi.org/10.1016/j.scitotenv.2018.06.004.

Zhang GS and Zhang FX (2020) Variations in aggregate-associated organic carbon and polyester microfibers resulting from polyester microfibers addition in a clayey soil. Environmental Pollution 258: article 113716, https://doi.org/10.1016/j.envpol.2019.113716.

Zhang KN, Li J, Li XQ and Zhang H (2017) Mechanisms and kinetics of oxytetracycline adsorption-desorption onto microplastics. Environmental Chemistry 36(12): 2531-2540 (in Chinese).

Zhang S, Yang X, Gertsen H et al. (2018) A simple method for the extraction and identification of light density microplastics from soil. Science of the Total Environment 616-617: 1056-1065, https://doi.org/ 10.1016/j.scitotenv.2017.10.213.

Zhang L, Xie Y, Liu J et al. (2020a) An overlooked entry pathway of microplastics into agricultural soils from application of sludge-based fertilizers. Environmental Science \& Technology 54(7): 4248-4255, https://doi.org/10.1021/acs.est.9b07905.

Zhang S, Han B, Sun Y and Wang F (2020b) Microplastics influence the adsorption and desorption characteristics of $\mathrm{Cd}$ in an agricultural soil.
Hazardous Materials 388: article 121775, https://doi.org/10.1016/j. jhazmat.2019.121775.

Zhang P, Huang P, Sun H, Ma J and Li B (2020c) The structure of agricultural microplastics (PT, PU and UF) and their sorption capacities for PAHs and PHE derivates under various salinity and oxidation treatments. Environmental Pollution 257: article 113525, https://doi.org/10.1016/j.envpol.2019.113525.

Zhao W, Zhao P, Tian Y et al. (2020) Investigation for synergies of ionic strength and flow velocity on colloidal-sized microplastic transport and deposition in porous media using the colloidal-AFM probe. Langmuir 36(22): 6292-6303, https://doi.org/10.1021/acs. langmuir.0c00116.

Zhou Q, Zhang H, Fu C et al. (2018) The distribution and morphology of microplastics in coastal soils adjacent to the Bohai Sea and the Yellow Sea. Geoderma 322: 201-208, https://doi.org/10.1016/j.geoderma. 2018.02.015.

Zhou Y, Liu X and Wang J (2019) Characterization of microplastics and the association of heavy metals with microplastics in suburban soil of central China. Science of the Total Environment 694: article 133798, https://doi.org/10.1016/j.scitotenv.2019.133798.

Zhu D, Bi QF, Xiang Q et al. (2018) Trophic predator-prey relationships promote transport of microplastics compared with the single Hypoaspis aculeifer and Folsomia candida. Environmental Pollution 235: 150-154, https://doi.org/10.1016/j.envpol.2017.12.058.

Zhu F, Zhu C, Wang C and Gu C (2019) Occurrence and ecological impacts of microplastics in soil systems: a review. Bulletin of Environmental Contamination and Toxicology 102(6): 741-749, https://doi.org/10.1007/s00128-019-02623-z.

Zon NF, Iskendar A, Azman S, Sarijan S and Ismail R (2018) Sorptive behaviour of chromium on polyethylene microbeads in artificial seawater. MATEC Web of Conferences 250: article 06001, https://doi. org/10.1051/matecconf/201825006001.

Zou J, Liu X, Zhang D and Yuan X (2020) Adsorption of three bivalent metals by four chemical distinct microplastics. Chemosphere $\mathbf{2 4 8}$ : article 126064, https://doi.org/10.1016/j.chemosphere.2020.126064.

Zubris KAV and Richards BK (2005) Synthetic fibers as an indicator of land application of sludge. Environmental Pollution 138(2): 201-211, https://doi.org/10.1016/j.envpol.2005.04.013.

\section{How can you contribute?}

To discuss this paper, please submit up to 500 words to the editor at journals@ice.org.uk. Your contribution will be forwarded to the author(s) for a reply and, if considered appropriate by the editorial board, it will be published as a discussion in a future issue of the journal. 